\title{
Matching, Sorting, and the Distributional Effects of InTERnATIONAL TRADE*
}

\author{
Gene M. Grossman \\ Princeton University
}

\author{
Elhanan Helpman \\ Harvard University and CIFAR
}

\author{
Philipp Kircher \\ University of Edinburgh
}

August 2014

\begin{abstract}
We study the distributional consequences of trade in a world with two industries and two heterogeneous factors of production. Productivity in each production unit reflects the ability of the manager and the abilities of the workers, with complementarity between the two. We begin by examining the forces that govern the sorting of worker and manager types to industries, and the matching of workers and managers within industries. We then consider how changes in relative output prices generated by changes in the trading environment affect sorting, matching, and the distributions of wages and salaries. We distinguish three mechanisms that govern the effects of trade on income distribution: trade increases demand for all types of the factor used intensively in the export sector; trade benefits those types of a factor that have a comparative advantage in the export sector; and trade induces a re-matching of workers and managers within both sectors, which benefits the more able types of the factor that achieves improved matches.
\end{abstract}

Keywords: heterogeneous labor, matching, sorting, productivity, wage distribution, international trade.

JEL Classification: F11, F16

\footnotetext{
${ }^{*}$ This is a revised version of our working paper Grossman et al. (2013), with the new title better reflecting the focus of this article. Part of this research was completed while Grossman was visiting STICERD at the London School of Economics and CREI at the University of Pompeu Fabra and while Helpman was visiting Yonsei University as SK Chaired Professor. They thank these institutions for their hospitality and support. The authors are grateful to Rohan Kekre, Ran Shorrer, Kirill Borusyak, and especially Kevin Lim for their research assistance. Arnaud Costinot, Oleg Itskhoki, Stephen Redding, Dan Trefler, Harald Uhlig, Jonathan Vogel, three anonymous referees, and numerous seminar participants provided helpful comments and suggestions. Anders Akerman and Marc-Andreas Muendler graciously helped with the preparation of data presented in Section 2. Finally, Grossman and Helpman thank the National Science Foundation and Kircher thanks the European Research Council for financial support.
} 


\section{Introduction}

How does international trade affect a country's income distribution? This age-old question has been the subject of a voluminous theoretical literature dating back at least to Ohlin (1933), Haberler (1936), Viner (1937), and of course Stolper and Samuelson (1941). But, until recently, research has focused almost exclusively on the relative earnings of a small number of aggregate (or homogeneous) factors of production. One can think of this research as addressing the determinants of "between-occupation" or "between-skill-group" distribution. There has also been a "betweenindustry" component to this line of inquiry, as reflected in the work by Jones (1971), Mayer (1974) and Mussa (1974) on models with "sector-specific" factors of production.

However, between-occupation and between-industry wage variation tell only part of the inequality story. Research using household-level data finds that within occupation-and-industry wage variation or within skill-group-and-industry variation contributes at least as much as does betweengroup variation to the overall level of earnings inequality in the United States, Germany, Sweden, and Brazil. ${ }^{1}$ Moreover, changes in within-group distributions account for a significant portion of the recent trends in wage inequality. While only the research on Brazil attempts to attribute some of these trends to changes in the trade environment, the evidence of substantial within-group dispersion suggests the need for a richer theoretical framework that incorporates factor heterogeneity in order to help us understand more fully the effects of globalization on income distribution.

In this paper, we introduce factor heterogeneity into a multi-factor model of resource allocation in order to study the distributional effects of international trade in finer detail. As in the familiar Hecksher-Ohlin model, we assume that output is produced by the combined efforts of two factors (or occupations), which we call "workers" and "managers." These factors are employed in two competitive industries. But here, the inelastic supply of each factor comprises a continuum of different types. Firms form production units that bring together a manager of some type with a group of workers. There are diminishing marginal returns to adding a greater number of workers to a team with a given manager, as in the standard model. Meanwhile, the productivity of a unit depends on the type of the manager and the types of the various workers. Firms must choose not only how many workers and managers to hire, but also what types to employ. Industries may differ both in their factor intensities (as reflected in the diminishing returns to workers per manager) and in the functions that relate productivity to types.

Our model builds not only on Heckscher and Ohlin, but also on Lucas (1978). Lucas assumed that a firm's productivity depends on the ability of its manager (or "entrepreneur"), but that agents are equally productive qua workers. His analysis focused on the sizes of production units as a function of the types of their managers, but he could not address the composition of these units in terms of manager-worker combinations. Eeckhout and Kircher (2012) extended Lucas's

\footnotetext{
${ }^{1}$ See, for example, Card et al. (2013) for Germany, Akerman et al. (2013) for Sweden, Helpman (2014) et al. for Brazil, Mouw and Kalleberg (2010) for the United States, and others.
} 
approach to allow for heterogeneity of both factors. Like Lucas, they modeled only a single goodproducing industry and so they could not study the effects of relative output prices on factor rewards. But they contributed a key result that we borrow here, namely a condition for positive assortative matching of workers and managers. To apply their insights, we posit the existence of complementarity between worker ability and manager ability in determining the productivity of production units in each industry. When these complementarities are strong enough, they imply that firms in an industry will combine better managers with better workers. ${ }^{2}$

In general equilibrium models with homogeneous factors of production, resource allocation can be fully described by the quantities of every input hired into each sector. With heterogeneous factors, the assignment of different types must also be considered. In such a setting, two important aspects of resource allocation that affect income distribution concern the sorting of heterogeneous managers and workers to industries and the matching of managers and workers in production units within each one. Sorting that is guided by comparative advantage generates endogenous sector specificity, which partly links workers' and managers' rewards to the prices of the goods they produce. Endogenous matching creates an additional channel-absent from previous, multi-sector trade models - through which changes in relative prices can affect the distribution of factor rewards. If the complementarities between manager and worker ability levels are strong enough to determine the composition of the production teams that form in general equilibrium, then changes in relative prices typically induce rematching of managers and workers in each industry. We will be interested in describing the rematching that results from an improvement in a country's terms of trade and in deriving the implications of such changes in the trade environment for within occupation-andindustry income inequality. ${ }^{3}$

We are not the first to study the implications of sorting and matching for income distribution. However, previous authors have considered the two forces only in isolation. For example, Ohnsorge and Trefler (2007) and Costinot and Vogel (2010) studied the links between trade and income distribution in an assignment model with heterogeneous workers and many sectors, but with a linear production function. In this setting, workers sort to sectors, but do not match with any other factors. ${ }^{4}$ Yeaple (2005) and Sampson (2014) allow for matching between heterogeneous workers and firms that have access to different technologies. These authors too adopt a linear production function, but since their firms produce differentiated products in a world of monopolistic competition, the hiring of additional labor generates decreasing returns in terms of revenue, and so they can analyze the sizes of production units. Our model incorporates the forces found in these earlier papers, but also identifies a novel and important interplay between matching and sorting; changes in relative prices generate shifts in the margins of factor sorting, which alter the

\footnotetext{
${ }^{2}$ See Garicano and Hubbard (2012) for direct evidence of positive assortative matching between managers and workers in the U.S. legal services industry and Fox (2009) for indirect evidence of such matching across a range of U.S. and Swedish industries.

${ }^{3}$ Krishna et al. (2014) report evidence of an endogenous reassignment of workers to firms following the Brazilian trade reform of 1991. They conclude based on this evidence that "[e]ndogenous matching of workers with firms is thus crucial in determining wage outcomes for workers in open economies" (p.252).

${ }^{4}$ See Ruffin (1988) for an antecedent of this approach.
} 
composition of types in each industry and so force a rematching of factor types.

In the next section, we revisit the Brazilian data examined by Helpman et al. (2014) in order to provide some motivating observations for the subsequent theoretical analysis. We find a strongly positive correlation between the mean wage of male workers employed in an industry and the mean salary of male managers and professionals employed in the same industry, suggestive of positive assortative matching across industries of worker and manager types. We use this observation later to guide our emphasis among the various sorting outcomes that can arise in our model. We also find significant changes in within-industry worker and manager earnings distribution over an eight-year period that spans the major Brazilian trade liberalization of 1991.

In Section 3, we lay out our general equilibrium model of competitive resource allocation with two heterogeneous factors of production. As already mentioned, the model extends the familiar Heckscher-Ohlin framework to allow for a continuum of types of both factors. In each of the two industries, the productivity of a production unit that includes a manager and some endogenouslychosen number of workers is an increasing, log-supermodular function of the "ability" of the manager and the ability levels of the associated workers. We take the relative output price as exogenous, but use it to represent the country's trading environment.

Section 4 derives the equilibrium conditions for profit-maximization, factor-market clearing, and wage and salary determination. We discuss the equilibrium sorting of workers and managers to industries, first for a case in which productivity is a constant-elasticity function of the ability of the manager and the abilities of the workers, and then for a case with stronger complementarities, namely when productivity is a strictly log-supermodular function of the types. In either case, sorting by each factor is guided by a cross-industry comparison of the ratio of the elasticity of productivity with respect to ability to the elasticity of output with respect to factor quantity. When complementarities are strong, the elasticities of productivity with respect to ability reflect the matches that take place, and so the sorting by each factor depends on the choices made by the other factor. After describing the sorting conditions, we define a threshold equilibrium as one in which sorting of each factor is fully described by a single cutoff such that all workers with ability above the cutoff are employed in one industry and the remainder are employed in the other, and similarly for managers. Several propositions provide sufficient conditions for the existence of a threshold equilibrium, first allowing for the possibility that high-ability workers and managers might not sort to the same sector, but then focusing on an equilibrium with positive assortative matching across industries.

After characterizing in Section 5 the matches that form between exogenously given sets of worker types and manager types and discussing how exogenous expansion of these sets induces rematching that has clear implications for income inequality, we turn in Section 6 to the main task at hand. Here we ask, how do changes in the trading environment, as reflected in a country's terms of trade, affect earnings inequality between occupations, between industries, and within occupation and industry. We begin again with the case of constant-elasticity (or Cobb-Douglas) productivity functions, which generates results that are instructive even if unrealistic. We show that in this environment, an 
increase in the relative price of a country's export good generates between-occupation redistribution that is reminiscent of the Stolper-Samuelson theorem and between-industry redistribution that is reminiscent of the Ricardo-Viner model with sector-specific factors, but it has no affect on within occupation-and-industry inequality. The complementarities between managers and workers are not strong enough in the Cobb-Douglas case to determine a unique pattern of matching, and the relative productivities of different factor types in an industry are independent of the matches that take place. With the stronger complementarities that are present when the productivity functions are strictly log supermodular, the matching pattern in general equilibrium is uniquely determined. Then endogenous rematching generates predictable changes in within occupation-and-industry income distributions.

In Section 6.2.1, we consider the distributional effects of price changes in an initial equilibrium in which the best workers and the best managers sort to opposite sectors. Although this configuration seems less empirically relevant than the alternative based on the evidence for Brazil (and also Sweden), the forces at work are easiest to understand in this case. An increase in the relative price of the good produced by the higher-ability types of workers and the lower-ability types of managers, for example, attracts to the industry marginal workers who are less able and marginal managers who are more able than those who are employed there initially. This results in match upgrading for all workers initially in the expanding sector and for those who remain in the contacting sector, which in turn spells a rise in within-occupation-and-industry inequality. The outcome for managers is just the opposite.

Finally, in Section 6.2.2, we take on the case that probably is most empirically relevant, namely one in which the most able workers and the most able managers sort to the same industry. We show that if factor intensities are similar in the two industries, a change in relative price must increase within-occupation-and-industry inequality for one factor and reduce it for the other. If, instead, factor intensities differ substantially across sectors, then a richer set of outcomes is possible. For example, an increase in the relative price of the worker-intensive good raises within-industry inequality among workers in the labor-intensive industry while reducing within-industry inequality among those in the manager-intensive industry.

Section 7 offers some concluding remarks.

\section{Some Motivating Observations}

We aim to provide a simple analytical framework that can shed light on the distributional implications of globalization in a world with a broad range of worker types. Our motivation comes in part from several recent findings in the empirical literature on earnings. Researchers such as Autor et al. (2008) and Kopczuk et al. (2010) have emphasized that trends in income inequality over the last decade cannot be well summarized by a single summary statistic, such as the relative wage of skilled versus unskilled workers or the college wage premium. Rather, in several countries, including the United Stages, inequality has been rising at the top end of the wage distribution, but 
constant or even declining at the bottom end of the distribution, generating what has been termed a "hollowing out" of the middle class. Also, Helpman et al. (2014) and Akerman et al. (2013) have documented that within-industry variation accounts for a large part of the cross-sectional evolution of wage inequality, even after controlling at a detailed level for workers' occupations. In Brazil, for example, the authors used a classification system that allows for 12 manufacturing sectors and more than 300 occupations and found that more than half of the change in wage inequality between 1986 and 1995 occurred within sectors and occupations. Together, these findings point to the need for a framework that allows for multiple worker types and that incorporates links between trade and relative wages for workers employed in the same occupation and industry.

To set the stage for our theoretical analysis, we draw on the set of linked employer-employee relationships that were surveyed by the Brazilian Ministry of Labor in its Relação Anual de Informaçoês Sociais (RAIS) and studied previously by Helpman et al. (2014). Our purpose in re-visiting these data is not to provide a set of targets that will be explained by our theory, but rather to highlight the rich pattern of outcomes that exist in reality and to establish some stylized facts that we can use to focus attention among the several "cases" that our model can generate.

We examine distributions of wages and salaries in twelve Brasileiro de Geografia e Estatistica (IBGE) industry categories for the years 1986 and 1994. ${ }^{5}$ These data represent labor-market outcomes before and after the major Brazilian trade liberalization of 1991, but before the impact was felt of the substantial stabilization program that Brazil undertook in 1994. Our model distinguishes two factors of production that we shall call "managers" and "workers," and so we compute earnings distributions in the Brazilian manufacturing industries separately for occupations classified in the Classificação Brasileira de Ocupações Category 1 (professional and managerial labor) and those in Categories 2-5 (skilled white-collar, unskilled white-collar, skilled blue-collar and unskilled-bluecollar labor).

In figure 1, we plot the log of the mean earnings for male managers and professionals in 1994 against the $\log$ of the mean wage for male workers, for each of the twelve manufacturing sectors. ${ }^{6}$ Apparently, the correlation across sectors between the mean earnings of managers and the mean wage of workers is strongly positive. In our later discussion, we will interpret this positive correlation to suggest the greater empirical relevance of circumstances in which the more able (and thus higher paid) managers sort to the same industry as do the more able workers, as compared to circumstances in which the more able managers sort to the same industry as the less able workers. ${ }^{7}$ For future reference, we record

Observation 1 There is a strong positive correlation between the mean wage of male managers employed in a Brazilian industry and the mean wage of male workers employed in the industry.

\footnotetext{
${ }^{5}$ Table 2 includes a list of the industries and their sector numbers.

${ }^{6}$ The plot for wages and salaries in 1986 is qualitatively similar.

${ }^{7}$ Figure A1 in the Appendix plots log of mean wages for Swedish managers and workers in 2004 in 14 manufacturing industries and shows a similar strong positive correlation. We thank Anders Akerman for computing these means from the Statistics Sweden database that is described in Akerman et al. (2013).
} 


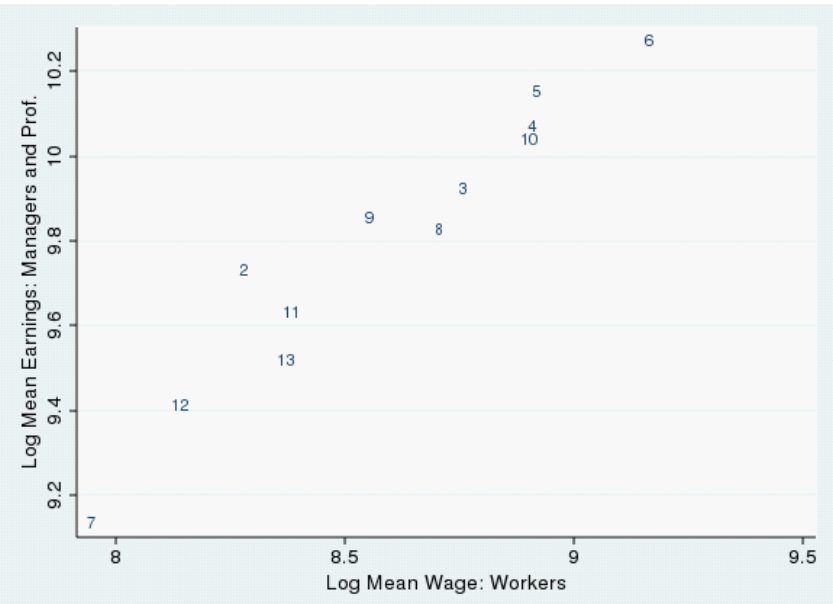

Figure 1: Variation across manufacturing industries of log mean salary of male managers and log mean wage of male workers in Brazil, 1994. Source: own calculations.

\begin{tabular}{|l|l|l|l|l|c|}
\cline { 3 - 6 } \multicolumn{2}{l}{} & \multicolumn{2}{l|}{ Male Workers } & \multicolumn{2}{l|}{ Male Managers } \\
\hline Industry & No. & 1986 & 1994 & 1986 & 1994 \\
Non-metallic mineral products & & & & & \\
Metallic products & 2 & 0.324 & 0.381 & 0.308 & 0.376 \\
Machinery, equipment and instruments & 3 & 0.252 & 0.276 & 0.219 & 0.260 \\
Electrical and telecommunications equipment & 4 & 0.240 & 0.266 & 0.226 & 0.224 \\
Transport equipment & 5 & 0.261 & 0.294 & 0.203 & 0.207 \\
Wood products and furniture & 6 & 0.192 & 0.236 & 0.163 & 0.192 \\
Paper and paperboard, and publishing and printing & 8 & 0.238 & 0.331 & 0.392 & 0.423 \\
Rubber, tobacco, leather and fur & 9 & 0.301 & 0.326 & 0.319 & 0.340 \\
Chemical and pharmaceutical products & 10 & 0.358 & 0.353 & 0.247 & 0.286 \\
Apparel and textiles & 11 & 0.275 & 0.309 & 0.347 & 0.393 \\
Footwear & 12 & 0.259 & 0.350 & 0.335 & 0.349 \\
Food, beverages, and ethyl alcohol & 13 & 0.268 & 0.345 & 0.411 & 0.398 \\
& & & & & \\
\hline All manufacturing industries & & 0.318 & 0.364 & 0.290 & 0.329 \\
\hline
\end{tabular}

Table 1: Theil index of inequality by manufacturing industry 
Table 1 reports the Theil index of income inequality separately for male workers and male managers and professionals in 1986 and in 1994, for each of the 12 manufacturing industries. ${ }^{8}$ In Table 2, we provide two decompositions of the these indexes for each year and for the change between them. The top part of the table shows a separate decomposition for each occupational group (i.e., workers and managers) into a component that represents dispersion within industries and one that represents dispersion between industries. ${ }^{9}$ The bottom part of the table provides a decomposition of inequality for all male workers and managers in manufacturing taken together into components for "within occupation and industry" and "between occupation and industry." We see that, in either case, the within component accounts for the largest share of the overall inequality in each year, as well as the majority of the change that occurred during the period that spanned the trade reform. We record this finding in

Observation 2 Within-industry inequality accounts for a majority of the income inequality for male workers and for male managers in Brazil in 1986 and 1994, and for a majority of the changes in inequality between 1986 and 1994. Within-occupation-and-industry inequality accounts for a majority of the income inequality for male workers and managers as a group in 1986 and 1994, and for a majority of the change in inequality between 1986 and 1994 .

In Figure 2, we plot the change in the Theil index for workers between 1986 and 1994 against the change in the Theil index for managers and professionals. The numbers in the figure again represent the different industries, in accordance with the labels provided in Table 2. The figure reveals a negative correlation of -0.20 between the changes in inequality for workers and that for managers; in industries where the spread in the salaries of workers increased greatly, that for managers generally increased little, or even decreased. We note

\footnotetext{
${ }^{8}$ We compute the Theil index of inequality in group $k$ as$$
T_{k}=\frac{1}{N_{k}} \sum_{i=1}^{N_{k}}\left(\frac{y_{i}}{\bar{y}_{k}} \cdot \ln \frac{y_{i}}{\bar{y}_{k}}\right)
$$

where $N_{k}$ is the number of individuals in group $k, y_{i}$ is the income of individual $i$, and $\bar{y}_{k}$ is the mean income among all individuals in group $k$.

${ }^{9}$ For a set of groups $k=1, \ldots, K$, the overall Theil index is

$$
T=\frac{1}{N} \sum_{k} \sum_{i} \frac{y_{i k}}{\bar{y}} \ln \frac{y_{i k}}{\bar{y}}
$$

where $y_{i k}$ is the income of worker $i$ in group $k, N=\sum_{k} N_{k}$ and $\bar{y}$ is the mean income. We compute the "within component" as

$$
T_{\text {within }}=\sum_{k} s_{k} T_{k}
$$

where $s_{k}=\frac{N_{k} \bar{y}_{k}}{N \bar{y}}$ is the income share of group $k$.The "between component" is

$$
T_{\text {between }}=\sum_{k} s_{k} \ln \frac{\bar{y}_{k}}{\bar{y}},
$$

so that $T=T_{\text {within }}+T_{\text {between }}$. 


\begin{tabular}{|c|c|c|c|c|c|c|}
\hline & \multicolumn{3}{|c|}{ Male Workers } & \multicolumn{3}{|c|}{ Male Managers } \\
\hline \multirow[b]{2}{*}{$\begin{array}{l}\text { Decomposition: } \\
\text { Within/Between Industry }\end{array}$} & 1986 & 1994 & Change & 1986 & 1994 & Change \\
\hline & & & & & & \\
\hline Total inequality & 0.318 & 0.364 & 0.045 . & 0.290 & 0.329 & 0.039 \\
\hline Within industry & 0.272 & 0.309 & 0.038 & 0.262 & 0.291 & 0.029 \\
\hline \multirow[t]{2}{*}{ Between industry } & 0.047 & 0.054 & 0.007 & 0.028 & 0.038 & 0.009 \\
\hline & \multicolumn{6}{|c|}{ Male Workers and Managers } \\
\hline \multirow[b]{2}{*}{$\begin{array}{l}\text { Decomposition: } \\
\text { Within/Between Industry and Occupation }\end{array}$} & \multicolumn{2}{|c|}{1986} & \multicolumn{2}{|c|}{1994} & \multicolumn{2}{|c|}{ Change } \\
\hline & & & & & & \\
\hline Total inequality & \multicolumn{2}{|c|}{0.423} & \multicolumn{2}{|c|}{0.467} & \multicolumn{2}{|c|}{0.043} \\
\hline Within occupation and industry & \multicolumn{2}{|c|}{0.269} & \multicolumn{2}{|c|}{0.305} & \multicolumn{2}{|c|}{0.036} \\
\hline Between occupation and industry & \multicolumn{2}{|c|}{0.154} & \multicolumn{2}{|c|}{0.161} & \multicolumn{2}{|c|}{0.007} \\
\hline
\end{tabular}

Table 2: Decomposition of income inequality

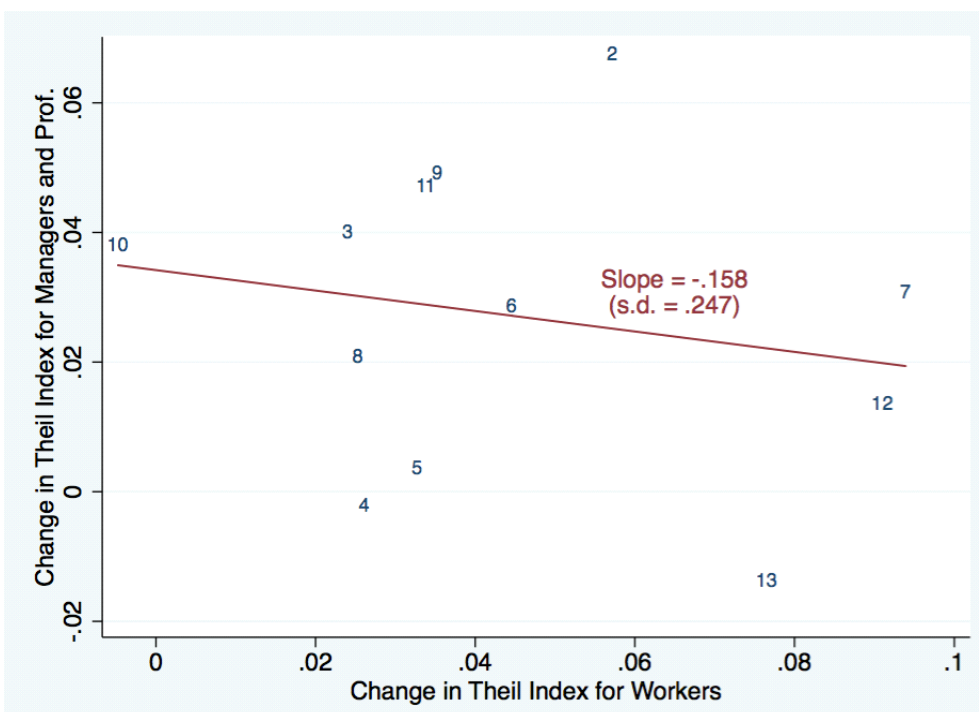

Figure 2: Correlation across industries of changes in income inequality for Brazilian workers and Brazilian Managers 
Observation 3 There is a negative correlation across industries between the change in the Theil index of earnings inequality between 1986 and 1994 for Brazilian workers and the change in the Theil index of earnings inequality for Brazilian managers.

Finally, in Figure 3, we associate these changes in inequality for each occupational group with changes in relative prices over the same period. We use wholesale price data (Indice de Precos por Atacado) computed by Fundação Getulio Vargas (FGV) and a concordance and aggregation to the twelve IGBE industry categories performed by Marc Muendler. ${ }^{10}$ The top panel in the figure shows that inequality among workers tended to rise in those industries that experienced an increase in relative price between 1986 and 1994. The correlation coefficient is 0.25 . Meanwhile, the bottom panel in the figure depicts a negative correlation between the change in the Theil index of inequality for managers and the evolution of the industry's relative price. In this case, we compute the correlation coefficient to be -0.45 . We make no claim that these correlations represent causal links between prices and inequality. Still, it is interesting that industry price changes have an opposite correlation with changes in inequality for the two factors, which we will find is a general prediction of our model.

Observation 4 The correlation across industries between the change in relative output price and the change in income inequality between 1986 and 1994 is positive for Brazilian workers and negative for Brazilian managers.

We offer these observations cautiously. For one thing, we have not attempted to isolate the influence of trade liberalization from other forces that may have impacted the wage and salary distributions in Brazil during the period under consideration. For another, we have not sought to verify that similar patterns have occurred after trade liberalization or increased exposure to trade in other countries, especially those with factor endowments similar to those in Brazil. While serious empirical analysis is beyond the scope of the current paper, the data for Brazil do suggest that trade impacts differently the earnings of those in an industry and occupation who differ in skill and ability, that within industry-and-occupation redistribution is at least as important as redistribution between those in different occupations and industries, that changes in inequality among managers and workers in an industry are negatively correlated, and that these inequality changes are correlated with relative price movements. Finally, the data suggest that greater emphasis should be placed on parameter configurations that imply sorting of the best managers and the best workers to the same sectors as compared to parameter configurations that imply otherwise.

\footnotetext{
${ }^{10}$ We begin with the IPA-DI series, which has been used for the Brazilian national accounts since 1944. FGV reports these prices at an FGV-specific industry level. Muendler used an internal crosswalks made available to him by IBGE to reset those data to the Nivel-100 industry level and then mapped the resulting prices to IGBE subsectors. He formed aggregates at the 12-industry level of the earnings data using sales data from the 1990 survey of manufacturing firms (PIA) that is described in Muendler (2004). Finally, we computed price indexes for 1986 and 1994 by averaging the monthly prices he gave us and constructed relative price changes by dividing the inflation in each price series by the average inflation rate. We are very grateful to Marc Muendler for his assistance in all this.
} 


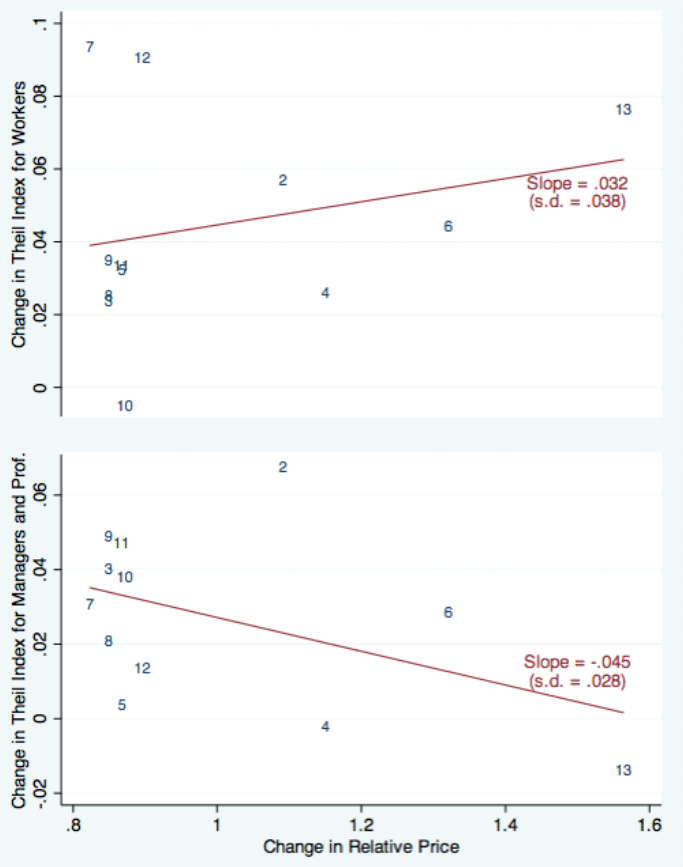

Figure 3: Correlation across industries of changes in income inequality and changes in relative prices

\section{The Economic Environment}

We study an economy that produces and trades two goods. This is a "Heckscher-Ohlin economy" with two factors of production that for concreteness we call "managers" and "workers" - except that there are many "types" of each factor. The inelastic supplies of the heterogeneous workers are represented by a density function $\bar{L} \phi_{L}\left(q_{L}\right)$, where $\bar{L}$ is the aggregate measure of workers in the economy and $\phi_{L}\left(q_{L}\right)$ is a probability density function (pdf) over worker types, $q_{L}$. Similarly, the economy is endowed with a density $\bar{H} \phi_{H}\left(q_{H}\right)$ of managers of type $q_{H}$, where $\bar{H}$ is the measure of managers and $\phi_{H}\left(q_{H}\right)$ is the pdf for manager types. For ease of exposition, we take $\phi_{L}\left(q_{L}\right)$ and $\phi_{H}\left(q_{H}\right)$ both to be continuous and strictly positive on their respective supports, $S_{L}=\left[q_{L \min }, q_{L \max }\right]$ and $S_{H}=\left[q_{H \min }, q_{H \max }\right]$.

We treat factor endowments as exogenous for simplicity, and in order to connect our analysis with previous studies of trade and factor prices in the spirit of Jones (1965, 1971), Mayer (1974), Mussa (1974), and others. It might also be interesting to allow for occupational choice, as in Lucas (1978), or human capital accumulation via education, as in Findlay and Kierzkowski (1983). Of course, other interpretations of the two factors also are possible. For example, if the factors are "labor" and "capital," one presumably would want to incorporate a choice of investment in machines of different types, as in Acemoğlu (1998).

Competitive firms can enter freely into either industry and access constant-returns-to-scale technologies. We describe the technology in industry $i$ in terms of the output that can be produced 
by a manager of some type $q_{H}$ when combined with workers of various types. The manager has an endogenous "span of control" - as in Garicano (2000) and Eeckhout and Kircher (2012) - inasmuch as she must allocate her fixed endowment of attention to the various workers placed under her control. If the productivity of each worker increases with the attention devoted by the manager, albeit with diminishing returns, then it generically is optimal for the firm to form production units that combine a given type of manager with an (endogenous) number of workers of a common type. ${ }^{11}$ To save on notation, we therefore can describe the technology in sector $i$ in terms of the amount of potential output $x_{i}$ that can be produced by a unit with one manager of type $q_{H}$ and $\ell$ workers of common type $q_{L}$, namely

$$
x_{i}=\psi_{i}\left(q_{H}, q_{L}\right) \ell^{\gamma_{i}}, \quad 0<\gamma_{i}<1, \text { for } i=1,2 \text {. }
$$

Here, $\psi_{i}\left(q_{H}, q_{L}\right)$ reflects the productivity of the production unit and $\gamma_{i}$ is a parameter that captures the diminishing returns to the size of the workforce that results from an increase in the manager's span of control. Since we allow for different degrees of diminishing returns in the two sectors $\left(\gamma_{1} \neq \gamma_{2}\right)$, the firms in different industries might find it optimal to combine a manager with different numbers of workers. This gives rise to a possible difference in factor intensities that is familiar from the traditional Heckscher-Ohlin theory. ${ }^{12}$ The new element is the productivity term $\psi_{i}\left(q_{H}, q_{L}\right)$, which is a function of the types of each of the factors. We assume that there exists an ordering of each factor type such that any change in the type index affects productivity in the same direction in both industries. Without further loss of generality, then, we can choose the order so that $\psi_{i}\left(q_{H}, q_{L}\right)$ is strictly increasing in each of its arguments for $i=1$ and $i=2$. Under this labeling convention, we refer to $q_{H}$ as the "ability" of the manager and $q_{L}$ as the ability of the associated workers.

Importantly, we posit the existence of a complementarity between the ability levels of the manager and the workers that are employed together in a production unit. More able workers are more productive than less able workers no matter who is their manager, but the more able workers are assumed to be relatively more productive compared to their less able counterparts when they are combined with a more able manager rather than a less able manager. ${ }^{13}$ Formally, we assume throughout that $\psi_{i}\left(q_{H}, q_{L}\right)$ is strictly increasing and twice continuously differentiable and we adopt

Assumption $1 \psi_{i}\left(q_{H}, q_{L}\right)$ is $\log$ supermodular for $i=1,2$.

Log supermodularity implies that $\psi_{i}\left(q_{H}^{\prime \prime}, q_{L}^{\prime \prime}\right) / \psi_{i}\left(q_{H}^{\prime \prime}, q_{L}^{\prime}\right) \geq \psi_{i}\left(q_{H}^{\prime}, q_{L}^{\prime \prime}\right) / \psi_{i}\left(q_{H}^{\prime}, q_{L}^{\prime}\right)$ for any $q_{H}^{\prime \prime}>q_{H}^{\prime}$

\footnotetext{
${ }^{11}$ The optimality of combining a given type of manager with workers of a common type arises in other contexts in which the manager has a span of control besides the particular description we offer here; see Eeckout and Kircher (2012). They show that the key assumption for this result is that there is no teamwork or synergy between workers in the firm, who interact only insofar as they compete for the manager's time and attention.

${ }^{12}$ The assumption of a power function for labor-i.e., that the technologies are Cobb-Douglas in factor quantitiesis made for expositional convenience; many of our results do not require this assumption, so long as there are no "factor intensity reversals."

${ }^{13}$ See, for example, Garicano and Hubbard (2012), who study assignment patterns in the U.S. legal services industry. They find that the more able partners (managers) team with the more able associates (workers) and argue that their data are best explained by the existence of complementarity between the managers' and workers' skill or ability.
} 
and $q_{L}^{\prime \prime}>q_{L}^{\prime}$. Notice that we allow the two industries to differ in the strength of the complementarities between factors, which along with the differences in factor intensities will play an important role in determining the sorting of the factor types to the two industries.

Much of our analysis will be carried out with a slightly stronger version of our assumption about complementarities, namely

Assumption $\mathbf{1}^{\prime} \psi_{i}\left(q_{H}, q_{L}\right)$ is strictly $\log$ supermodular for $i=1,2$.

In this case, the weak inequality described in the previous paragraph becomes a strong inequality.

We take all factor markets to be perfectly competitive and frictionless. That is, firms can hire managers and workers of any type at salaries $r\left(q_{H}\right)$ and wages $w\left(q_{L}\right)$ that vary with ability, of course, but that the individual firm takes as given. There is no imperfect information about individuals' abilities, no search costs of any sort, and no unemployment. Adding frictions to the formation of production units would be an interesting extension, but is beyond the scope of the current paper. ${ }^{14}$

As in other models with perfect competition, the impact of the trading environment on local factor prices is conveyed via relative output prices. For example, the opening of trade from autarky generates an increase in the relative price of a country's export good. So does a subsequent improvement in its terms of trade. An import tariff raises the relative domestic price of a country's import good, except under the conditions of the so-called Metzler paradox (Metzler, 1949). The relative domestic prices in turn determine the equilibrium wage schedule $w\left(q_{L}\right)$ and the salary schedule $r\left(q_{H}\right)$. Accordingly, we can study the effects of changes in the trading environment on the earnings distribution by considering the comparative static changes in the wage and salary schedules that result from an arbitrary change in relative prices. There is no need to spell out the foreign supply conditions, the domestic and foreign demand conditions, or the international equilibrium conditions for our present purposes. ${ }^{15}$

\section{Sorting and Matching of Managers and Workers}

In this section, we lay out the conditions for profit maximization and factor-market clearing in the domestic economy, taking output prices as given. These conditions determine inter alia the sorting of the different types of workers and managers to the two industries, the matching of workers and managers in production units within each sector, and the equilibrium schedules of wages and salaries. We will characterize the patterns of sorting and matching that can arise in equilibrium

\footnotetext{
${ }^{14}$ In our working paper, Grossman et al. (2013), we allow for directed search by workers in an environment with unemployment generated by search frictions. In that setting, many results have a similar flavor to those derived here, but trade affects the distribution of employment across workers of different abilities, as well as the distribution of wages.

${ }^{15}$ In Grossman et al. (2013) we discuss the determinants of the trade pattern in a world with two countries that share common homothetic demands and common technologies. We considered countries that differ in their aggregate endowments of managers and workers and in their distributions of factor types.
} 
and describe some properties of the earnings schedules. Discussion of the responses of wages and salaries to changes in relative prices is deferred until Section 6 below.

Consider a firm in sector $i$ that employs a manager of some type $q_{H}$. This firm must choose the type of workers $q_{L}$ and the number of workers $\ell$ to combine with the manager, given the output price and the wage schedule. The firm's profit, gross of its salary payment to the manager, is given by

$$
\pi_{i}\left(\ell, q_{L} ; q_{H}\right)=p_{i} \psi_{i}\left(q_{H}, q_{L}\right) \ell^{\gamma_{i}}-w\left(q_{L}\right) \ell
$$

where $p_{i}$ is the price of good $i$ and $w\left(q_{L}\right)$ is the competitive wage paid to a worker with ability $q_{L}$. The first-order condition with respect to $\ell$ yields the conditional labor demand,

$$
\ell\left(q_{L} ; q_{H}\right)=\left[\frac{\gamma_{i} p_{i} \psi_{i}\left(q_{H}, q_{L}\right)}{w\left(q_{L}\right)}\right]^{\frac{1}{1-\gamma_{i}}}
$$

which is the number of workers the firm would hire if it were to employ a manager with ability $q_{H}$, choose workers of type $q_{L}$, and face the wage schedule $w\left(q_{L}\right)$.

Next, we substitute $\ell\left(q_{L} ; q_{H}\right)$ into the expression for $\pi_{i}\left(\ell, q_{L} ; q_{H}\right)$ and compute the first-order condition with respect to $q_{L}$. This yields the firm's optimal choice of worker type, given the type of its manager and taking into account the corresponding size of the optimal production unit. The first-order condition can be written as

$$
\frac{\varepsilon_{i L}\left(q_{H}, q_{L}\right)}{\gamma_{i}}=\varepsilon_{w}\left(q_{L}\right)
$$

where $\varepsilon_{i L}\left(q_{H}, q_{L}\right) \equiv q_{L}\left[\partial \psi_{i}\left(q_{H}, q_{L}\right) / \partial q_{L}\right] / \psi_{i}\left(q_{H}, q_{L}\right)$ is the elasticity of productivity in sector $i$ with respect to worker ability and $\varepsilon_{w}\left(q_{L}\right) \equiv q_{L}\left[\partial w\left(q_{L}\right) / \partial q_{L}\right] / w\left(q_{L}\right)$ is the elasticity of the wage schedule. Evidently, the firm sets the ratio of the elasticity of output with respect to worker ability to the elasticity of output with respect to worker quantity equal to the elasticity of the wage schedule. ${ }^{16}$ The optimal choice of ability reflects the fact that the firm has two ways to expand output, either by hiring better workers or by hiring more workers. The rate at which wages rise with ability dictates the appropriate trade-off between the two.

Let $q_{L}=m_{i}\left(q_{H}\right)$ denote the solution to (3), if the equation has a unique solution. Then $m_{i}\left(q_{H}\right)$ tells us the type of workers that the firm would combine with a manager of ability $q_{H}$ if it happened to hire such a manager. For the economy as a whole, the matching function $m\left(q_{H}\right)$, if it is well determined, consists of $m_{1}\left(q_{H}\right)$ for $q_{H} \in Q_{H 1}$ and $m_{2}\left(q_{H}\right)$ for $q_{H} \in Q_{H 2}$, where $Q_{H i}$ is the set of managers that is hired in equilibrium in sector $i$.

Who are the managers that actually are hired into sector $i$ in equilibrium? Were a firm to hire a manager with ability $q_{H}$ and pay her the market salary, $r\left(q_{H}\right)$, its net profit would be $\Pi_{i}\left(q_{H}\right)=\tilde{\pi}_{i}\left(q_{H}\right)-r\left(q_{H}\right)$, where $\tilde{\pi}_{i}\left(q_{H}\right) \equiv \max _{\left\{\ell, q_{L}\right\}} \pi_{i}\left(\ell, q_{L} ; q_{H}\right)$ is achieved by choosing $\ell$ and $q_{L}$

\footnotetext{
${ }^{16}$ This condition is analagous to the ones in Costinot and Vogel (2010) and Sampson (2014), except that those papers have $\gamma_{i}=1$, because workers are the only factor of production and output is linear in labor quantity. A second, heterogeneous factor of production - such as we have introduced here - is necessary to generate re-matching within sectors, which in turn is needed to explain changes in within-occupation-and-industry wage distribution.
} 
according to (2) and (3). ${ }^{17}$ Note that, in a competitive equilibrium, every firm operating in sector $i$ breaks even, which implies that $\Pi_{i}\left(q_{H}\right)=0$ for all $q_{H} \in Q_{H i}$. Note too that the firms in sector $j$ should not be able to make strictly positive profits by hiring the managers that sort in equilibrium into sector $i$, or else they would hire these managers instead. This implies that $\Pi_{j}\left(q_{H}\right) \leq 0$ for all $q_{H} \in Q_{H i}, j \neq i$. We will return to these zero-profit and optimality conditions below.

\subsection{Matching and Sorting with Cobb-Douglas Productivity}

It is instructive to begin first with a special case in which productivity is a constant elasticity function of the ability of the manager and that of the worker. For this case, we can write

$$
\psi_{i}\left(q_{H}, q_{L}\right)=q_{H}^{\beta_{i}} q_{L}^{\alpha_{i}} \text { for } i=1,2 ; \alpha_{i}, \beta_{i}>0
$$

For obvious reasons, we shall refer to this as the case of "Cobb-Douglas productivity."

The Cobb-Douglas productivity function has several special properties that are important in this context. First, the function is log supermodular, but it is not strictly log supermodular; it satisfies Assumption 1 but not Assumption 1'. Second, the elasticity of output with respect to worker ability, $\varepsilon_{i L}\left(q_{H}, q_{L}\right)$, is a constant $\alpha_{i}$ in this case, and independent of both $q_{H}$ and $q_{L}$. We can define analogously the elasticity of output with respect to manager ability, $\varepsilon_{i H}\left(q_{H}, q_{L}\right) \equiv$ $q_{H}\left[\partial \psi_{i}\left(q_{H}, q_{L}\right) / \partial q_{H}\right] / \psi_{i}\left(q_{H}, q_{L}\right)$. This too is a constant, equal to $\beta_{i}$, in the case of Cobb-Douglas productivity.

With $\varepsilon_{i L}=\alpha_{i}$, the first-order condition (3) for a firm's interior choice of worker type in sector $i$ requires that $\varepsilon_{w}\left(q_{L}\right)=\alpha_{i} / \gamma_{i}$. However, with an arbitrary wage schedule, this condition will only be satisfied by a finite number (possibly only one) of values of $q_{L}$. Facing such an arbitrary schedule, all firms active in an industry would hire one of these finite number of types. Such choices would not be consistent with full employment of the continuum of worker types that sorts to an industry. We conclude that, as a requirement for full employment, the wage schedule must have a constant elasticity $\alpha_{1} / \gamma_{1}$ for the range of workers hired into sector 1 and it must have a constant elasticity $\alpha_{2} / \gamma_{2}$ for the range of workers hired into sector 2 . In other words,

$$
w\left(q_{L}\right)=w_{i} q_{L}^{\alpha_{i} / \gamma_{i}} \text { for all } q_{L} \in Q_{L i}, i=1,2,
$$

for some constants, $w_{1}$ and $w_{2}$, where $Q_{L i}$ is the set of workers hired in sector $i$. The wage schedule dictated by (4) makes all firms operating in industry $i$ indifferent between the potential employees in $Q_{L i}$.

Notice that the wage schedule in (4) leaves firms in industry $i$ indifferent among the potential employees in $Q_{L i}$ no matter what is the type of their manager. Indeed, the Cobb-Douglas productivity function makes the relative productivity of any two workers independent of manager type. It follows that matching of workers and managers is not well determined for the case of Cobb-Douglas

\footnotetext{
${ }^{17}$ Of course, this statement assumes that (2) has a unique solution; otherwise, the firm chooses any worker type $q_{L}$ that maximizes $\pi_{i}$ along with the corresponding quantity, $\ell\left(q_{L} ; q_{H}\right)$.
} 


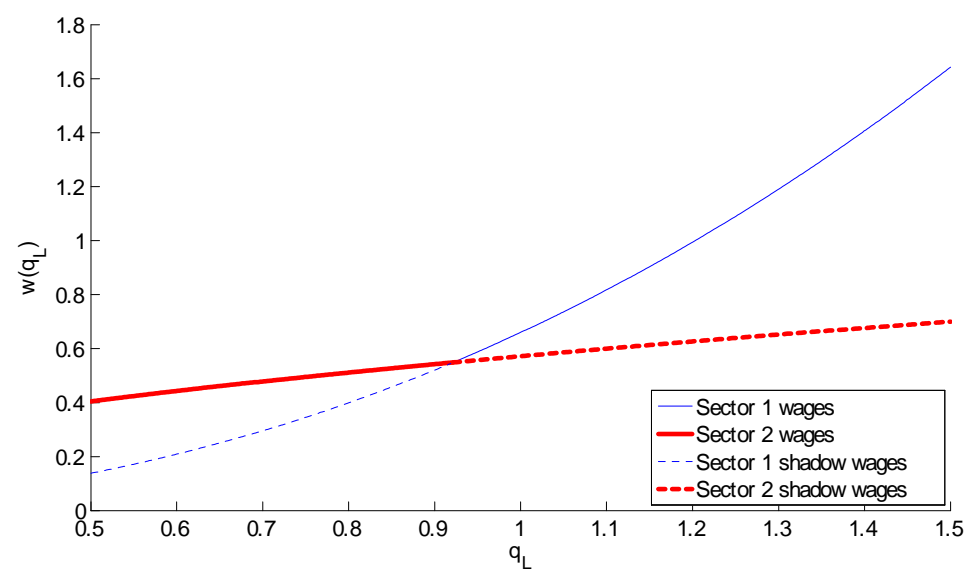

Figure 4: Wage Schedule

productivity; any matches between workers in $Q_{L i}$ and managers in $Q_{H i}$ can be consistent with equilibrium, provided that the numbers in all production units are consistent with (2) and the requirements for aggregate factor-market clearing are satisfied.

Which workers are employed in industry 1 and which in industry 2? Consider Figure 4, which depicts the qualitative features of the equilibrium wage schedule for the case in which $s_{L} \equiv \alpha_{1} / \gamma_{1}-$ $\alpha_{2} / \gamma_{2}>0$. Once the "wage anchors", $w_{1}$ and $w_{2}$, have been determined in the general equilibrium, the solid curve in the figure represent the equilibrium wage schedule that satisfies (4). The broken curves show what the wages for different types of workers would have to be in order to make the firms in an industry indifferent between hiring these types and the types that are actually employed in equilibrium. The fact that $\alpha_{1} / \gamma_{1}>\alpha_{2} / \gamma_{2}$ implies that the solid curve lies above the broken curve for industry 2 to the right of the point of intersection, $q_{L}^{*}$, and that the solid curve lies above the broken curve for industry 1 to the left of the intersection point. In equilibrium, the firms in industry 1 are willing to hire any workers with ability above $q_{L}^{*}$, but not those with ability below this level. Meanwhile, the firms in industry 2 are willing to hire any workers with ability below $q_{L}^{*}$, but not those with ability above this level. Evidently, those with ability above $q_{L}^{*}$ sort to industry 1 and those with ability below $q_{L}^{*}$ sort to industry 2 , and the marginal workers with ability equal to $q_{L}^{*}$ are paid the same wage by both sectors. Sorting of workers is guided by $s_{L}$, the cross-industry comparison of the ratio of the elasticity of productivity with respect to ability to the elasticity of output with respect to quantity.

What about the managers? In the appendix we show that the zero profit condition, $\Pi_{i}\left(q_{H}\right)=0$ for all $q_{H} \in Q_{H i}$, together with (2), (3) and (4), imply that

$$
r\left(q_{H}\right)=r_{i} q_{H}^{\beta_{i} /\left(1-\gamma_{1}\right)} \text { for all } q_{H} \in Q_{H i}, i=1,2,
$$

where $r_{i}$ is a constant analogous to $w_{i} \cdot{ }^{18}$ Then the condition that $\Pi_{j}\left(q_{H}\right) \leq 0$ for all $q_{H} \in Q_{H i}$,

\footnotetext{
${ }^{18}$ The constants, $w_{1}$ and $w_{2}$, are determined along with $q_{L}^{*}$ by a pair of labor-market clearing conditions for the
} 
$j \neq i$, (i.e., that firms do not want to hire the managers employed in the opposite sector) dictates the sorting pattern for managers: If $s_{H} \equiv \beta_{1} /\left(1-\gamma_{1}\right)-\beta_{2} /\left(1-\gamma_{2}\right)>0$, then managers with ability above some cutoff $q_{H}^{*}$ sort to sector 1 and those with ability below $q_{H}^{*}$ sort to sector 2 ; otherwise, the sorting pattern is just the opposite. Notice that the sorting pattern for managers can be understood similarly to that for workers. Constant returns to scale implies that the elasticity of output with respect to the number of managers in sector $i$ is $1-\gamma_{i}$. So, the sorting of managers is guided by a cross-industry comparison of the ratio of the elasticity of productivity with respect to manager ability to the elasticity of output with respect to the number of managers. ${ }^{19}$

The case of Cobb-Douglas productivity generates what we will call a threshold equilibrium; the sorting pattern in general equilibrium is characterized by a pair of boundary points, $q_{L}^{*}$ and $q_{H}^{*}$, such that all workers with ability above $q_{L}^{*}$ sort to some sector and all workers with ability below $q_{L}^{*}$ sort to the other, and similarly all managers with ability above $q_{H}^{*}$ sort to some sector while those with ability below $q_{H}^{*}$ sort to the other. ${ }^{20}$ We note for future reference that there are two possible types of threshold equilibrium that can emerge. If $s_{L}$ and $s_{H}$ share the same sign, then the most able workers and the most able managers sort to the same sector. We will refer to this below as an $H H / L L$ equilibrium, to convey that the "high types" of both factors sort together, as do the "low types." Alternatively, if $s_{L}$ and $s_{H}$ are opposite in sign, then the more able managers sort to the same sector as the less able workers. We will refer to such an outcome as an $H L / L H$ equilibrium. Recall Observation 1 in Section 2, which suggests that the $H H / L L$ equilibrium may be the more empirically relevant of the two.

\subsection{Matching and Sorting with Strictly Log Supermodular Productivity}

Armed with an understanding of the knife-edge case of Cobb-Douglas productivity, we turn to a case with stronger complementarities between manager and worker abilities that arises under Assumption 1'.

When the productivity function $\psi_{i}\left(q_{H}, q_{L}\right)$ for $i=1,2$ is strictly log supermodular, the arguments presented in Eeckhout and Kircher (2012) imply positive assortative matching (PAM) in each industry. That is, among the workers and managers that sort to any industry, the better workers are teamed with the better managers. This is true, because the productivity of a group of more able workers relative to that of a group of less able workers is higher when the groups are combined with a more able manager compared to when they are combined with a less able manager. As we shall see, the equilibrium may or may not exhibit PAM for the economy as a whole.

In the appendix, we show that the solution to the firms' profit maximization problem and the requirements for factor-market clearing together generate equilibrium allocation sets $Q_{L i}$ and $Q_{H i}$

two sectors (which are provided in the appendix) and the requirement that the wage function is continuous at $q_{L}^{*}$; i.e., $w_{1}\left(q_{L}^{*}\right)^{\alpha_{1} / \gamma_{1}}=w_{2}\left(q_{L}^{*}\right)^{\alpha_{2} / \gamma_{2}}$. Given $w_{1}$ and $w_{2}$, the salary anchors $r_{1}$ and $r_{2}$ are readily calculated.

${ }^{19}$ We do not consider the non-generic situations that arise when $s_{L}=0$ or $s_{H}=0$, in which case the heterogeneous workers or managers would be indifferent as to their choice of sector.

${ }^{20}$ For some prices, there may be complete specialization in one sector or the other, in which case $q_{L}^{*}=q_{L}$ min or $q_{L}^{*}=q_{L \max }$ and $q_{H}^{*}=q_{H \text { min }}$ or $q_{H}^{*}=q_{H \text { max }}$. In such cases, marginal changes in prices have no effect on the equilibrium, and so they are uninteresting for our purposes. We do not consider them any further. 
that are unions of closed intervals. (A threshold equilibrium is the special case in which each $Q_{F i}$ for $F=H, L$ and $i=1,2$ is a single closed interval.)

Recall now that $m_{i}\left(q_{H}\right)$ is the common ability level of the workers who would be teamed with a manager of ability $q_{H}$ if that manager happened to be employed in sector $i$. The equilibrium matching function for the economy, which we denoted by $m\left(q_{H}\right)$, consists of $m_{1}\left(q_{H}\right)$ for $q_{H} \in Q_{H 1}$ and $m_{2}\left(q_{H}\right)$ for $q_{H} \in Q_{H 2}$. The matching function generates a pair of closed graphs,

$$
M_{i}=\left[\left\{q_{H}, q_{L}\right\} \mid q_{L} \in m_{i}\left(q_{H}\right) \text { for all } q_{H} \in Q_{H i}\right], i=1,2,
$$

where $M_{i}$ represents the production units that form in sector $i$ in equilibrium. These graphs comprise a union of connected sets $M_{i}^{n}$, i.e., $M_{i}=\cup_{n \in N_{i}} M_{i}^{n}$, such that $m_{i}\left(q_{H}\right)$ is continuous and strictly increasing in each set but may jump discontinuously between them. The fact that $m_{i}\left(q_{H}\right)$ is strictly increasing in each set is a reflection of PAM.

We prove in the appendix that the equilibrium wage schedule is differentiable everywhere and use the notation for the matching function to rewrite (3) slightly as

$$
\frac{\varepsilon_{i L}\left[q_{H}, m\left(q_{H}\right)\right]}{\gamma_{i}}=\varepsilon_{w}\left[m\left(q_{H}\right)\right] \text { for all }\left\{q_{H}, m\left(q_{H}\right)\right\} \in M_{i}^{n, i n t}, i=1,2,
$$

where $M_{i}^{n, i n t}$ is the interior of the set $M_{i}^{n}$. This way of expressing a firm's optimal choice of workers given the identity of the manager emphasizes the fact that the elasticity of productivity with respect to worker ability depends upon the particular matches between workers and managers that actually form in equilibrium. These matches in turn reflect the sorting patterns of workers and managers to industries.

Using (2) and (3), the zero-profit condition $\Pi_{i}\left(q_{H}\right)=0$ for all $q_{H} \in Q_{H i}$ can be written now as

$$
r\left(q_{H}\right)=\gamma_{i}^{\frac{\gamma_{i}}{1-\gamma_{i}}}\left(1-\gamma_{i}\right) p_{i}^{\frac{1}{1-\gamma_{i}}} \psi_{i}\left[q_{H}, m\left(q_{H}\right)\right]^{\frac{1}{1-\gamma_{i}}} w\left[m\left(q_{H}\right)\right]^{-\frac{\gamma_{i}}{1-\gamma_{i}}} \quad \text { for all } q_{H} \in Q_{H i}, i=1,2
$$

This equation and (6) imply that

$$
\frac{\varepsilon_{i H}\left[q_{H}, m\left(q_{H}\right)\right]}{1-\gamma_{i}}=\varepsilon_{r}\left(q_{H}\right) \text { for all }\left\{q_{H}, m\left(q_{H}\right)\right\} \in M_{i}^{n, i n t}, i=1,2,
$$

where $\varepsilon_{r}\left(q_{H}\right) \equiv q_{H}\left[\partial r\left(q_{H}\right) / \partial q_{H}\right] / r\left(q_{H}\right)$. Notice the similarity with (6); profit maximization and zero profits ensure that the ratio of the elasticity of productivity with respect to manager ability to the elasticity of output with respect to manager quantity is equal, in equilibrium, to the elasticity of the salary schedule. But, as with workers, the elasticity of productivity with respect to (manager) ability depends on the matches that take place.

Equations (6) and (8) comprise a pair of differential equations that relate the matching function, the wage schedule and the salary schedule. ${ }^{21} \mathrm{~A}$ third such equation can be derived from the

\footnotetext{
${ }^{21}$ To see that these are differential equations, note that $\varepsilon_{w}\left[m\left(q_{h}\right)\right] \equiv m\left(q_{H}\right) w^{\prime}\left[m\left(q_{H}\right)\right] / w\left[m\left(q_{H}\right)\right]$ and $\varepsilon_{r}\left[q_{H}\right] \equiv$ $q_{H} r^{\prime}\left(q_{H}\right) / r\left(q_{H}\right)$.
} 
requirements for factor-market clearing. To this end, consider any connected set of managers $\left[q_{H a}, q_{H}\right]$ that sorts to industry $i$ and the set of workers $q_{L} \in\left[m\left(q_{H a}\right), m\left(q_{H}\right)\right]$ with whom these managers are matched in equilibrium. A profit-maximizing firm in sector $i$ that employs a manager with ability $q_{H}$ and workers of ability $q_{L}$ hires $\gamma_{i} r\left(q_{H}\right) /\left(1-\gamma_{i}\right) w\left(q_{L}\right)$ workers per manager. Since the matching function is everywhere increasing, it follows that

$$
\bar{H} \int_{q_{H a}}^{q_{H}} \frac{\gamma_{i} r(q)}{\left(1-\gamma_{i}\right) w[m(q)]} \phi_{H}(q) d q=\bar{L} \int_{m\left(q_{H a}\right)}^{m\left(q_{H}\right)} \phi_{L}[m(q)] d q,
$$

where the left-hand side is the measure of workers hired collectively by all firms operating in sector $i$ that employ managers with ability between $q_{H a}$ and $q_{H}$ and the right-hand side is the measure of workers available to be teamed with those managers. Since the left-hand side is differentiable in $q_{H}$ as long as $q_{H}$ is not a boundary point between managers that sort to different industries, this equation implies that the matching function $m\left(q_{H}\right)$ also is differentiable at such points. That being the case, we can differentiate the labor-market clearing condition with respect to $q_{H}$ to derive a differential equation for the matching function, namely

$$
\bar{H} \frac{\gamma_{i} r\left(q_{H}\right)}{\left(1-\gamma_{i}\right) w\left[m\left(q_{H}\right)\right]} \phi_{H}\left(q_{H}\right)=\bar{L} \phi_{L}\left[m\left(q_{H}\right)\right] m^{\prime}\left(q_{H}\right) \text { for all }\left\{q_{H}, m\left(q_{H}\right)\right\} \in M_{i}^{n, i n t}, i=1,2 \text {. }
$$

This condition states that the workers demanded by a (small) set of managers with ability in a small range around $q_{H}$ equals the density of workers in the economy that match with these managers.

At last, we are in a position to characterize an equilibrium allocation for the economy, given prices. Such an allocation is fully described by a quadruple of sets, $Q_{i F}$ for $F=H, L$ and $i=1,2$, a continuous wage schedule $w\left(q_{L}\right)$, a continuous salary schedule $r\left(q_{H}\right)$ and a piecewise continuous matching function $m\left(q_{H}\right)$ that satisfy the differential equations (6), (8) and (9) and that yield zero profits per (7) for any active sector (and non-positive profits for any inactive sector).

The sorting patterns in this economy can in principle be quite complex. We wish to identify conditions that ensure a simple pattern - in particular, a threshold equilibrium — which, as we have seen, is the pattern that always emerges in an economy with Cobb-Douglas productivity functions. To motivate our first proposition, recall Figure 4. The figure shows the wage function and shadow wage functions that result with Cobb-Douglas productivity. To the right of the cutoff, $q_{L}^{*}$, the firms in industry 1 are willing to pay the (high-ability) workers more than firms in industry 2 , because the ratio of the elasticity of productivity with respect to worker ability to the elasticity of output with respect to number of workers, $\varepsilon_{i L} / \gamma_{i}=\alpha_{i} / \gamma_{i}$, is higher there. Similarly, to the left of $q_{L}^{*}$, it is industry 2 that is willing to pay the (low-ability) workers more, because $\varepsilon_{i L} / \gamma_{i}$ is lower there. The wage and shadow-wage functions reflects these elasticity ratios at each point in the ability distribution.

The wage and shadow-wage functions also reflect these elasticity ratios in an economy with strictly log supermodular productivity functions; see (3). A potential complication arises, however, because the elasticity ratio for a worker depends upon the identity of the manager with whom 
the worker is matched, which in turn depends upon the incentives for sorting that confront the managers. But suppose that the elasticity ratio in industry 1 is higher than in industry 2 , even if in the former case the workers of some ability level are teamed with the economy's least able manager and in the latter case they are teamed with the economy's most able manager. Considering the complementarity between worker and manager ability levels, the elasticity ratio in industry 1 for a given worker then must be higher than that in industry 2 for the matches that actually take place, no matter what they happen to be. These circumstances ensure the existence of a cutoff ability level for workers $q_{L}^{*}$ such that firms in industry 1 are willing to pay workers with ability above $q_{L}^{*}$ more than industry 2 , and the opposite is true for workers with ability less than $q_{L}^{*}$ - for much the same reasons as in the case of Cobb-Douglas productivity. In the appendix, we formally prove

Proposition 1 Suppose that Assumption $1^{\prime}$ holds and that

$$
\frac{\varepsilon_{i L}\left(q_{H \min }, q_{L}\right)}{\gamma_{i}}>\frac{\varepsilon_{j L}\left(q_{H \max }, q_{L}\right)}{\gamma_{j}}
$$

for all $q_{L} \in S_{L}, \quad i \neq j, \quad i \in\{1,2\}$. Then, in any competitive equilibrium with employment of workers in both sectors, the more able workers with $q_{L}>q_{L}^{*}$ are employed in sector $i$ and the less able workers with $q_{L}<q_{L}^{*}$ are employed in sector $j$, for some $q_{L}^{*} \in S_{L}$.

We have seen for the case of Cobb-Douglas productivity that an analogous condition that compares elasticity ratios across sector guides the sorting of managers. Specifically, whichever industry has the higher ratio of the elasticity of productivity with respect to manager ability to the elasticity of output with respect to manager quantity attracts the more able managers. Again, with a general, strictly log supermodular productivity function the sorting incentives for the other factor (workers, in this case) can complicate this comparison of elasticity ratios. But, in analogy to Proposition 1, they will not do so if the forces attracting the more able managers to sort to a sector would remain active even if the match there were consummated with the economy's least able workers and the match in the other sector were consummated with the economy's most able workers. We record

Proposition 2 Suppose that Assumption $1^{\prime}$ holds and that

$$
\frac{\varepsilon_{i H}\left(q_{H}, q_{L \min }\right)}{1-\gamma_{i}}>\frac{\varepsilon_{j H}\left(q_{H}, q_{L \max }\right)}{1-\gamma_{j}}
$$

for all $q_{H} \in S_{H}, \quad i \neq j, \quad i \in\{1,2\}$. Then, in any competitive equilibrium with employment of managers in both sectors, the more able managers with $q_{H}>q_{H}^{*}$ are employed in sector $i$ and the less able managers with $q_{H}<q_{H}^{*}$ are employed in sector $j$, for some $q_{H}^{*} \in S_{H}$.

Clearly, if the inequality in Proposition 1 holds for some $i$ and $j$ and the inequality in Proposition 2 also holds for some $i^{\prime}$ and $j^{\prime}$, then the outcome is a threshold equilibrium. As with the case of Cobb-Douglas productivity, such an equilibrium can take one of two forms. If $i=i^{\prime}$ and $j=j^{\prime}$, 
then the more able workers sort to the same sector as the more able managers, which characterizes an $H H / L L$ equilibrium. Alternatively, if $i=j^{\prime}$ and $j=i^{\prime}$, then the more able workers sort to the opposite sector from the more able managers, which defines an $H L / L H$ equilibrium.

It is possible to provide a weaker sufficient condition for the existence of a threshold equilibrium of the $H H / L L$ variety. If the most able managers sort to industry 1 , this can only strengthen the incentives for the most able workers to sort there too in light of the complementarities between factor types. Similarly, if the most able workers sort to industry 1, this will strengthen the incentives for the most able managers to do so as well. This reasoning motivates the following proposition (proven in the appendix), that has less stringent conditions for the emergence of an $H H / L L$ threshold equilibrium.

Proposition 3 Suppose that Assumption $1^{\prime}$ holds. If

$$
\frac{\varepsilon_{i L}\left(q_{H}, q_{L}\right)}{\gamma_{i}}>\frac{\varepsilon_{j L}\left(q_{H}, q_{L}\right)}{\gamma_{j}} \text { for all } q_{H} \in S_{H}, \quad q_{L} \in S_{L}
$$

and

$$
\frac{\varepsilon_{i H}\left(q_{H}, q_{L}\right)}{1-\gamma_{i}}>\frac{\psi_{j H}\left(q_{H}, q_{L}\right)}{1-\gamma_{j}} \text { for all } q_{H} \in S_{H}, \quad q_{L} \in S_{L},
$$

for $i \neq j, i=1$ or $i=2$, then in any competitive equilibrium with employment of managers and workers in both sectors, the more able managers with $q_{H}>q_{H}^{*}$ and the more able workers with $q_{L}>q_{L}^{*}$ are employed in sector $i$, while the less able managers with $q_{H}<q_{H}^{*}$ and the less able workers with $q_{L}<q_{L}^{*}$ are employed in sector $j$, for some $q_{H}^{*} \in S_{H}$ and some $q_{L}^{*} \in S_{L}$.

The difference in the antecedents in Propositions 1 and 2 on the one hand and in Proposition 3 on the other is that, in the former, we compare the elasticity ratio for each factor when it is combined with the least able type of the other factor in one sector versus the most able type in the other sector, whereas in the latter we compare the elasticity ratios for common partners in the two sectors. The difference arises, because an $H H / L L$ equilibrium has PAM within and across industries, whereas an $H L / L H$ equilibrium has PAM only within industries. In an $H L / L H$ equilibrium, an able manager in sector $i$ might be tempted to move to sector $j$ despite a generally greater responsiveness of productivity to ability in $i$, because the better workers have incentive to sort to $j$, and with log supermodularity of $\psi_{j}(\cdot)$, the able manager stands to gain most from this superior match. In contrast, in an $H H / L L$ equilibrium, the able manager in sector $i$ would find less able workers to match with were she to move to sector $j$, so the temptation to switch sectors in order to upgrade partners is not present.

We have provided sufficient conditions for the existence of a threshold equilibrium in which the allocation set for each factor and industry comprises a single, connected interval. These conditions are not necessary, however, because the matches available to types that are quite different from the marginal type might not overturn their strong comparative advantage in one sector or the other. Nonetheless, not all parameter configurations give rise to equilibria with such a simple sorting 


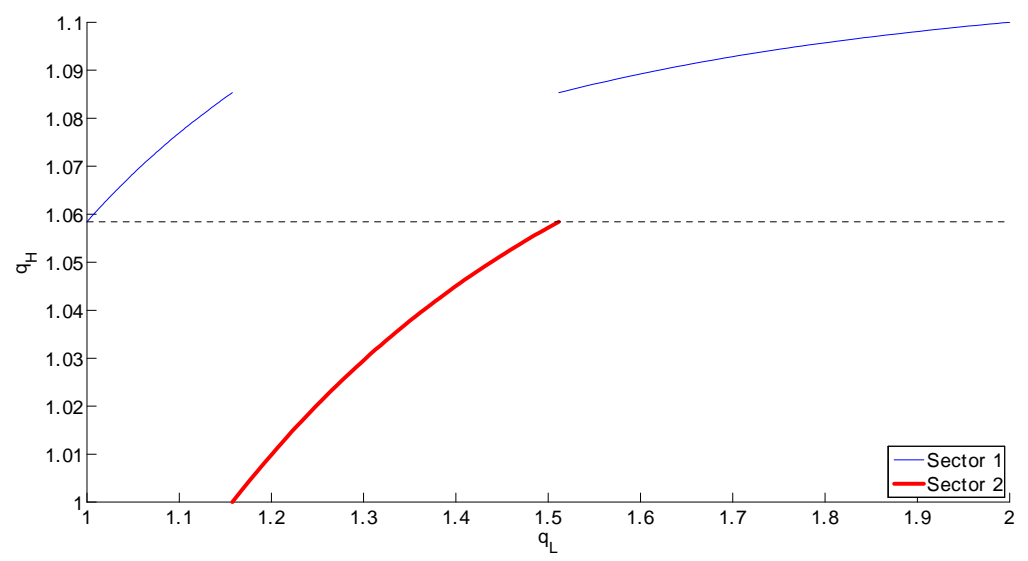

Figure 5: Matching: The most and least able workers and the most able mangers sort into sector 1

pattern. An example of a more complex sorting pattern is illustrated in Figure $5 .^{22}$ The figure shows, for each worker type indicated along the horizontal axis, the sector in which that worker is employed and the type of the manager with whom he is matched. In this example, the most able and least able workers sort to sector 1 while an intermediate interval of worker types sort to sector 2. The firms in sector 1 hire the economy's most able managers whereas those in sector 2 hire those with ability below some threshold level. Notice that graphs $M_{1}$ and $M_{2}$ display the general properties that we described above; they are unions of connected sets, with a matching function $m\left(q_{H}\right)$ that is continuous and increasing within any such set. The figure reflects a "sorting reversal" for workers that arises because the elasticity ratio for labor is higher in sector 1 when worker ability is low or high, but higher in sector 2 for a middle range of abilities. Of course, other sorting patterns besides that depicted in Figure 5 also are possible.

\section{$5 \quad$ Matching and Earnings within Groups}

Before we turn to the effects of changes in the trade environment on the distributions of wages and salaries, it will prove useful to examine in some detail the implications of our equilibrium conditions for the particular matches that form among a group of workers and a group of managers that happen to be combined in equilibrium, and for the distributions of wages and salaries in the two groups. To this end, consider a group of managers comprising all those with ability in the interval $Q_{H}=\left[q_{H a}, q_{H b}\right]$ and a group of workers comprising all those with ability in the interval $Q_{L}=\left[q_{L a}, q_{L b}\right]$. Suppose these two groups happen to sort to some industry $i$ in a competitive equilibrium and that, collectively, the managers and workers in these two groups happen to be matched together, exhaustively. We are interested in the properties of the solution to the system of differential equations comprising (6), (8) and (9) along with the zero-profit condition, (7), and the two boundary conditions, $q_{L a}=m_{i}\left(q_{H a}\right)$ and $q_{L b}=m_{i}\left(q_{H b}\right)$. Throughout this section, we

\footnotetext{
${ }^{22}$ The functional forms and parameter values underlying this example are presented in Lim (2013).
} 


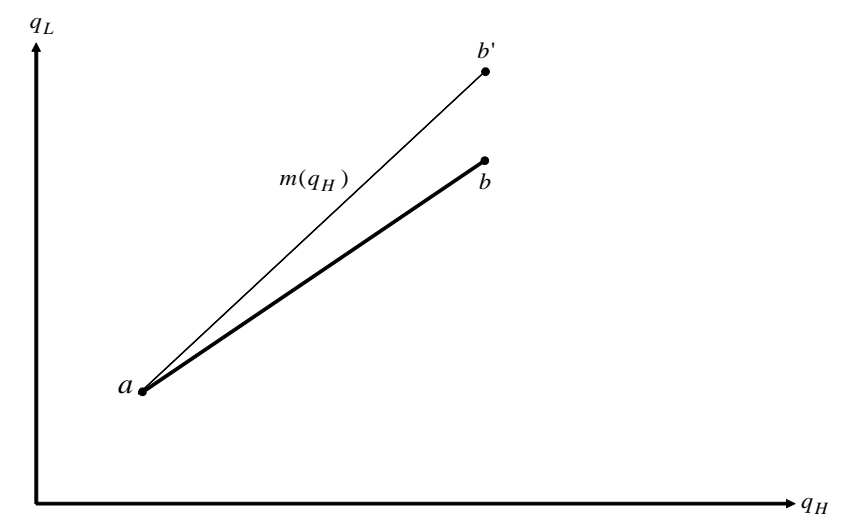

Figure 6: Shift in the matching function when $q_{L b}$ rises to $q_{L b^{\prime}}$.

assume the existence of strong complementarities between worker and manager types; i.e., we take productivity to be a strictly log supermodular function of the two ability levels, as embodied in Assumption 1'.

In the appendix, we prove that the solution has several notable properties. First, if the price $p_{i}$ were to rise without any change in the composition of the two groups, then the matches between particular members of the groups would remain unchanged and all wages and salaries would rise by the same proportion as the output price. Second, if the number of managers in $Q_{H}$ were to increase by some proportion $h$ relative to the number of workers in $Q_{L}$, without any change in the relative densities of the different types, then the wages of all workers in $Q_{L}$ would rise by the proportion $\left(1-\gamma_{i}\right) h$, while the salaries of all types in $Q_{H}$ would fall by the proportion $\gamma_{i} h$. Again, there would be no change in the matching between manager and worker types.

Now suppose that one or both of the groups were to expand or contract on the extensive margin without any change in the composition of types among the original members of the two groups. That is, suppose that $Q_{H}$ were to change to $Q_{H}^{\prime}=\left[q_{H a}^{\prime}, q_{H b}^{\prime}\right]$ and $Q_{L}$ were to change to $Q_{L}^{\prime}=\left[q_{L a}^{\prime}, q_{L b}^{\prime}\right]$, but with no change in $\bar{L} \phi_{L}\left(q_{L}\right)$ or $\bar{H} \phi_{H}\left(q_{H}\right)$. We find (see Lemma 2 in the appendix) that the matching functions that apply before and after the change can intersect at most once. Moreover (see Lemma 6), if such an intersection exists, the situation with the steeper matching function at the point of intersection also has lower wages and higher salaries for all ability levels of workers and managers that are common to the two settings. This reflects the associated changes in the sizes of the production units; a steeper matching function implies that each manager is teamed with a larger group of workers, which enhances the marginal product of the manager and reduces the marginal product of the workers at any given ability level of either factor.

These points can be seen more clearly with the aid of Figure 6. The figure depicts the adjustment in matching that would result from a change in a single boundary point, an increase in the uppermost ability level of workers in the group from $q_{L b}$ to $q_{L b^{\prime}}$. The curve $a b$ represents the match- 
ing that takes place between the initial groups of workers and managers, whereas $a b^{\prime}$ represents the matching of the same set of managers with the broader set of workers. Naturally, the two curves have a point in common, at $a$; PAM ensures that the managers with ability $q_{H a}$ match with the workers of ability $q_{L a}$ in both circumstances. By Lemma 2 in the appendix, the two curves can have at most one point in common, so there can be no further points of intersection. That is, the new matching function $a b^{\prime}$ must lie uniformly above $a b$ to the right of point $a$. In the new equilibrium with a broader (and better) group of workers, every manager in $Q_{H}$ with ability greater than $q_{H a}$ achieves a better match than before. Meanwhile, every worker with ability greater than $q_{L a}$ but less than or equal to $q_{L b}$ pairs with a less able manager than before. Finally, Lemma 6 implies that salaries rise for all managers in $Q_{H}$, while wages fall for all workers in $Q_{L}$.

The adjustment in matching that is illustrated in Figure 6 also has implications for withingroup inequality. Consider the wage distribution among workers in $Q_{L}$. The differential equation (6) implies that

$$
\ln w_{i}\left(q_{L c}\right)-\ln w_{i}\left(q_{L c^{\prime}}\right)=\int_{q_{L c}}^{q_{L c^{\prime}}} \frac{\psi_{i L}\left[\mu_{i}(x), x\right]}{\gamma_{i} \psi_{i}\left[\mu_{i}(x), x\right]} d x, \text { for all } q_{L c,} q_{L c^{\prime}} \in Q_{L}
$$

where $\mu_{i}(\cdot)$ is the inverse of $m_{i}(\cdot)$. If follows that, if all workers with ability levels between $q_{L c}$ and $q_{L c^{\prime}}, q_{L c}>q_{L c^{\prime}}$, are teamed with less able managers than before, the wage of the more able worker of type $q_{L c}$ declines relative to that of the less able worker of type $q_{L c^{\prime}}$. The downgrading of managers is detrimental to both of these workers, but the strong complementarity between factor types means that it is especially so to the more able of the pair. Specifically, strict log supermodularity of $\psi_{i}\left(q_{H}, q_{L}\right)$ implies that $\psi_{i L}\left(q_{H}, q_{L}\right) / \psi_{i}\left(q_{H}, q_{L}\right)$ is a strictly increasing function of $q_{H}$. It follows that a rematching of a group of workers with less able managers, as depicted in Figure 6, generates a narrowing of wage inequality within the group $Q_{L} \cdot{ }^{23}$ By a similar argument (and using the differential equation (8) for salaries), the rematching depicted in Figure 6 generates a spread in the salary distribution for managers in $Q_{H}$ inasmuch as these managers all see their matches improve.

Similar reasoning can be used to describe the shift in the matching function - and the wage and salary responses - for changes in the other boundary points. For example, if the lower boundary of the interval of managers rises from $q_{\mathrm{Ha}}$ to $q_{H a^{\prime}}$, the matching function shifts downward (thereby connecting a point to the right of $a$ in Figure 6 with point $b$ ), and thus the manager types that remain in the sector find that their matches deteriorate while all workers in $Q_{L}$ match with better managers than before. Such a rematching narrows the salary distribution, while exacerbating wage inequality.

In short, whenever the matches improve for a group of workers employed in some sector, they deteriorate for the managers there, and vice versa. As a result, within-occupation-and-industry inequality among workers and managers tend to shift in opposite directions. This implication of

\footnotetext{
${ }^{23}$ Costinot and Vogel (2010) and Sampson (2014) find similar results for wage inequality when workers downgrade their matches with firms that differ in technological sophistication.
} 
our model gives it the potential to rationalize Observation 3 in Section 2, namely that changes in inequality among Brazilian workers and managers are negatively correlated across industries.

\section{The Effects of Trade on Earnings Inequality}

We come finally to the main concern of our analysis: How does trade affect the distribution of income within and between occupations and industries? We study the effects of trade by examining the comparative statics with respect to output prices. In a world of competitive industries, an opening of trade induces an increase in the relative price of a country's export good. An expansion of trade opportunities that improves a country's terms of trade does likewise. So too does a reduction in a country's import tariff or other trade barriers, except under the conditions for the Metzler paradox. So, we can study the effects of trade without introducing the details of other countries by simply investigating how output prices feed through to factor markets. ${ }^{24}$

To preview what lies ahead, we will identify and describe three forces that are at work in this setting. Two are familiar and one is new. First, whenever $\gamma_{1} \neq \gamma_{2}$, our model features factor intensity differences across industries. As is well known from the Stolper-Samuelson theorem, this consideration introduces an effect of trade on between-occupation distribution; an increase in the relative price of a good tends to increase demand for all types of the factor used intensively in producing that good, while reducing the demand for all types of the other factor. Second, our model incorporates factor heterogeneity that, whenever $\psi_{1}(\cdot) \neq \psi_{2}(\cdot)$, generates comparative advantage for certain types of each factor in one industry or the other. This feature introduces an effect of trade on between-industry distribution; an increase in the relative price of a good tends to increase the rewards for all types of both occupations that enjoy a comparative advantage in producing that good, and to reduce the returns to types that hold a comparative disadvantage in doing so. This effect is familiar from the Ricardo-Viner model with sector specificity. Finally, whenever $\psi_{i}\left(q_{H}, q_{L}\right)$ exhibits strict $\log$ supermodularity, our model determines the matches that form between managers and workers in each industry. This feature introduces an effect of trade on within-group (occupation-and-industry) distribution.

\subsection{Wages and Salaries with Cobb-Douglas Productivity}

As before, it is instructive to begin with the knife-edge case in which productivity in each sector is log supermodular, but not strictly so. We revisit an economy with Cobb-Douglas productivity; i.e., $\psi_{i}\left(q_{H}, q_{L}\right)=q_{H}^{\beta_{i}} q_{L}^{\alpha_{i}}$ for $i=1,2, \alpha_{i}, \beta_{i}>0$.

Recall from Section 4.1 that, with Cobb-Douglas productivity in each sector, the sorting of factors to sectors is guided by a cross-industry comparison of the ratio of the elasticity of productivity with respect to a factor's ability to the elasticity of output with respect to factor quantity. That

\footnotetext{
${ }^{24}$ In our working paper, Grossman et al. (2013), we link the pattern of trade to cross-country differences in quantities and distributions of the two factors. Thus, we treat the the price change that results from an opening of trade as an endogenous reflection of factor-endowment differences. Here, we take the price changes as exogenous in order to focus attention on the distributional implications of changes in the trade environment.
} 
is, when $\alpha_{i} / \gamma_{i}>\alpha_{j} / \gamma_{j}$, higher ability confers a comparative advantage among workers for employment in industry $i$, while when $\beta_{i^{\prime}} /\left(1-\gamma_{i^{\prime}}\right)>\beta_{j^{\prime}} /\left(1-\gamma_{j^{\prime}}\right)$, higher ability confers a comparative advantage among managers for employment in industry $i^{\prime}$. The matches that form between workers and managers that sort to an industry are indeterminate.

It is clear from (4) and (5) that trade has no effect on within-group inequality in these circumstances. The relative wage of any two workers with ability levels $q_{L a}$ and $q_{L b}$ that are both employed in the same sector $i$ before and after any change in the trading environment is fully determined by their relative ability levels; i.e., $w\left(q_{L a}\right) / w\left(q_{L b}\right)=\left(q_{L a} / q_{L b}\right)^{\alpha_{i} / \gamma_{i}}$. Similarly, the relative salary of any two managers with ability levels $q_{H a}$ and $q_{H b}$ that are employed in sector $i$ prior and subsequent to a change in the trading environment is $r\left(q_{H a}\right) / r\left(q_{H b}\right)=\left(q_{H a} / q_{H b}\right)^{\beta_{i} /\left(1-\gamma_{i}\right)}$. Evidently, the complementarity between factor types must be strong enough to induce endogenous meaningful rematching, or else relative wages within any occupation-and-industry group will be fixed by technological considerations and unaffected by trade.

The effects of trade on between-occupation and between-industry inequality can be seen from the comparative-static responses of the wage anchors, $w_{1}$ and $w_{2}$, and the salary anchors, $r_{1}$ and $r_{2}$. These comparative statics can be computed from six equations that also determine $q_{L}^{*}$ and $q_{H}^{*}$ : two equations that ensure that the demand for workers that sort to each sector equals the supply of workers that does so; two equations that ensure that the wage and salary schedules are continuous at $q_{L}^{*}$ and $q_{H}^{*}$, respectively; and two equations that ensure that profits are zero in each industry. The equations and calculations are provided in the appendix.

The Ricardo-Viner and Stolper-Samuelson forces can be seen most clearly in certain limiting cases. Suppose, for example, that $\gamma_{1} \approx \gamma_{2}$; i.e., there are only small cross-industry differences in the diminishing returns to the number of workers per manager and thus small differences in the intensity of factor use. In this case, if $\alpha_{i}>\alpha_{j}$, then an increase in the price ratio $p_{i} / p_{j}$ generates an increase in $w_{i}$ relative to $w_{j}$ and if $\beta_{i^{\prime}}>\beta_{j^{\prime}}$, an increase in $p_{i^{\prime}} / p_{j^{\prime}}$ generates an increase in $r_{i^{\prime}}$ relative to $r_{j^{\prime}}$. Consider for example the effect of the price change on workers. With $\gamma_{i} \approx \gamma_{j}$, the fact that $\alpha_{i}>\alpha_{j}$ implies that high-ability workers have a comparative advantage in sector $i$ relative to sector $j$, and vice versa for low-ability workers. Then, if the relative price of good $i$ increases, this changes the between-industry distribution, favoring those (high-ability workers) employed in sector $i$ relative to those (low-ability workers) employed in sector $j$. An analogous explanation applies to the changes in the between-industry distribution of managerial salaries.

Now suppose that $\gamma_{i}>\gamma_{j}$, whereas $\alpha_{1} / \gamma_{1} \approx \alpha_{2} / \gamma_{2}$ and $\beta_{1} /\left(1-\gamma_{1}\right) \approx \beta_{2} /\left(1-\gamma_{2}\right)$. With this constellation of parameters, the forces that give certain types of each factor a comparative advantage in one sector or the other are muted. No matter what sorting pattern emerges, the predominant effect of trade will be on the between-occupation distribution. In particular, since sector $i$ makes relatively intensive use of workers and sector $j$ makes relatively intensive use of managers, an increase in $p_{i} / p_{j}$ increases both $w_{i}$ and $w_{j}$ relative to both $r_{i}$ and $r_{j}$. All workers gain relative to all managers. Indeed, we can go further to say - as an extension of the StolperSamuelson theorem - that when $\gamma_{i}>\gamma_{j}$, an increase in the relative price of good $i$ raises the real 
income of every type of worker and reduces the real income of every type of manager.

Another instructive case has $\gamma_{i} \approx \gamma_{j}$ and $\beta_{1} \approx \beta_{2}$, but $\alpha_{i}>\alpha_{j}$. Then, there is little difference in factor intensity and little difference in the relative productivity of managers of different abilities in the two sectors. What remains is a strong tendency for the high-ability workers to sort to industry $i$ and the low-ability workers to sort to industry $j$, in accordance with their comparative advantages. This is a case where the workers have industry specificity, but the managers do not (or only slightly so). As in the classic Ricardo-Viner model (e.g., Jones, 1971), we find that when $p_{i} / p_{j}$ rises, the real incomes of all (high-ability) workers who start in industry $i$ increase while the real incomes of all (low-ability) workers who end up in industry $j$ fall. In other words, trade benefits the worker types that have specificity in the export sector but harms the worker types that have specificity in the import-competing sector. ${ }^{25}$ In contrast, trade has a qualitatively similar impact on all manager types; their real salaries rise in terms of good $i$ but fall in terms of good $j$.

In less extreme cases, the Stolper-Samuelson and Ricardo-Viner forces coexist. We find that the worker types with comparative advantage in industry $i$ always gain relative to those with comparative advantage in industry $j$ when the relative price of good $i$ rises. Similarly, the manager types that sort to industry $i$ gain relative to those that sort to industry $j$. Whether a group of workers or a group of managers benefits absolutely, and not just relatively, from a change in the trade environment depends on the direction and strength of the Stolper-Samuelson forces; for example, all workers may gain from an increase in $p_{i} / p_{j}$ if industry $i$ is much more labor intensive than industry $j$, whereas only some may gain if the difference in factor intensity is smaller, and all may lose if the factor-intensity ranking runs in the opposite direction. These findings are reminiscent of those described by Mussa (1982) for an economy with "imperfect factor mobility" and by Grossman (1983) for an economy with "partially mobile capital."

The results described in this section are interesting and will help us to understand those that follow. But they are not consistent with the evidence presented in Section 2, in particular because they imply that trade has no effect on within occupation-and-industry earnings inequality. We have noted, for example, that within-group variation accounted for a majority of the overall change in Brazilian income inequality that occurred during the period that spanned the trade liberalization of 1991. To allow for changes in within-group inequality, we must re-introduce Assumption $1^{\prime}$.

\subsection{Wages and Salaries with Strictly Log Supermodular Productivity}

We henceforth assume that productivity in each sector is a strictly log supermodular function of the ability of the manager and the abilities of the workers; i.e., we adopt Assumption 1'. We shall limit our attention to threshold equilibria; i.e., those that can be characterized by a pair of cutoff points, $q_{L}^{*}$ and $q_{H}^{*}$, such that all workers with ability above the cutoff sort to one industry and all those with ability below the cutoff sort to the other, and similarly for managers.

\footnotetext{
${ }^{25}$ If we instead assume that $\gamma_{i}>\gamma_{j}$ and that $\alpha_{i} / \gamma_{i}>\alpha_{j} / \gamma_{j}$, but that $\beta_{i} /\left(1-\gamma_{i}\right) \approx \beta_{j} /\left(1-\gamma_{j}\right)$, then the StolperSamuelson forces reinforce the positive effects of an increase in $p_{i} / p_{j}$ on the high-ability workers while offsetting the negative effects of this price change on the low-ability workers. In such circumstances, the real incomes of the most able workers must rise, whereas those of the least able workers can rise or fall.
} 
In the appendix we prove a general result that applies to all threshold equilibria. Consider the effects of a change in the relative price $p_{i} / p_{j}$ on output levels and factor allocation. Not surprisingly, an increase in $p_{i} / p_{j}$ induces a rise in the aggregate output of good $i$ and a decline in the aggregate output of good $j$. In principle, this could be accomplished by a reallocation of only one factor from industry $j$ to industry $i$; for example, workers might move from $j$ to $i$, while managers might move in the opposite direction. In fact, however, this does not happen in any threshold equilibrium. When $p_{i} / p_{j}$ rises, the numbers of workers and managers employed in sector $i$ both expand, while the numbers employed in sector $j$ contract. In terms of the cutoffs values that describe a threshold equilibrium, this reallocation implies an adjustment of both extensive margins. If, for example, high-ability workers sort to industry $i$ in equilibrium, then an increase in $p_{i} / p_{j}$ causes $q_{L}^{*}$ to fall. But if low-ability workers sort to industry $i, q_{L}^{*}$ rises. Similarly for managers, the direction of movement of $q_{H}^{*}$ varies according to the initial sorting pattern so that, in any case, the number of managers in industry $i$ grows.

\subsubsection{Inequality in an $H L / L H$ Equilibrium}

As we recall, a threshold equilibrium can be one of two types; either the more able types of both factors sort to the same industry (an $H H / L L$ equilibrium) or the more able types of one factor sort to the same industry as the less able types of the other (an $H L / L H$ equilibrium). We will begin with the latter, even though it is somewhat at odds with the evidence we discussed in Section 2. In both Brazil and Sweden, as we noted, there is a strong positive correlation across industries in the mean wage of workers and the mean salary of managers. This observation is most consistent with an equilibrium pattern in which the more able types of both factors sort similarly. Notwithstanding, there are some pairwise industry comparisons in the data for both countries in which the ranking of average incomes across sectors is different for the two factors. The analysis in this section might therefore be relevant for some industries and some countries. Moreover, the results for the $H L / L H$ equilibrium are easier to explain, and so it helps to begin here in order to build intuition.

In Figure 7, the solid curves $c d$ and $a b$ depict the qualitative features of the two segments of the inverse matching function in an $H L / L H$ equilibrium. Each curve is upward sloping, representing the positive assortative matching that occurs in each sector. In the figure, industry $i$ attracts the economy's best managers, i.e., those with ability levels above $q_{H}^{*}$. But this industry employes

the least able workers, those with ability levels below $q_{L}^{*}$. Evidently, PAM does not hold for the economy as a whole.

Now suppose that $p_{i} / p_{j}$ rises, as when the country opens to trade and begins to export good $i$. As we have noted, the allocations of workers and of managers to industry $i$ expand on the extensive margins. In other words, $q_{L}^{*}$ rises to a point like $\tilde{q}_{L}^{*}$, while $q_{H}^{*}$ falls to a point like $\tilde{q}_{H}^{*}$. Accordingly, the new boundary points for industry $j$ move to $a^{\prime}$ and $b^{\prime}$, whereas those for industry $i$ become $c^{\prime}$ and $d^{\prime}$.

The ex post inverse matching function for industry $j$ connects $a^{\prime}$ with $b^{\prime}$. But, by Lemma 2 in the appendix, it cannot cross $a b$ more than once. Evidently, the new curve for industry $i$ must 


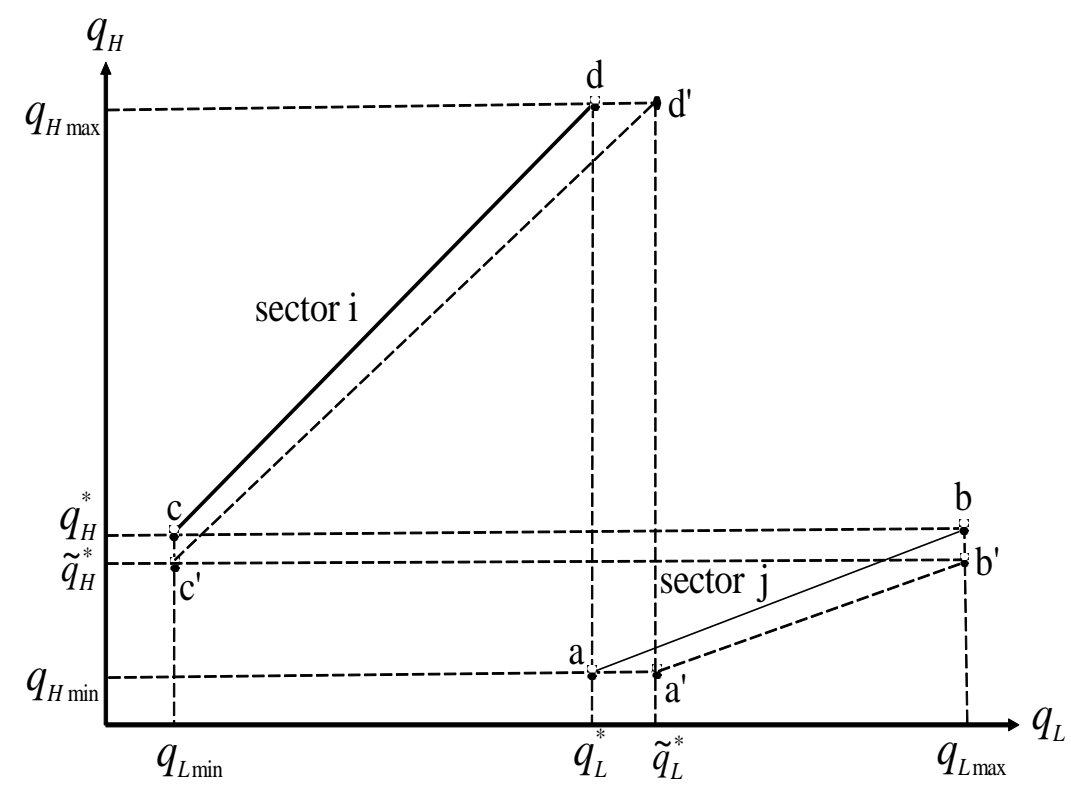

Figure 7: Effects of a rise in $p_{i} / p_{j}$ on matching: $H L / L H$ equilibrium

lie everywhere below the initial curve, as drawn. By similar reasoning, the new inverse matching function for industry $i$ also must lie everywhere below the old curve; it must connect $c^{\prime}$ and $d^{\prime}$ and it cannot cross $c d$ twice. We conclude that every worker initially employed in industry $i$ and every worker who remains employed in industry $j$ matches with a less able manager than before. Only the workers that switch sectors team with better managers than they did prior to the price hike. Correspondingly, all of the managers in the economy who initially were employed in industry $i$ or who remain employed in industry $j$ are matched with more able workers than before. Those who switch sectors - namely, those who were initially matched with the very best workers in the economy - experience a deterioration in match.

The rematching described in the previous paragraph has strong implications for within occupationand-industry income inequality. Consider the relative wage of any two workers with abilities $q_{L a}$ and $q_{L b}, q_{L a}>q_{L b}$, who were employed in sector $i$ prior to the increase in the relative price and who, of course, remain so afterward. The downward shift in the inverse matching function, $\mu_{i}\left(q_{L}\right)$ implies, by (10), that the relative wage $w\left(q_{L a}\right) / w\left(q_{L b}\right)$ declines. Both workers - and all others originally employed in industry $i$ - experience a downgrading of their manager. The partial effect of this is detrimental to the productivity of both, but especially so for the more able of the two. As we shall see, this does not necessarily mean that the workers lose in real terms, as there are between-occupation and between-industry effects yet to be considered. But it does mean that the wage schedule among workers in industry $i$ tilts in favor of those at the bottom end of the industry's pay scale. Within occupation-and-industry wage inequality declines among workers initially employed in the export sector.

The same is true among workers that remain employed in sector $j$ subsequent to the contraction 

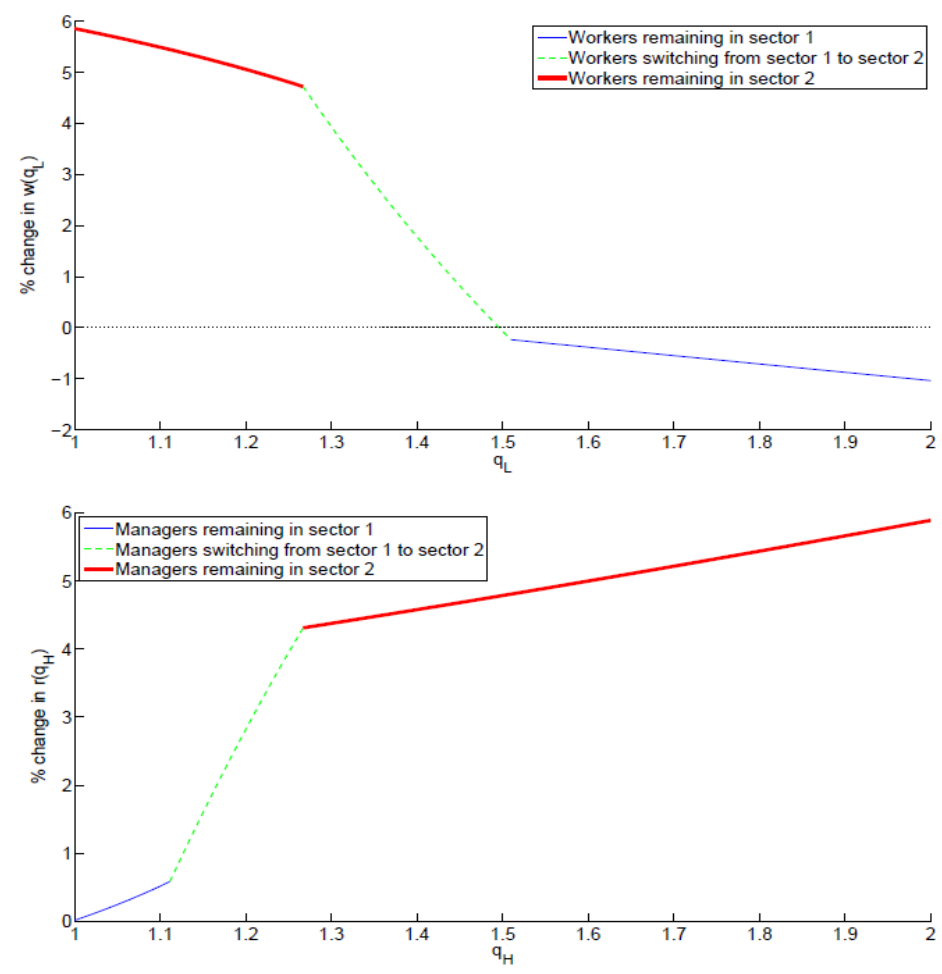

Figure 8: Effects of a $5 \%$ increase in $p_{2}$ on wages and salaries in an $H L / L H$ equilibrium without Stolper-Samuelson forces

of that industry. Among any two such workers, the downward shift in $\mu_{j}\left(q_{L}\right)$ implies a relative wage gain for the less able of the two. This tilting of the wage schedule spells a decline in within occupation-and-industry inequality for this group of workers as well. Moreover, wage inequality also declines for the set of workers that switches industries. ${ }^{26}$ It follows that a plot of proportional wage changes against $q_{L}$ is downward sloping along its entire length; see the top panel of Figure 8 (discussed further below) for an example. This implies, of course, that wage inequality declines among workers as a whole. We emphasize too that every worker in industry $i$ gains relative to any counterpart in industry $j$, which is an indication of between-industry wage redistribution. This redistribution is analogous to what we described in Section 6.1 for the case of Cobb-Douglas productivity. It reflects the fact that a worker's type confers comparative advantage in one industry or the other and so imparts a degree of sector specificity.

The results for managerial salaries are analogous. The match improvements for managers that initially were employed in sector $i$ and for those that continue to be employed in sector $j$ imply a widening of the within occupation-and-industry salary distribution for both of these groups. Income inequality also rises among the set of managers that reallocates from industry $j$ to industry $i$, and

\footnotetext{
${ }^{26}$ Consider two workers, with abilities $q_{L c}$ and $q_{L d}$ that both switch industries, with $q_{L c}>q_{L d}$. By (6), the elasticity of the wage schedule $\varepsilon_{w}\left(q_{L}\right)$ is determined, ex post, by the elasticity ratio for the expanding industry $i$; whereas beforehand it was determined by the elasticity ratio for the contracting industry $j$. The condition for the sorting of high-abiilty workers to sector $i$ implies that the former elasticity ratio is higher. Accordingly, the wage elasticity falls among this group of workers.
} 
among the occupation as a whole. We summarize our findings about the effects of relative price movements on wage and salary inequality in an $H L / L H$ equilibrium with the following proposition:

Proposition 4 Suppose that Assumption 1' holds and that there exists a threshold equilibrium with an $H L / L H$ sorting pattern for all $p_{i} \in\left[p_{i 0}, p_{i 1}\right]$. Then an increase in $p_{i}$ from $p_{i 0}$ to $p_{i 1}$ raises within occupation-and-industry income inequality and overall income inequality for the factor whose highability types sort to industry $i$ and reduces within occupation-and-industry income inequality and overall income inequality for the factor whose high-ability types sort to industry $j$.

Notice that Proposition 4 makes no reference to the factor intensities in the two sectors.

While Proposition 4 speaks to inequality within occupations, it says nothing about redistribution between occupations, nor about the effects of trade on the (absolute) real income levels of any groups. For this we turn to numerical simulations and to the intuition that we developed for the case of Cobb-Douglas productivity. Figure 8 presents the outcome of a simulation with $\gamma_{1}=\gamma_{2}$, although qualitatively similar results apply whenever the difference between the relative factor intensities of the two sectors is reasonably small. ${ }^{27}$ The figure shows the percentage change in wages (in the top panel) and salaries (in the bottom panel) across the full range of ability levels in response to a $5 \%$ increase in the price of good 2. This is a case where Stolper-Samuelson forces are absent, and the findings are consistent with the intuition of the Ricardo-Viner model. First, the highest-ability manager and the lowest-ability worker both see their incomes rise by more than $5 \%$, which indicates real income gains for both. These individuals are the ones with the strongest comparative advantage in industry 2, the expanding industry. In general, incomes of those (workers or managers) who are initially employed in industry 2 rise substantially relative to those of their occupational counterparts that remain employed in industry 1 . In this example, all the workers who remain in industry 1 suffer nominal wage losses and thus declines in real incomes. The managers in industry 1 , on the other hand, see small salary gains, and so their real incomes might rise if their expenditures are sufficiently biased toward the good they produce. In any case, the figure highlights the between-industry redistribution that results from the specificity of the different factor types. The figure also shows, as previously noted, a ubiquitous narrowing of the wage distribution and spreading of the salary distribution that reflects the rematching in each industry.

Figure 9 depicts the wage and salary responses to a $10 \%$ increase in the price of good 2 for an economy with a substantial difference in factor intensities; in particular, industry 2 is significantly more worker-intensive than industry $1 .^{28}$ The outcomes reflect the strong between-occupation distributional forces at work in this case. All of the workers, regardless of ability, see a rise in

\footnotetext{
${ }^{27}$ The details of the simulation method and the parameter values and results for many examples are provided in Kim (2013). All examples use truncated Pareto distributions for the distributions of worker and manager abilities and a CES specification for $\psi_{i}\left(q_{H}, q_{L}\right)$, with an elasticity of substitution less than one that ensures strict log supermodularity.

${ }^{28}$ The astute reader may have noticed that we illustrate the effects of a $10 \%$ price increase here, whereas Figure 8 depicted the effects of a smaller, $5 \%$ change. Since our model is not log linear, price hikes of different percentage amounts have quantitatively different effects on factor prices. We have chosen the numerical examples in order to enhance visual clarity.
} 

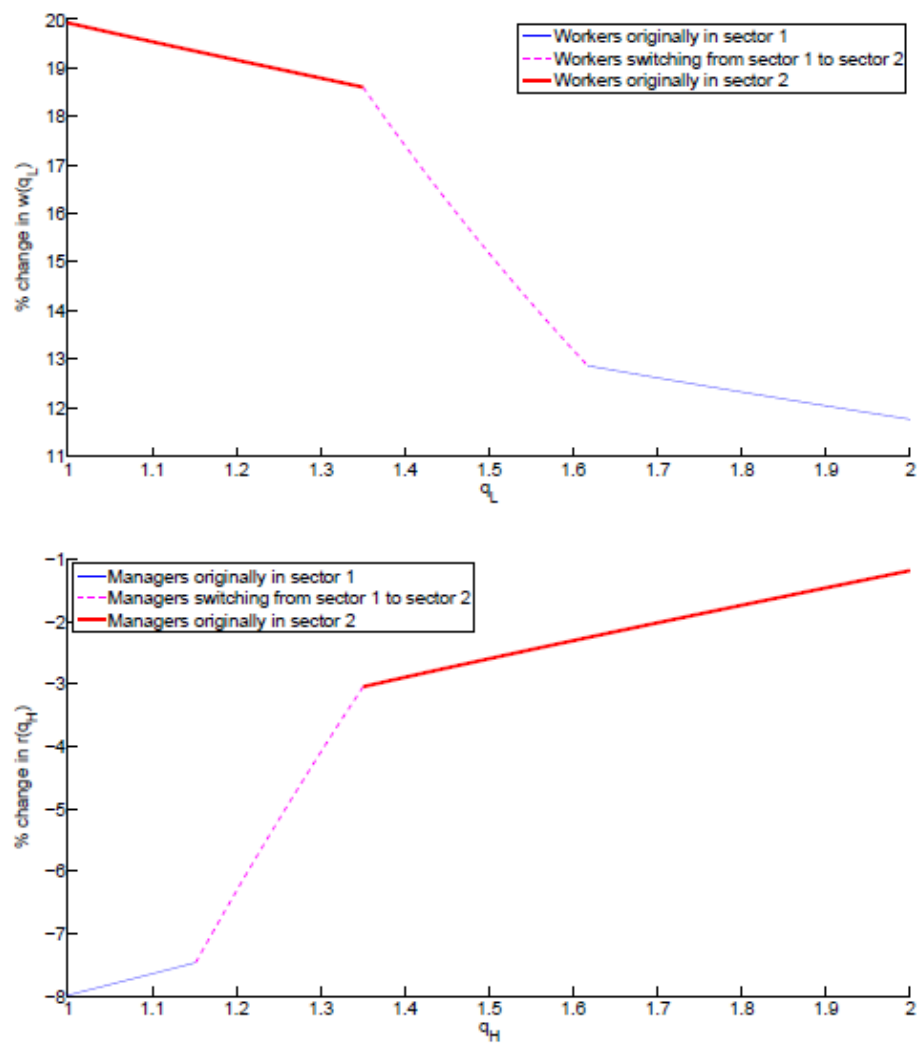

Figure 9: Effects of a $10 \%$ increase in $p_{2}$ on wages and salaries in an $H L / L H$ equilibrium with strong Stolper-Samuelson forces 


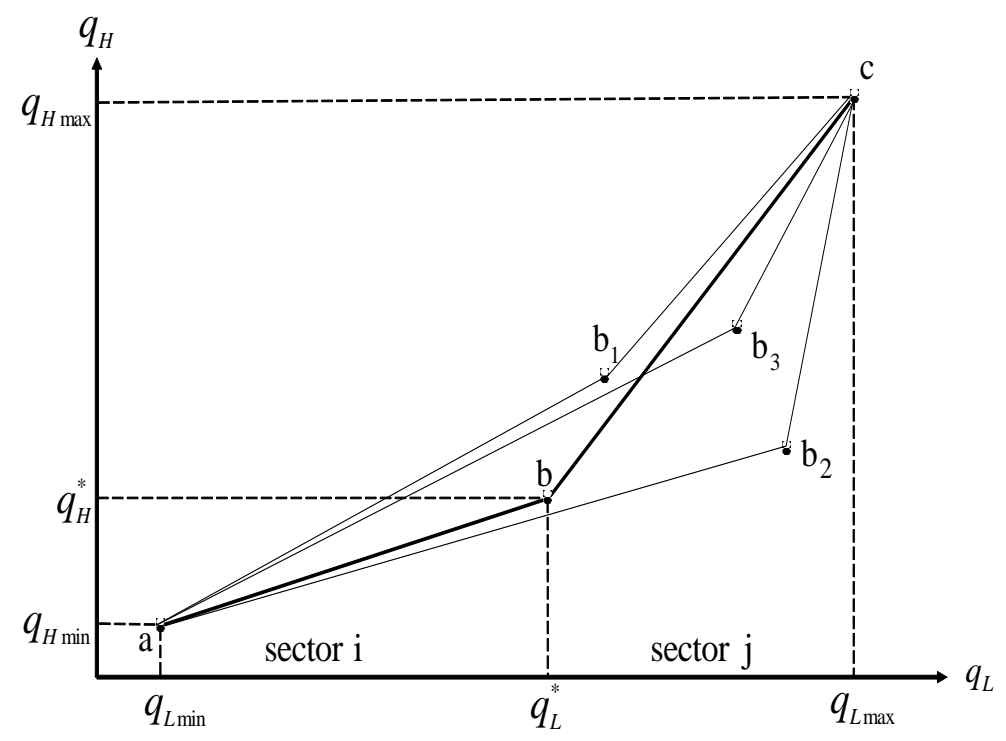

Figure 10: Effects of a rise in $p_{i} / p_{j}$ on matching: $H H / L L$ equilibrium

real wage, while all of the managers suffer real income losses. Of course, the workers employed in industry 2 fare better than their counterparts in industry 1 , since their types confer a comparative advantage in producing good 2. Similarly, the very able managers employed in industry 2 experience smaller real income losses than their less able counterparts. Again, the figure shows the ubiquitous increase in salary inequality and ubiquitous fall in wage inequality that are prescribed by Proposition 4 .

A host of other configurations can emerge, but all can be understood similarly with reference to the relevant factor intensities that generate between-occupation redistribution and the sectorspecificities that generate between-industry redistribution; see Lim (2013) for further examples. Rather than dwell on these intermediate cases, we turn now to the wage and salary effects of trade in an $H H / L L$ equilibrium.

\subsubsection{Inequality in an $H H / L L$ Equilibrium}

The data for Brazil and Sweden reveal a strong positive correlation between the average wage paid to workers and the average salary paid to managers and professionals in the same industry. These data suggest that positive assortative matching takes place not only within industries, but across industries as well. In terms of the threshold equilibria that can arise in our model, only the $H H / L L$ equilibrium exhibits such economy-wide PAM.

In Figure 10, the thick curve $a b c$ represents the qualitative features of the inverse matching function in an initial $H H / L L$ equilibrium. The curve is upward sloping along its entire length, reflecting PAM within and across sectors. Now suppose that $p_{i} / p_{j}$ rises, inducing a reallocation of resources to industry $i$. From our earlier discussion, we know that both $q_{L}^{*}$ and $q_{H}^{*}$ must increase, which means that point $b$ shifts up and to the right. The figure depicts three conceivable locations 
for the new threshold, at $b_{1}, b_{2}$ and $b_{3}$. Lim (2013) provides numerical examples of each such possibility.

If the new threshold falls at a point such as $b_{1}$, the outcome implies improved matching for all workers who were initially in sector $i$ and for all those who remain in sector $j$, and indeed for those who switch sectors as well. Meanwhile, all managers find themselves teamed with less able workers than before. If, instead, the new threshold falls at a point such as $b_{2}$, the managers see their matches improve, while workers see their's deteriorate. Finally, if the new threshold point is $b_{3}$, workers who were initially in sector $i$ are matched with better managers than before, whereas the opposite is true for those workers who remain in sector $j$. Managers who were initially in sector $i$ rematch with less able workers, while managers who remain in sector $j$ see an upgrade in their charges. $^{29}$

To understand when each outcome may occur and its implications for inequality, we suppose first that relative factor intensities are the same in the two industries; i.e., $\gamma_{1}=\gamma_{2}$. In such circumstances, the two sectoral matching functions $m_{i}\left(q_{H}\right)$ and $m_{j}\left(q_{H}\right)$ of an $H H / L L$ equilibrium must shift in the same direction in response to any small changes in the relative price $p_{i} / p_{j} .{ }^{30}$ Although we have not been able to prove that the same must occur for large price changes, neither could we find any numerical counterexamples. It seems that with $\gamma_{1}=\gamma_{2}$, the threshold must shift to a point like $b_{1}$ or $b_{2}$, with matches either improving for all workers and deteriorating for all managers, or vice versa. ${ }^{31}$

Figure 11 depicts the wage and salary effects of a $20 \%$ increase in the price of the good produced by the economy's least able workers and managers when factor intensities are the same in both industries and when workers' matches improve and managers' matches deteriorate everywhere. $^{32}$ Notice first that the improved matching for workers implies a ubiquitous increase in within occupation-and-industry wage inequality, while wages rise in the low-paying industry 2 relative to those in the high-paying industry 1. An economy-wide measure of wage inequality will reflect a balancing of these offsetting forces. Meanwhile, managerial salaries become more equal both within industries, across industries, and for the economy as a whole. Clearly, factor specificity explains the cross-industry redistribution, while rematching in the presence of factor complementarities explains the within-industry effects.

We can also deduce the implications for real incomes in this case. Notice that the inverse

\footnotetext{
${ }^{29}$ It is also possible for the matches to improve for workers remaining in sector $j$, while deteriorating for those who were initially in sector $i$; see figure 18 in Lim (2013) for an example. In such a case, the matching function in sector $i$ is steeper than that in sector $j$, and the former shifts down while the latter shifts up.

${ }^{30}$ This claim is proved in the appendix.

${ }^{31} \mathrm{Lim}$ (2013) finds a systematic pattern in these outcomes. As depicted in Figure 10, let $i$ be the industry that attracts the less able workers and managers and suppose that the relative price of this good rises. Further, suppose that the productivity function in sector $i$ is $\psi_{i}\left(q_{H}, q_{L}\right)=\left(\beta_{i} q_{H}^{\rho_{i}}+\alpha_{i} q_{L}^{\rho_{i}}\right)^{1 / \rho_{i}}$ for $\rho_{i}<0$. Then Lim finds an upward shift in the inverse matching functions in both sectors whenever (i) $\alpha_{i} / \beta_{i}=\alpha_{j} / \beta_{j}=1$ and $\gamma_{i}=\gamma_{j}<1 / 2$; (ii) $\alpha_{i} / \beta_{i}=\alpha_{j} / \beta_{j}>1$ and $\gamma_{i}=\gamma_{j}=1 / 2$; and (iii) $\alpha_{i} / \beta_{i}<\alpha_{j} / \beta_{j}=1$ and $\gamma_{i}=\gamma_{j}=1 / 2$. If, instead, the inequalities in (i) or (ii) are reversed, or if $\alpha_{j} / \beta_{j}<\alpha_{i} / \beta_{i}=1$ and $\gamma_{i}=\gamma_{j}=1 / 2$, then the inverse matching function shifts down in both sectors.

${ }^{32}$ Other cases with $\gamma_{1}=\gamma_{2}$ can be understood similarly in terms of whether prices increase for the sector that employs the more able types or the less able types and whether matches for workers improve or deteriorate.
} 

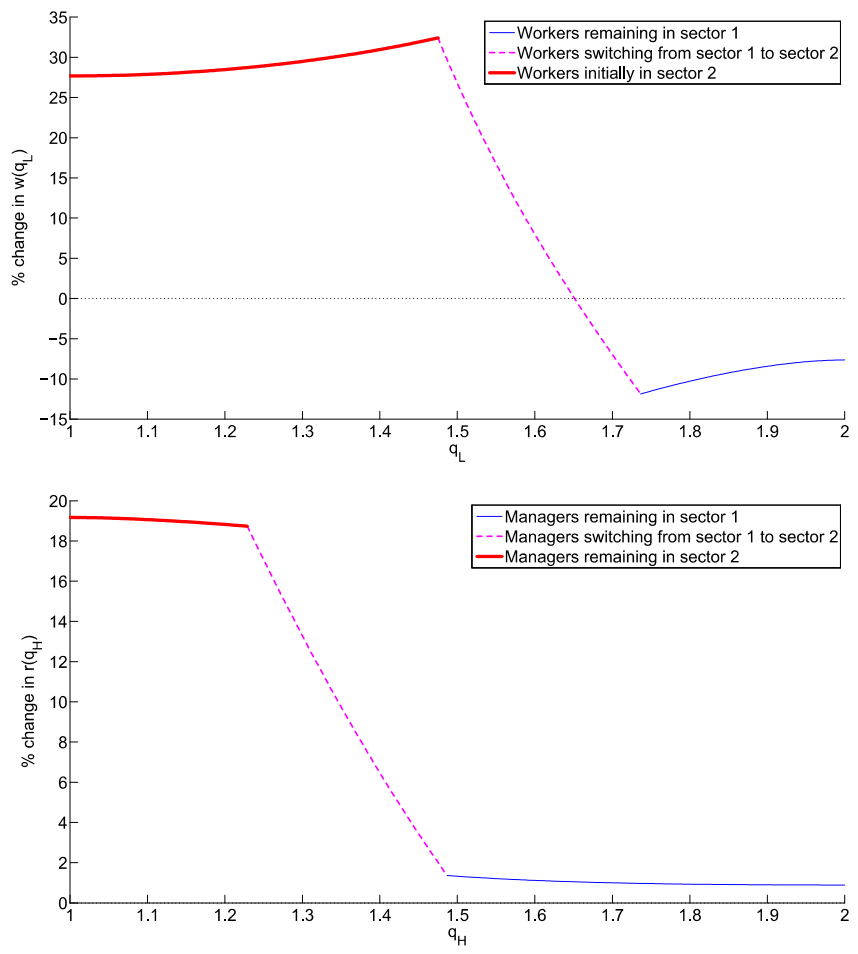

Figure 11: Effects of a $20 \%$ increase in $p_{2}$ on wages and salaries in an $H H / L L$ equilibrium without Stolper-Samuelson forces

matching function becomes steeper at point $a$ in Figure 10 when the threshold shifts from $b$ to $b_{1}$. By Lemmas 1 and 6 in the appendix, this implies that the real income of the economy's least able worker must rise. A fortiori, real wages rise for all workers who were initially employed in sector 2. Meanwhile, the inverse matching function becomes flatter at point $c$, which implies a fall in the real income for the economy's most able worker and, a fortiori, for all workers who remain employed in industry 1 after the price change. In these circumstances, the salaries of the least able managers must fall in terms of good 2, while the salaries of the most able managers must rise in terms of good $1 .^{33}$ It follows that real incomes may increase (or decrease) for some (or all) of the managers, depending on the composition of their consumption baskets.

We recap the findings that apply when factor intensities are the same in the following proposition:

Proposition 5 Suppose that Assumption $1^{\prime}$ holds, that $\gamma_{i}=\gamma_{j}$, and that that there exists a threshold equilibrium with an $H H / L L$ sorting pattern. Then a small increase in the relative price $p_{i} / p_{j}$ improves matches for all types of one factor and worsens matches for all types of the other. If the relative price of the good produced by the less able types rises and matches improve for all types of factor $F, F \in\{H, L\}$, and deteriorate for all types of factor $K, K \neq F$, then within occupation-andindustry income inequality increases for factor $F$ and declines for factor $K$ in both sectors, while

\footnotetext{
${ }^{33}$ These statements follow from the fact that the inverse matching function becomes steeper at $a$ but flatter at $c$.
} 

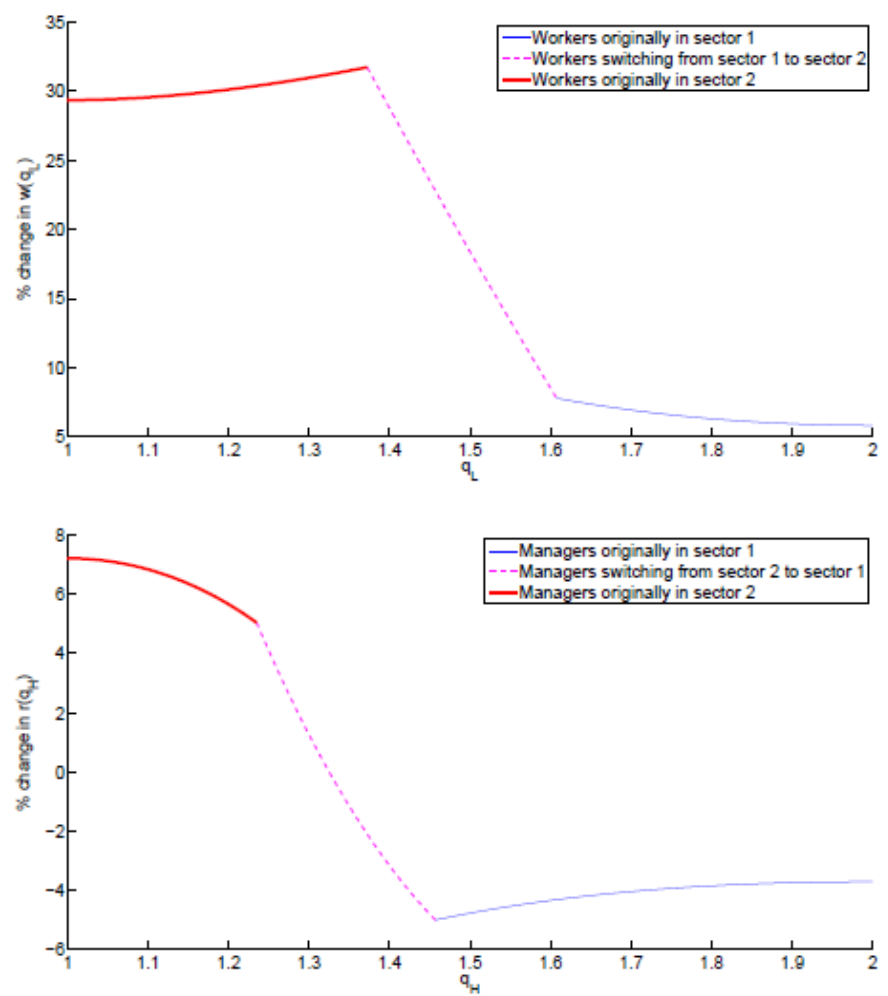

Figure 12: Effects of a $20 \%$ increase in $p_{2}$ on wages and salaries in an $H H / L L$ equilibrium with opposite shifts in sectoral matching functions and moderate Stolper-Samuelson forces

between-industry inequality declines for both factors. Real incomes rise for all types of factor $F$ that are initially employed in the expanding sector and decline for all types of factor $F$ that remain employed in the contracting sector.

Notice that the effects on within occupation-and-industry inequality, on between-industry inequality, and on real incomes described in Proposition 5 do not rely on the assumption that factor intensities are the same in the two industries. They arise anytime the matching functions shift in the same direction in both sectors. However, such shifts in the sectoral matching functions are more likely to occur when the factor-intensity difference is small.

We turn next to the case in which the difference between $\gamma_{1}$ and $\gamma_{2}$ is larger and gives rise to opposing shifts in the two sectoral matching functions. Figure 10 illustrates such an outcome, when the threshold shifts to a point like $b_{3}$. Alternatively, the inverse matching function for sector $i$ might be steeper than that for sector $j$, and then the former might shift down while the latter shifts up. In the appendix, we prove that the inverse matching function for sector $i$ is flatter than that for sector $j$ (as shown in the figure) if and only if $\gamma_{i}>\gamma_{j}$; i.e., sector $i$ is relatively labor intensive compared to sector $j$. In any case, if matching improves for workers in one sector and deteriorates for those in the other, it always improves for those in the labor-intensive industry. When the labor-intensive sector is also the one that attracts the economy's least able workers, an increase in 
the relative price of the labor-intensive good generates a spreading of the wage distribution in that sector, a contraction of the wage distribution in the other, and a narrowing of between-industry wage inequality thanks to the relative gains for those types with a comparative advantage in sector $i$. Meanwhile, salary inequality narrows among managers in the expanding sector, widens among those who remain in the contracting sector, and diminishes between industries. Figure 12 provides another example from Lim (2013).

In the example depicted in the Figure 12, all workers initially employed in sector 2 enjoy gains in real incomes. This is always true when the labor-intensive sector employs the least able workers and the relative price of the labor-intensive good rises, because Lemmas 1 and 6 in the appendix ensure that the real wage in terms of good 2 increases for the worker with ability $q_{L \text { min }}$ and other workers initially employed in the industry fare even better. The figure shows that the wages of workers who remain in sector 1 increase less than in proportion to the rise in the price of good 2, but a stronger Stolper-Samuelson force could generate real income gains for all workers in the economy. Meanwhile, all managers who remain in sector 1 see a decline in their real salaries inasmuch as the Stolper-Samuelson force and the Ricardo-Viner force push in the same direction for these individuals. The decline in real income for the managers of type $q_{H}$ max is ensured by Lemma 6, and the other managers who remain in the industry lose ground relative to these most able types.

Our final proposition summarizes our findings for an $H H / L L$ equilibrium in which the sectoral matching functions shift in opposite directions in the two industries. This requires of course that factor intensities differ significantly across the two sectors.

Proposition 6 Suppose that Assumption 1' holds and that there exists a threshold equilibrium with an $H H / L L$ sorting pattern. If an increase in the relative price $p_{i} / p_{j}$ improves matches for factor $F$ in one sector but not the other, then the matches must improve in the sector that uses factor $F$ intensively. This generates an increase in within occupation-and-industry inequality for types of factor $F$ employed in the F-intensive sector and a reduction in within occupation-and-industry inequality for types employed in the other sector. Between industry inequality rises for both factors if and only if sector $i$ attracts the economy's more productive types. If industry $i$ uses factor $F$ relatively intensively, then real incomes must rise for all types of factor $F$ initially employed in industry $i$ and must fall for all types of factor $K, K \neq F$, that remain employed in industry $j$.

Notice that the outcomes described in Proposition 6 and illustrated in Figure 12 are very much consistent with Observation 4 in Section 2; the correlation across industries between the change in relative price and the change in within-occupation-and-industry inequality are opposite in sign for the two factors. ${ }^{34}$

The approach taken in this section can provide guidance to the empirical researcher. Our results point to the importance of distinguishing employees by occupation and industry when studying the

\footnotetext{
${ }^{34}$ The equilibria represented by points $b_{1}$ and $b_{2}$ in Figure 10 might also be consistent with Observation 4 , but those equilibria do not necessarily imply opposite correlations for the two factors without the imposition of further parameter restrictions.
} 
effects of trade on income inequality. As we know from the classic papers in neoclassical trade theory, the distributional effects of changes in the trade environment can differ for managers versus workers and for employees in an export industry versus those in an import-competing industry. To this we add the observation that the effects of trade on within occupation-and-industry inequality also can vary by occupation and sector. The model yields strong predictions about these effects once we know the equilibrium sorting patterns of the factors, the relative factor intensities in the import competing versus export industries, and the size of the factor-intensity differences across industries. The $H H / L L$ equilibrium in particular yields a rich menu of possible outcomes, while offering enough restrictions to be empirically meaningful. It should be possible to condition future empirical research on trade and inequality on the attributes that govern factor sorting and the cross-industry pattern of factor-intensity differences.

\section{Concluding Remarks}

We have developed a framework that can be used to study the effects of trade on income inequality. Our model features two industries, two factors of production, and perfect competition, in keeping with a familiar setting from neoclassical trade theory. Indeed, we have chosen this economic environment so that we might draw on a deep understanding of the distributional effects of trade in the Heckscher-Ohlin and Ricardo-Viner models. To the standard, Heckscher-Ohlin set-up, we have added heterogeneous types of each of the two factors of production. With this simple extension, our model is capable of generating rich predictions about the effects of trade on within occupationand-industry income inequality. Such effects seem to be important in the data, yet are beyond the reach of much of the existing literature.

Redistribution within occupations and industries occurs in response to relative price changes whenever there exist sufficiently strong complementarities between the types of the various factors in determining the productivity of a production unit. We have assumed that productivity in each unit is a $\log$ supermodular function of the ability of the manager and the ability levels of the workers, with output per manager being the product of productivity and a concave function of the number of workers. We have allowed for cross-sectoral differences in factor intensity as well as differences in the complementarities between worker and manager types.

In this setting, the sorting of factor types to industries is guided by a cross-sectoral comparison of the ratio of the elasticity of productivity with respect to an employee's ability relative to the elasticity of output with respect to factor quantity. However, the elasticities of productivity with respect to worker ability may depend on the type of the manager with whom the worker cooperates, and similarly for managers. For this reason, the forces that determine sorting for workers and managers can be interdependent. We have described equilibria in which the more able workers and more able managers sort to the same industry, as well as equilibria in which the more able workers sort to the same industry as the less able managers. More complex sorting patterns also are possible. 
The effects of trade on income distribution are mediated by relative product prices. Accordingly, we have studied how changes in commodity prices affect the equilibrium wage and salary schedules. We have focused on threshold equilibria in which all the more able workers sort to one industry while the less able workers sort to the other, and similarly for managers. The wage and salary correlations for Brazil and Sweden demand that special attention be paid to equilibria with positive assortative matching across industries.

Our analysis blends Stolper-Samuelson forces, Ricardo-Viner forces, and new forces that reflect factor complementarities. In particular, a rise in the price of the labor-intensive product tends to increase all wages relative to all salaries. A rise in the price of a country's export good tends to favor those types of workers and managers that have a comparative advantage in the export sector, as reflected in the sorting pattern. And a change in any price tends to generate rematching of workers and managers, according to the change in the composition of types in each industry that results from the intersectoral resource movements. When the matches for a factor improve in an industry, within occupation-and-industry inequality rises, as the more able (and better paid) types benefit relatively more from the upgrading of their partners than their less able counterparts.

Our approach to introducing factor heterogeneity could be applied to other trade models. For example, it would be straightforward to incorporate matching of heterogeneous types of multiple factors in a setting à la Sampson (2014) with monopolistic competition and fixed costs of exporting. Or one could do so in a model of horizontal foreign direct investment, to study the formation of international production teams, as in Antràs et al. (2006). We think it would be particularly interesting to introduce search frictions to capture possible impediments to the perfect matching of worker and manager types. In such a setting, one could ask how globalization impacts the formation of production teams and thereby the productivity of firms. 


\section{References}

[1] Acemoğlu, Daron, 1998. "Directed Technical Change and Wage Inequality," Quarterly Journal of Economics 113(4), 1055-1089.

[2] Akerman, Anders, Helpman, Elhanan, Itskhoki, Oleg, Muendler, Marc-Andreas and Redding, Stephen J., 2013. "Sources of Wage Inequality," American Economic Review Papers and Proceedings 103(3), 214-219.

[3] Antràs, Pol, Garicano, Luis and Rossi-Hansberg, Esteban, 2006. "Offshoring in a Knowledge Economy," Quarterly Journal of Economics 121(1), 31-77.

[4] Autor, David H., Katz, Lawrence F., and Kearney, Melissa S., 2008. "Trends in U.S. Wage Inequality: Revising the Revisionists," Review of Economics and Statistics 90(2), 300-23.

[5] Card, David, Heining, Jörg, and Kline, Patrick, 2013. "Workplace Heterogeneity and the Rose of West German Wage Inequality," Quarterly Journal of Economics 128(3), 967-1015.

[6] Costinot, Arnaud and Vogel, Jonathan E., 2010. "Matching and Inequality in the World Economy," Journal of Political Economy 118(4), 747-86.

[7] Eeckhout, Jan and Kircher, Philipp, 2012. "Assortative Matching with Large Firms: Span of Control over More versus Better Workers." Downloadable at http://homepages.econ.ed.ac.uk/ pkircher/Papers/Sorting-and-Factor-Intensity.pdf.

[8] Findlay, Ronald and Kierzkowski, Henryk, 1983. "International Trade and Human Capital: A Simple General Equilibrium Model," Journal of Political Economy 91(6), 957-78.

[9] Fox, Jeremy T., 2009. "Firm-Size Wage Gaps, Job Responsibility, and Hierarchical Matching," Journal of Labor Economics 27(1), 83-126.

[10] Garicano, Luis, 2000. "Hierarchies and the Organization of Knowledge in Production," Journal of Political Economy 108(5), 874-904.

[11] Garicano, Luis and Hubbard, Thomas N., 2012. "Learning about the Nature of Production from Equilibrium Assignment Patterns," Journal of Economic Behavior and Organization 84 (1), 136-53.

[12] Grossman, Gene M., 1983. "Partially-Mobile Capital: A General Approach to Two-Sector Trade Theory," Journal of International Economics 15(1-2), 1-17.

[13] Grossman, Gene M., Helpman, Elhanan, and Kircher, Philipp, 2013. "Matching and Sorting in the Global Economy," NBER Working Paper No. 17550.

[14] Haberler, Gottfried, 1936. The Theory of International Trade, with its Applications to Commercial Policy, translated from the German, London: William Hodge. 
[15] Helpman, Elhanan, Itskhoki, Oleg, Muendler, Marc-Andreas and Redding, Stephen J., 2014. "Trade and Inequality: From Theory to Estimation," Downloadable at https://www.princeton.edu/ itskhoki/papers/TradeInequalityEvidence.pdf.

[16] Jones, Ronald, 1965. "The Structure of Simple General Equilibrium Models," Journal of Political Economy 73(6), 557-72.

[17] Jones, Ronald, 1971. "A Three-Factor Model in Theory, Trade and History," J. Bhagwati, R. Jones, R. Mundell and J. Vanek, eds., Trade, Balance of Payments and Growth, Amsterdam: North-Holland.

[18] Kopczuk, Wojciech, Saez, Emmanuel, and Song, Jae, 2010. "Earnings Inequality and Mobility in the United States: Evidence from Social Security Data Since 1937," Quarterly Journal of Economics 125(1), 91-128.

[19] Krishna, Pravin, Poole, Jennifer P. and Senses, Mine Zeynep, 2014. "Wage Effects of Trade Reform with Endogenous Worker Mobility," Journal of International Economics 93(2), 239-52.

[20] Lim, Kevin, 2013. "Numerical Simulations for 'Matching and Sorting in the Global Economy'."

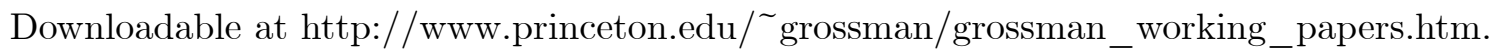

[21] Lucas, Robert E., Jr., 1978. "On the Size Distribution of Business Firms," The Bell Journal of Economics 9(2), 508-23.

[22] Mayer, Wolfgang, 1974. "Short-Run and Long-Run Equilibrium for a Small, Open Economy," Journal of Political Economy 82(5), 955-67.

[23] Metzler, Lloyd A., 1949. "Tariffs, the Terms of Trade, and the Distribution of National Income," Journal of Political Economy 57(1), 1-29.

[24] Mouw, Ted and Kalleberg, Arne L., 2010. "Occupations and the Structure of Wage Inequality in the United States, 1980s to 2000s," American Sociological Review 75(3), 402-31.

[25] Muendler, Marc-Andreas, 2004. "Trade, Technology, and Productivity: A Study of Brazilian Manufacturers, 1986-1998", CESifo Working Paper No. 1148

[26] Mussa, Michael, 1974. "Tariffs and the Distribution of Income: The Importance of Factor Specificity, Substitutability, and Intensity in the Short and Long Run," Journal of Political Economy 82(5), 1191-1203.

[27] Mussa, Michael, 1982. "Imperfect Factor Mobility and the Distribution of Income," Journal of International Economics 12(1-2), 125-141.

[28] Ohlin, Bertil, 1933. Interregional and International Trade, Cambridge: Harvard University Press. 
[29] Ohnsorge, Franziska and Trefler, Daniel, 2007. "Sorting it Out: International Trade with Heterogeneous Workers," Journal of Political Economy 115(5), 868-92.

[30] Ruffin, Roy, 1988. "The Missing Link: The Ricardian Approach to the Factor Endowment Theory of International Trade," American Economic Review 78(4), 759-72.

[31] Sampson, Thomas, 2014. "Selection into Trade and Wage Inequality," American Economic Journal: Macroeconomics 6(3), 157-202.

[32] Stolper, Wolfgang and Samuelson, Paul A., 1941. "Protection and Real Wages," Review of Economic Studies 9(1), 58-73.

[33] Viner, Jacob, 1937. Studies in the Theory of International Trade, New York: Harper and Row.

[34] Yeaple, Stephen R., 2005. "A Simple Model of Firm Heterogeneity, International Trade, and Wages," Journal of International Economics 65(1), 1-20. 


\title{
Appendix for "Matching, Sorting, and the Distributional Effects of International Trade"
}

\author{
by
}

\author{
Gene M. Grossman, Elhanan Helpman, and Phillip Kircher
}

This appendix provides proofs of results and figures stated in the main text.

\section{Figure for Section 2}

Figure 13 depicts the relationship between the average salary of managers and the average wage of workers of Swedish employees in manufacturing industries in 2004, in analogy to Figure 1 in the main text for Brazil. Each point represents one industry; the log of the average salary of managers is measured on the vertical axis while the log of the average wage of workers is measured on the horizontal axis. It is again apparent that industries with higher salaries of managers have also higher wages.

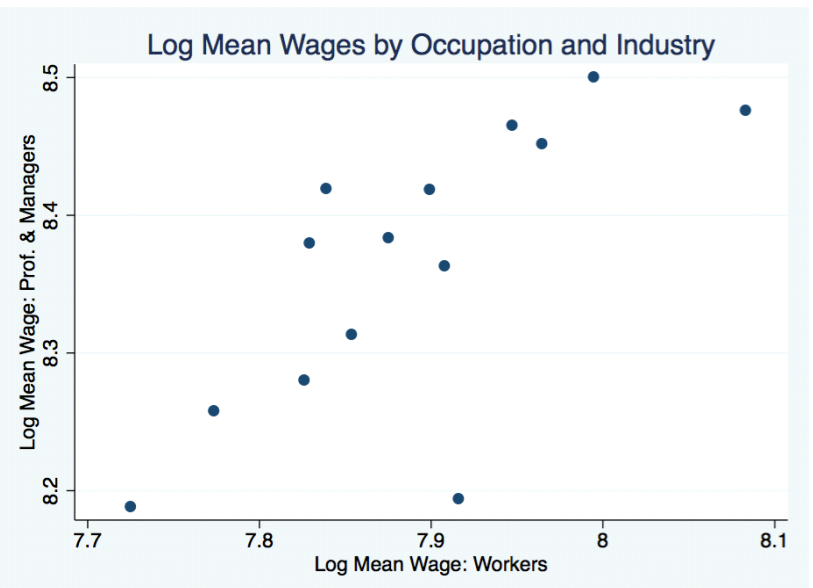

Figure 13: Variation across manufacturing industries of log mean salary of managers and log mean wage of workers in Sweden: 2004. Source: private communication, Anders Akerman.

\section{Proofs for Section 4.1}

Consider Cobb-Douglas productivity according to Assumption 1. Labor demand (2) then takes the form

$$
\ell\left(q_{L}, q_{H}\right)=\left[\frac{\gamma_{i} p_{i} q_{H}^{\beta_{i}} q_{L}^{\alpha_{i}}}{w\left(q_{L}\right)}\right]^{\frac{1}{1-\gamma_{i}}}
$$

Substituting (11) into the expression for net profits $\pi_{i}\left(\ell, q_{L} ; q_{H}\right)-r\left(q_{H}\right)$ yields

$$
\tilde{\pi}_{i}\left(q_{L}, q_{H}\right)=\bar{\gamma}_{i} p_{i}^{\frac{1}{1-\gamma_{i}}}\left(q_{H}^{\beta_{i}} q_{L}^{\alpha_{i}}\right)^{\frac{1}{1-\gamma_{i}}} w\left(q_{L}\right)^{-\frac{\gamma_{i}}{1-\gamma_{i}}}-r\left(q_{H}\right),
$$


where $r\left(q_{H}\right)$ is the salary of a manager with ability $q_{H}$ and $\bar{\gamma}_{i} \equiv \gamma_{i}^{\frac{\gamma_{i}}{1-\gamma_{i}}}\left(1-\gamma_{i}\right)$. Every firm chooses the ability of its workers and the ability of its manager so as to maximize profits, yet free entry dictates that these profits must be equal to zero in equilibrium. Let $M_{i}$ be the set of all matches that maximize profits in sector $i$. For each pairing $\left(q_{L}, q_{H}\right)$ in $M_{i}$,

$$
r\left(q_{H}\right)=\bar{\gamma}_{i} p_{i}^{\frac{1}{1-\gamma_{i}}}\left(q_{H}^{\beta_{i}} q_{L}^{\alpha_{i}}\right)^{\frac{1}{1-\gamma_{i}}} w\left(q_{L}\right)^{-\frac{\gamma_{i}}{1-\gamma_{i}}}, \quad i=1,2
$$

by dint of the zero-profit condition. Recall from (4) the equilibrium wage schedule

$$
w\left(q_{L}\right)=w_{i} q_{L}^{\alpha_{i} / \gamma_{i}} \text { for } q_{L} \in Q_{L i}^{i n t}
$$

where the superscript "int" denotes the interior of the set. Substitutions into the previous equation establishes the salary schedule for managers

$$
r\left(q_{H}\right)=r_{i} q_{H}^{\beta_{i} /\left(1-\gamma_{i}\right)} \text { for } q_{H} \in Q_{H i}^{i n t},
$$

where $r_{i}$ is a "salary anchor" analogous to $w_{i}$.

As discussed in the main text, these wages and salaries leave a firm indifferent among workers and managers within a sector, and so matching between managers and workers within a sector is indeterminate. Sorting to sectors is not indeterminate, though, but higher worker types sort into sector 1 if $s_{L}=\alpha_{1} / \gamma_{1}-$ $\alpha_{2} / \gamma_{2}>0$ and higher firm types sort into sector 1 if $s_{H}=\beta_{1} /\left(1-\gamma_{1}\right)-\beta_{2} /\left(1-\gamma_{2}\right)>0$. Let $q_{L}^{*}$ and $q_{H}^{*}$ denote the worker and firm type that is indifferent between sectors.

To describe the equilibrium, we invoke factor-market clearing, continuity of worker wages, continuity of managerial salaries, and the zero-profit conditions. For concreteness, let us focus on the case in which $s_{H}>0$ so that the more able managers sort to industry 1 ; the opposite case can be handled similarly.

It proves convenient to define $e_{H i}\left(q_{H}\right)=q_{H}^{\beta_{i} /\left(1-\gamma_{i}\right)}$ as the effective managerial input of a manager with ability $q_{H}$ who works in sector $i$. Then the aggregate supplies of effective managerial input in sectors 1 and 2 are

$$
H_{1}=\bar{H} \int_{q_{H}^{*}}^{q_{H} \max } q_{H}^{\frac{\beta_{1}}{1-\gamma_{1}}} \phi_{H}\left(q_{H}\right) d q_{H},
$$

and

$$
H_{2}=\bar{H} \int_{q_{H} \min }^{q_{H}^{*}} q_{H}^{\frac{\beta_{2}}{1-\gamma_{2}}} \phi_{H}\left(q_{H}\right) d q_{H},
$$

respectively. Note that $H_{1} / \bar{H}$ depends only on $q_{H}^{*}$ and is a monotonically decreasing function, and $H_{2} / \bar{H}$ also depends only on $q_{H}^{*}$ and is monotonically increasing.

Consider now the supply and demand for effective labor in sector 1 , where we define $e_{L i}\left(q_{L}\right)=q_{L}^{\alpha_{i} / \gamma_{i}}$ as the effective labor provided by a worker of ability $q_{L}$ in sector $i$. From the labor demand equation (11), a firm in sector 1 combines a manager with $e_{H i}$ units of effective managerial input with $e_{H i}\left(\gamma_{i} p_{i} / w_{i}\right)^{1 /\left(1-\gamma_{i}\right)}$ units of effective labor. Therefore, the $H_{1}$ units of effective managerial input that are hired into sector 1 are combined with $H_{1}\left(\gamma_{1} p_{1} / w_{1}\right)^{1 /\left(1-\gamma_{1}\right)}$ units of effective labor. Noting the definition of $H_{1}$ and equating the 
demand for effective labor in sector 1 with the supply of effective labor among those with ability above $q_{L}^{*}$, we have

$$
\bar{H}\left(\frac{\gamma_{1} p_{1}}{w_{1}}\right)^{\frac{1}{1-\gamma_{1}}} \int_{q_{H}^{*}}^{q_{H} \max } q_{H}^{\frac{\beta_{1}}{1-\gamma_{1}}} \phi_{H}\left(q_{H}\right) d q_{H}=\bar{L} \int_{q_{L}^{*}}^{q_{L} \max } q_{L}^{\frac{\alpha_{1}}{\gamma_{1}}} \phi_{L} d q_{L} .
$$

A similar condition applies in sector 2, where labor-market clearing requires

$$
\bar{H}\left(\frac{\gamma_{2} p_{2}}{w_{2}}\right)^{\frac{1}{1-\gamma_{2}}} \int_{q_{H} \min }^{q_{H}^{*}} q_{H}^{\frac{\beta_{2}}{1-\gamma_{2}}} \phi_{H}\left(q_{H}\right) d q_{H}=\bar{L} \int_{q_{L} \min }^{q_{L}^{*}} q_{L}^{\frac{\alpha_{2}}{\gamma_{2}}} \phi_{L} d q_{L} .
$$

Continuity of the wage schedule at $q_{L}^{*}$ requires that

$$
w_{1}\left(q_{L}^{*}\right)^{\frac{\alpha_{1}}{\gamma_{1}}}=w_{2}\left(q_{L}^{*}\right)^{\frac{\alpha_{2}}{\gamma_{2}}} .
$$

The salary function for managers must also be continuous and firms that hire managers with ability $q_{H}^{*}$ must earn zero profits in either sector. Together, these considerations imply

$$
\bar{\gamma}_{1} p_{1}^{\frac{1}{1-\gamma_{1}}} w_{1}^{-\frac{\gamma_{1}}{1-\gamma_{1}}}\left(q_{H}^{*}\right)^{\frac{\beta_{1}}{1-\gamma_{1}}}=\bar{\gamma}_{2} p_{2}^{\frac{1}{1-\gamma_{2}}} w_{2}^{-\frac{\gamma_{2}}{1-\gamma_{2}}}\left(q_{H}^{*}\right)^{\frac{\beta_{2}}{1-\gamma_{2}}}
$$

Equations (18)-(21) comprise four equations that can be used to solve for the two wage anchors, $w_{1}$ and $w_{2}$, and the two cutoffs, $q_{L}^{*}$ and $q_{H}^{*}$. The effective supply of managers in sectors 1 and $2, H_{1}$ and $H_{2}$, can then be solved from (16) and (17). Finally, the salary anchors for the managers can be computed from the zero-profit conditions, which imply

$$
r_{i}=\bar{\gamma}_{i} p_{i}^{\frac{1}{1-\gamma_{i}}} w_{i}^{-\frac{\gamma_{i}}{1-\gamma_{i}}} \text { for } i=1,2
$$

This completes our characterization of the supply-side equilibrium for an economy that faces prices $p_{1}$ and $p_{2}$.

\section{Proofs for Section 4.2}

Consider strictly log-supermodular productivity, i.e., Assumption 1' holds. Substituting the optimal labor supply (2) into the gross profit function $\pi_{i}\left(\ell, q_{L} ; q_{H}\right)$ and deducting manager salaries yields net profit

$$
\tilde{\pi}_{i}\left(q_{H}, q_{L}\right)=\bar{\gamma}_{i} p_{i}^{\frac{1}{1-\gamma_{i}}} \psi_{i}\left(q_{H}, q_{L}\right)^{\frac{1}{1-\gamma_{i}}} w\left(q_{L}\right)^{-\frac{\gamma_{i}}{1-\gamma_{i}}}-r\left(q_{H}\right) \text {, where } \bar{\gamma}_{i} \equiv \gamma_{i}^{\frac{\gamma_{i}}{1-\gamma_{i}}}\left(1-\gamma_{i}\right)
$$

The firm identifies the most suitable workers to combine with the manager, taking the continuous and strictly 
increasing wage schedule as given. ${ }^{35}$ This yields a profit function,

$$
\Pi_{i}\left(q_{H}\right)=\max _{q_{L} \in S_{L}} \tilde{\pi}_{i}\left(q_{H}, q_{L}\right)
$$

for $q_{H} \in S_{H}, i=1,2$. This profit function describes a firm's profits per manager when it hires mangers of ability $q_{H}$ and optimizes the choice of workers. Finally, the firm selects $q_{H}$ to maximize $\Pi_{i}\left(q_{H}\right)$, given the continuous and strictly increasing salary schedule, $r\left(q_{H}\right) \cdot{ }^{36}$ In equilibrium

$$
\max _{q_{H} \in Q_{H i}} \Pi_{i}\left(q_{H}\right)=0 \text { and } \max _{q_{H} \in S_{H}} \Pi_{i}\left(q_{H}\right) \leq 0
$$

where $Q_{H i}$ is the set of types of managers that sort into sector $i$. Firms break even when among the mangers that sort into their sector they hire those that bring about the highest profits, and their profits cannot be raised by hiring mangers from the other sector.

Denote by $m_{i}\left(q_{H}\right)$ the solution set to problem (24). Because $S_{L}$ and $S_{H}$ are compact, $m_{i}\left(q_{H}\right)$ is upper hemicontinuous (because $\tilde{\pi}_{i}\left(q_{L}, q_{H}\right)$ is a continuous function), and $m_{i}\left(q_{H}\right)$ is closed-valued, the graph

$$
G_{i}=\left[\left\{q_{H}, q_{L}\right\} \mid q_{L} \in m_{i}\left(q_{H}\right) \text { for all } q_{H} \in S_{H}\right]
$$

is closed. The matching correspondence satisfies

$$
m\left(q_{H}\right)= \begin{cases}m_{1}\left(q_{H}\right) & \text { for } q_{H} \in Q_{H 1}, \\ m_{2}\left(q_{H}\right) & \text { for } q_{H} \in Q_{H 2}\end{cases}
$$

and the equilibrium allocation graph in sector $i$ is

$$
M_{i}=\left[\left\{q_{H}, q_{L}\right\} \mid q_{L} \in m_{i}\left(q_{H}\right) \text { for all } q_{H} \in Q_{H i}\right] \subseteq G_{i} .
$$

Since $Q_{H i} \subseteq S_{H}$, the graph $M_{i}$ is also closed.

Now consider a connected subset $M_{i}^{n} \subseteq M_{i}$ :

$$
M_{i}^{n}=\left[\left\{q_{H}, q_{L}\right\} \mid q_{L} \in m_{i}\left(q_{H}\right) \text { for all } q_{H} \in\left[q_{H 1}, q_{H 2}\right] \subseteq Q_{H i}\right] .
$$

Since $M_{i}$ is a closed graph, such a subset exists and there exists an interval $\left[q_{L 1}, q_{L 2}\right], q_{L 2}>q_{L 1}$, that satisfies both (i) $m_{i}\left(q_{H}\right) \in\left[q_{L 1}, q_{L 2}\right]$ for all $q_{H} \in\left[q_{H 1}, q_{H 2}\right]$ and (ii) for every point $q_{L} \in\left[q_{L 1}, q_{L 2}\right]$ there exists a managerial ability level $q_{H} \in\left[q_{H 1}, q_{H 2}\right]$ satisfying $q_{L} \in m_{i}\left(q_{H}\right)$. This means that, in $M_{i}^{n}$, workers of ability $\left[q_{L 1}, q_{L 2}\right]$ are matched with managers of ability $\left[q_{H 1}, q_{H 2}\right]$ and all workers and managers have matches. Then, as Eeckhout and Kircher (2012) have shown, strict $\log$ supermodularity of $\psi_{i}(\cdot)$ ensures

\footnotetext{
${ }^{35}$ The strict monotonicity of the wage function follows from the strict monotonicity of the productivity functions $\psi_{i}\left(q_{H}, q_{L}\right)$; if wages were declining over some range of abilities, all firms would prefer to hire the most able workers in this range. The continuity of the wage function follows from the continuity of the productivity function; if wages were to jump at some $q_{L}^{\prime}$, firms would strictly prefer workers with ability a shade below $q_{L}^{\prime}$ to workers with ability a shade above $q_{L}^{\prime}$, because the former would be only slightly less productive but would cost discretely less. Below we also prove that the wage function must be differentiable in the interior of the ability range employed by an industry.

${ }^{36}$ The salary schedule must be continuous and strictly increasing for the same reason that the wage schedule must be continuous and strictly increasing.
} 
strict positive assortative matching (PAM) between the factors allocated to sector $i$. It follows that $m_{i}\left(q_{H}\right)$ is a continuous and strictly increasing function in the interior of $\left[q_{H 1}, q_{H 2}\right] . M_{i}$ consists of a union of connected sets, $M_{i}=\cup_{n \in N_{i}} M_{i}^{n}$, such that $m_{i}\left(q_{H}\right)$ is continuous and strictly increasing in each such set and $m_{i}\left(q_{H}\right)$ jumps upwards between them.

We now establish the differentiability of $w(\cdot)$ in $M_{i}^{n, \text { int }} \cdot{ }^{37}$ Let $m^{-1}(\cdot)$ be the inverse of the sectoral matching function in $M_{i}^{n, i n t}$. Since $m(\cdot)$ is continuous and strictly increasing in $M_{i}^{n, i n t}$, this inverse exists. Now consider an interval $\left[q_{L}^{\prime}, q_{L}^{\prime}+d q_{L}\right) \in M_{i}^{n, i n t}$. The zero-profit condition (7) implies

$$
w\left(q_{L}^{\prime}\right)=\bar{\gamma}_{i}^{\frac{1-\gamma_{i}}{\gamma_{i}}} p_{i}^{\frac{1}{\gamma_{i}}} \psi_{i}\left[m^{-1}\left(q_{L}^{\prime}\right), q_{L}^{\prime}\right]^{\frac{1}{\gamma_{i}}} r\left[m^{-1}\left(q_{L}^{\prime}\right)\right]^{-\frac{1-\gamma_{i}}{\gamma_{i}}}
$$

and profit maximization implies

$$
w\left(q_{L}^{\prime}+d q_{L}\right) \geq \bar{\gamma}_{i}^{\frac{1-\gamma_{i}}{\gamma_{i}}} p_{i}^{\frac{1}{\gamma_{i}}} \psi_{i}\left[m^{-1}\left(q_{L}^{\prime}\right), q_{L}^{\prime}+d q_{L}\right]^{\frac{1}{\gamma_{i}}} r\left[m^{-1}\left(q_{L}^{\prime}\right)\right]^{-\frac{1-\gamma_{i}}{\gamma_{i}}}
$$

Together, these expressions imply

$$
w\left(q_{L}^{\prime}+d q_{L}\right) \geq w\left(q_{L}^{\prime}\right)\left\{\frac{\psi_{i}\left[m^{-1}\left(q_{L}^{\prime}\right), q_{L}^{\prime}+d q_{L}\right]}{\psi_{i}\left[m^{-1}\left(q_{L}^{\prime}\right), q_{L}^{\prime}\right]}\right\}^{\frac{1}{\gamma_{i}}} .
$$

Similarly, (7) implies

$$
w\left(q_{L}^{\prime}+d q_{L}\right)=\bar{\gamma}_{i}^{\frac{1-\gamma_{i}}{\gamma_{i}}} p_{i}^{\frac{1}{\gamma_{i}}} \psi_{i}\left[m^{-1}\left(q_{L}^{\prime}+d q_{L}\right), q_{L}^{\prime}+d q_{L}\right]^{\frac{1}{\gamma_{i}}} r\left[m^{-1}\left(q_{L}^{\prime}+d q_{L}\right)\right]^{-\frac{1-\gamma_{i}}{\gamma_{i}}}
$$

and profit maximization implies

$$
w\left(q_{L}^{\prime}\right) \geq \bar{\gamma}_{i}^{\frac{1-\gamma_{i}}{\gamma_{i}}} p_{i}^{\frac{1}{\gamma_{i}}} \psi_{i}\left[m^{-1}\left(q_{L}^{\prime}+d q_{L}\right), q_{L}^{\prime}\right]^{\frac{1}{\gamma_{i}}} r\left[m^{-1}\left(q_{L}^{\prime}+d q_{L}\right)\right]^{-\frac{1-\gamma_{i}}{\gamma_{i}}}
$$

Together, these expressions imply

$$
w\left(q_{L}^{\prime}\right) \geq w\left(q_{L}^{\prime}+d q_{L}\right)\left\{\frac{\psi_{i}\left[m^{-1}\left(q_{L}^{\prime}+d q_{L}\right), q_{L}^{\prime}\right]}{\psi_{i}\left[m^{-1}\left(q_{L}^{\prime}+d q_{L}\right), q_{L}^{\prime}+d q_{L}\right]}\right\}^{\frac{1}{\gamma_{i}}} .
$$

Inequalities (26) and (27) jointly imply

$$
\begin{aligned}
& \frac{w\left(q_{L}^{\prime}\right)}{\psi_{i}\left[m^{-1}\left(q_{L}^{\prime}\right), q_{L}^{\prime}\right]^{\frac{1}{\gamma_{i}}}}\left[\frac{\psi_{i}\left[m^{-1}\left(q_{L}^{\prime}\right), q_{L}^{\prime}+d q_{L}\right]^{\frac{1}{\gamma_{i}}}-\psi_{i}\left[m^{-1}\left(q_{L}^{\prime}\right), q_{L}^{\prime}\right]^{\frac{1}{\gamma_{i}}}}{d q_{L}}\right] \leq \frac{w\left(q_{L}^{\prime}+d q_{L}\right)-w\left(q_{L}^{\prime}\right)}{d q_{L}} \\
& \leq \frac{w\left(q_{L}^{\prime}\right)}{\psi_{i}\left[m^{-1}\left(q_{L}^{\prime}+d q_{L}\right), q_{L}^{\prime}\right]^{\frac{1}{\gamma_{i}}}}\left[\frac{\psi_{i}\left[m^{-1}\left(q_{L}^{\prime}+d q_{L}\right), q_{L}^{\prime}+d q_{L}\right]^{\frac{1}{\gamma_{i}}}-\psi_{i}\left[m^{-1}\left(q_{L}^{\prime}+d q_{L}\right), q_{L}^{\prime}\right]^{\frac{1}{\gamma_{i}}}}{d q_{L}}\right] .
\end{aligned}
$$

Since the productivity function is continuous, strictly increasing, and differentiable, and since the inverse of the sectoral matching function is continuous and strictly increasing in this range, taking the limit as $d q_{L} \rightarrow 0$

\footnotetext{
${ }^{37}$ This proof is similar to the proof of differentiability of the wage function in Sampson (2014).
} 
implies that the derivative of $w(\cdot)$ at $q_{L}^{\prime}$ exists and

$$
\frac{d w\left(q_{L}^{\prime}\right)}{d q_{L}}=\frac{w\left(q_{L}^{\prime}\right)}{\psi_{i}\left[m^{-1}\left(q_{L}^{\prime}\right), q_{L}^{\prime}\right]^{\frac{1}{\gamma_{i}}}} \frac{\partial \psi_{i}\left[m^{-1}\left(q_{L}^{\prime}\right), q_{L}^{\prime}\right]^{\frac{1}{\gamma_{i}}}}{\partial q_{L}} .
$$

Similar arguments can be used to show that the salary function is differentiable.

We now prove Proposition 2 by contradiction. (Proposition 1 can be proved similarly.) To this end, suppose that the inequality condition holds, but the equilibrium is such that there are managers employed in sector $j$ who have greater ability than some managers employed in sector $i$. In such circumstances, there exists an ability level $\tilde{q}_{H}$ at one of the boundaries between $Q_{H i}$ and $Q_{H j}$ such that managers with ability in $\left(\tilde{q}_{H}-\varepsilon_{i}, \tilde{q}_{H}\right) \subset Q_{H i}^{i n t}$ are employed in sector $i$ and managers with ability $\left(\tilde{q}_{H}, \tilde{q}_{H}+\varepsilon_{j}\right) \subset Q_{H j}^{i n t}$ are employed in sector $j$, for $\varepsilon_{i}>0$ and $\varepsilon_{j}>0$ small enough. Moreover, the equilibrium conditions (6)-(9) are satisfied, the matching function $m\left(q_{H}\right)$ is continuous at $Q_{H i}^{i n t}$ and $Q_{H j}^{i n t}$ close to $\tilde{q}_{H}$ (but can be discontinuous at the boundary point between these sets), the wage function $w\left(q_{L}\right)$ is continuous and increasing in $S_{L}$ and differentiable in $Q_{L i}^{i n t}$ and $Q_{L j}^{i n t}$, and the salary function $r\left(q_{H}\right)$ is continuous and increasing in $S_{H}$ and differentiable in $Q_{H i}^{i n t}$ and $Q_{H j}^{i n t}$.

Now recall the continuous profit function $\Pi_{i}\left(q_{H}\right)$ defined in (24). In equilibrium, $\Pi_{i}\left(q_{H}\right)=0$ for all $q_{H} \in Q_{H i}$, but the maximal profits $\Pi_{i}\left(q_{H}\right)$ may differ from zero for $q_{H} \notin Q_{H i}$. Therefore $\Pi_{i}\left(q_{H}\right)=0$ for all $q_{H} \in\left(\tilde{q}_{H}-\varepsilon_{i}, \tilde{q}_{H}\right)$ and, by continuity, $\lim _{q_{H} / \tilde{q}_{H}} \Pi_{i}\left(q_{H}\right)=0$.

Next consider the profits that would accrue to an entrepreneur that hires a manager with ability $\tilde{q}_{H}+\varepsilon$ in order to produce good $i$, where $\varepsilon<\varepsilon_{j}$. Choosing workers so as to maximize profits, this entrepreneur earns $\Pi_{i}\left(\tilde{q}_{H}+\varepsilon\right) \geq \tilde{\pi}_{i}\left[\tilde{q}_{H}+\varepsilon, m\left(\tilde{q}_{H}^{-}\right)\right]$, where $m\left(\tilde{q}_{H}^{-}\right)=\lim _{\varepsilon \backslash 0} m\left(\tilde{q}_{H}-\varepsilon\right)$ and $\lim _{\varepsilon \backslash 0} \Pi_{i}\left(\tilde{q}_{H}+\varepsilon\right)=$ $\lim _{\varepsilon \backslash 0} \tilde{\pi}_{i}\left[\tilde{q}_{H}+\varepsilon, m\left(\tilde{q}_{H}^{-}\right)\right]=0$. The first-order approximation to $\tilde{\pi}_{i}\left[\tilde{q}_{H}+\varepsilon, m\left(\tilde{q}_{H}^{-}\right)\right]$is

$$
\tilde{\pi}_{i}\left[\tilde{q}_{H}+\varepsilon, m\left(\tilde{q}_{H}^{-}\right)\right] \approx \varepsilon \tilde{\pi}_{i H}\left[\tilde{q}_{H}+\varepsilon, m\left(\tilde{q}_{H}^{-}\right)\right]
$$

where $\tilde{\pi}_{i H}(\cdot)$ is the partial derivative of $\tilde{\pi}_{i}(\cdot)$ with respect to $q_{H}$. This derivative exists because the salary function is differentiable in $Q_{H j}^{i n t}$, and

$$
\begin{aligned}
& \tilde{\pi}_{i H}\left[\tilde{q}_{H}+\varepsilon, m\left(\tilde{q}_{H}^{-}\right)\right] \\
& =\bar{\gamma}_{i} p_{i}^{\frac{1}{1-\gamma_{i}}} \psi_{i}\left[\tilde{q}_{H}+\varepsilon, m\left(\tilde{q}_{H}^{-}\right)\right]^{\frac{1}{1-\gamma_{i}}} w\left[m\left(\tilde{q}_{H}^{-}\right)\right]^{-\frac{\gamma_{i}}{1-\gamma_{i}}} \frac{\psi_{i H}\left[\tilde{q}_{H}+\varepsilon, m\left(\tilde{q}_{H}^{-}\right)\right]}{\left(1-\gamma_{i}\right) \psi_{i}\left[\tilde{q}_{H}+\varepsilon, m\left(\tilde{q}_{H}^{-}\right)\right]}-r^{\prime}\left(\tilde{q}_{H}+\varepsilon\right) \\
& =\left\{\frac{\psi_{i}\left[\tilde{q}_{H}+\varepsilon, m\left(\tilde{q}_{H}^{-}\right)\right]}{\psi_{i}\left[\tilde{q}_{H}, m\left(\tilde{q}_{H}^{-}\right)\right]}\right\}^{\frac{1}{1-\gamma_{i}}} r\left(\tilde{q}_{H}^{-}\right) \frac{\psi_{i H}\left[\tilde{q}_{H}+\varepsilon, m\left(\tilde{q}_{H}^{-}\right)\right]}{\left(1-\gamma_{i}\right) \psi_{i}\left[\tilde{q}_{H}+\varepsilon, m\left(\tilde{q}_{H}^{-}\right)\right]}-r^{\prime}\left(\tilde{q}_{H}+\varepsilon\right),
\end{aligned}
$$

where the last equality uses the free-entry condition (7), which applies to sector 1 at points in $Q_{H i}^{i n t}$ in the conjectured equilibrium, and $r\left(\tilde{q}_{H}^{-}\right)=r\left(\tilde{q}_{H}\right)$ due to the continuity of the salary function. Since $\tilde{q}_{H}+\varepsilon \in Q_{H j}^{i n t}$, condition (8) implies

$$
\lim _{\varepsilon \searrow 0} \tilde{\pi}_{i H}\left[\tilde{q}_{H}+\varepsilon, m_{i}\left(\tilde{q}_{H}^{-}\right)\right]=r\left(\tilde{q}_{H}\right)\left\{\frac{\psi_{i H}\left[q_{H}, m_{i}\left(\tilde{q}_{H}^{-}\right)\right]}{\left(1-\gamma_{i}\right) \psi_{i}\left[q_{H}, m_{i}\left(\tilde{q}_{H}^{-}\right)\right]}-\frac{\psi_{j H}\left[q_{H}, m\left(\tilde{q}_{H}^{+}\right)\right]}{\left(1-\gamma_{j}\right) \psi_{j}\left[q_{H}, m\left(\tilde{q}_{H}^{+}\right)\right]}\right\},
$$

where $m\left(\tilde{q}_{H}^{+}\right)=\lim _{\varepsilon \backslash 0} m\left(\tilde{q}_{H}+\varepsilon\right)$. It now follows from the supposition of Proposition 2 that the right-hand 


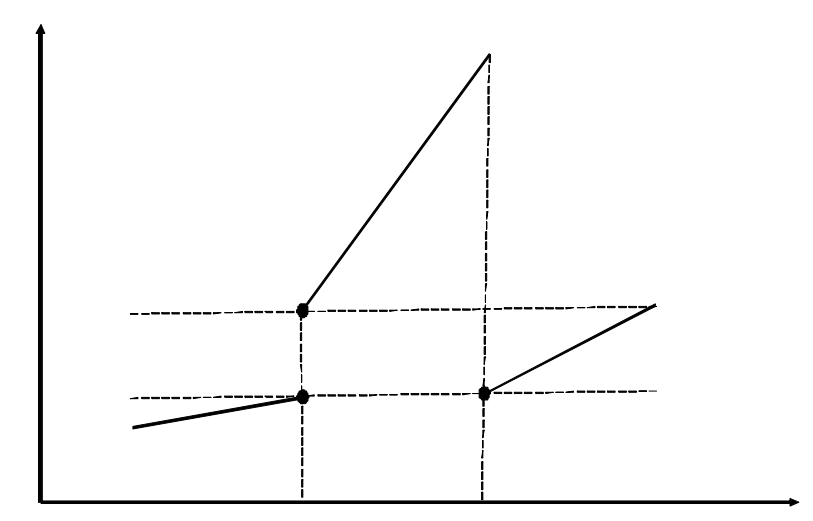

Figure 14: Matching function with discontinuity

side of this equation is strictly positive irrespective of the values of $m_{i}\left(\tilde{q}_{H}^{-}\right)$and $m\left(\tilde{q}_{H}^{+}\right)$, and therefore that $\tilde{\pi}_{i H}\left[\tilde{q}_{H}+\varepsilon, m_{i}\left(\tilde{q}_{H}^{-}\right)\right]>0$ for $\varepsilon$ small enough, which contradicts the zero-profit condition as profits rise above zero. This contradicts the supposition that in equilibrium there are managers employed in sector $j$ who are more able than some managers employed in sector $i$. Consequently, every manager in sector $i$ has greater ability than any manager employed in sector $j$. This completes the proof.

Next we prove Proposition 3. Suppose that the inequality conditions in Proposition 3 hold but the equilibrium is such that there exist managers in sector 2 who are more able than some managers in sector 1. In such circumstances, there exists an ability $\tilde{q}_{H}$ at one of the boundary points between $Q_{H 1}$ and $Q_{H 2}$ such that managers of ability $\tilde{q}_{H}-\varepsilon_{1}$ are employed in sector 1 and managers of ability $\tilde{q}_{H}+\varepsilon_{2}$ are employed in sector 2 for $\varepsilon_{1}>0$ and $\varepsilon_{2}>0$ small enough. Let $m\left(\tilde{q}_{H}^{-}\right)=\lim _{q_{H} / \tilde{q}_{H}} m\left(q_{H}\right)$ and $m\left(\tilde{q}_{H}^{+}\right)=\lim _{q_{H} \backslash \tilde{q}_{H}} m\left(q_{H}\right)$ Then

$$
\lim _{\varepsilon \rightarrow 0} \tilde{\pi}_{i H}\left[\tilde{q}_{H}+\varepsilon, m\left(q_{H}^{-}\right)\right]=r\left(\tilde{q}_{H}\right)\left[\frac{\psi_{1 H}\left[\tilde{q}_{H}, m\left(\tilde{q}_{H}^{-}\right)\right]}{\left(1-\gamma_{1}\right) \psi_{1}\left[\tilde{q}_{H}, m\left(\tilde{q}_{H}^{-}\right)\right]}-\frac{\psi_{2 H}\left[\tilde{q}_{H}, m\left(\tilde{q}_{H}^{+}\right)\right]}{\left(1-\gamma_{2}\right) \psi_{2}\left[\tilde{q}_{H}, m\left(\tilde{q}_{H}^{+}\right)\right]}\right],
$$

which we derive in the same way as in the proof of Proposition 2. Under the supposition that the managers to the left of $\tilde{q}_{H}$ sort into sector 1 and those to the right of $\tilde{q}_{H}$ sort into sector 2 the partial derivative in (28) cannot be positive and therefore

$$
\frac{\psi_{1 H}\left[\tilde{q}_{H}, m\left(\tilde{q}_{H}^{-}\right)\right]}{\left(1-\gamma_{1}\right) \psi_{1}\left[\tilde{q}_{H}, m\left(\tilde{q}_{H}^{-}\right)\right]} \leq \frac{\psi_{2 H}\left[\tilde{q}_{H}, m\left(\tilde{q}_{H}^{+}\right)\right]}{\left(1-\gamma_{2}\right) \psi_{2}\left[\tilde{q}_{H}, m\left(\tilde{q}_{H}^{+}\right)\right]}
$$

In view of the first inequality in Proposition 3 and the strict log supermodularity of the productivity function, this inequality implies $m\left(\tilde{q}_{H}^{+}\right)>m\left(\tilde{q}_{H}^{-}\right)$. That is, the matching function is discontinuous at $\tilde{q}_{H}$ and it jumps upwards there. As a result, there must exist an ability level for workers $\check{q}_{L} \in\left[m\left(\tilde{q}_{H}^{-}\right), m\left(\tilde{q}_{H}^{+}\right)\right]$such that workers in the range $\left(\check{q}_{L}-\check{\varepsilon}_{1}, \check{q}_{L}\right)$ are employed in sector 1 and workers in the range $\left(\check{q}_{L}, \check{q}_{L}+\check{\varepsilon}_{2}\right)$ are employed in sector 2 , for $\check{\varepsilon}_{1}$ and $\check{\varepsilon}_{2}$ small enough. Due to the upward jump of the matching function and due to PAM in each sector, in this range of worker types the ability of managers matched with workers in sector 1 must be strictly greater than the ability of managers matched with workers in sector 2. This is illustrated in Figure 
14. At point $A$, we have $q_{H}=\tilde{q}_{H}$ and the matching function exhibits an upward jump from point $A$ to $C$. The supposition is that managers to the left of $A$ sort into sector 1 and managers to the right of $A$ sort into sector 2, as illustrated in the figure. Clearly, workers with ability between points $A$ and $C$ must be matched with managers in some sector. Segment $x$ illustrates a possible matching of these workers with high-ability managers. It is not possible for $x$ to be sector 2, however, because this would imply non-monotonic matching in this sector, which is ruled out by the strict log supermodularity of the productivity function there. So $x$ must be sector 1 . In this case, $\breve{q}_{L}$ is the ability of workers at point $C$. Workers with ability just below $C$ are employed in sector 1 and workers with ability just above $C$ are employed in sector 2. Evidently, the ability of managers with whom these workers are matched in sector 1 is higher than the ability of managers with whom their slightly better peers are matched in sector 2 . It can be seen from the figure that a similar outcome obtains if the matching along $x$ is to the left of point $A$, except that in this case $x$ stands for sector 2 and $\check{q}_{L}$ is the ability of workers at point $A$. Evidently, in this case too, at points around $\check{q}_{L}$ the ability of managers matched with workers in sector 1 is higher than the ability of managers matched with workers in sector 2 .

In short, consider the inverse function $m_{1}^{-1}\left(q_{L}\right)$ for $q_{L} \in\left(\check{q}_{L}-\check{\varepsilon}_{1}, \check{q}_{L}\right)$; this inverse exists in the specified range because $m_{1}\left(q_{H}\right)$ is continuous and strictly increasing at points in $\left(\tilde{q}_{H}-\varepsilon, \tilde{q}_{H}\right)$ for $\varepsilon$ small enough. Similarly, consider the inverse function $m_{2}^{-1}\left(q_{L}\right)$ for $q_{L} \in\left(\check{q}_{L}, \check{q}_{L}+\check{\varepsilon}_{2}\right)$; this inverse also exists in the specified range because $m_{2}\left(q_{H}\right)$ is continuous and strictly increasing at points in $\left(\tilde{q}_{H}, \tilde{q}_{H}+\varepsilon\right)$ for $\varepsilon$ small enough. Moreover, under the supposition of our sorting pattern $m^{-1}\left(q_{L}\right)=m_{1}^{-1}\left(q_{L}\right)$ for $q_{L} \in\left(\check{q}_{L}-\check{\varepsilon}_{1}, \check{q}_{L}\right)$ and $m^{-1}\left(q_{L}\right)=m_{2}^{-1}\left(q_{L}\right)$ for $q_{L} \in\left(\check{q}_{L}, \check{q}_{L}+\check{\varepsilon}_{2}\right)$ and the argument in the previous paragraph showed that $m^{-1}\left(q_{L}\right)=m_{1}^{-1}\left(q_{L}\right)>m^{-1}\left(q_{L}^{\prime}\right)=m_{2}^{-1}\left(q_{L}^{\prime}\right)$ for $q_{L} \in\left(\check{q}_{L}-\check{\varepsilon}_{1}, \check{q}_{L}\right)$ and $q_{L}^{\prime} \in\left(\check{q}_{L}, \check{q}_{L}+\check{\varepsilon}_{2}\right)$. Taking limits as $\check{\varepsilon}_{1}, \check{\varepsilon}_{2} \searrow 0$, this implies that $m^{-1}\left(\check{q}_{L}^{-}\right)>m^{-1}\left(\check{q}_{L}^{+}\right)$.

Next, following steps similar to those used in the proof of Proposition 2, which considered the response of profits to variations in the ability of managers at points around $\tilde{q}_{H}$, an analysis of the response of profits to variations in the ability of workers at points around $\check{q}_{L}$ establishes that a necessary condition for optimality is

$$
\frac{\psi_{1 L}\left[m^{-1}\left(\check{q}_{L}^{-}\right), \check{q}_{L}\right]}{\gamma_{1} \psi_{1}\left[m^{-1}\left(\check{q}_{L}^{-}\right), \check{q}_{L}\right]} \leq \frac{\psi_{2 L}\left[m^{-1}\left(\check{q}_{L}^{+}\right), \check{q}_{L}\right]}{\gamma_{2} \psi_{2}\left[m^{-1}\left(\check{q}_{L}^{+}\right), \check{q}_{L}\right]} .
$$

In view of the second inequality in Proposition 3 and the strict $\log$ supermodularity of the productivity function, this inequality implies $m^{-1}\left(\check{q}_{L}^{+}\right)=m_{2}^{-1}\left(\check{q}_{L}^{+}\right)>m_{1}^{-1}\left(\check{q}_{L}^{-}\right)=m^{-1}\left(\check{q}_{L}^{-}\right)$, which contradicts the above established result that $m_{1}^{-1}\left(\check{q}_{L}^{-}\right)>m_{2}^{-1}\left(\check{q}_{L}^{+}\right)$. It follows that the best managers sort into sector 1 . By symmetrical arguments the best workers also sort into sector 1.

\section{Proofs for Section 5}

Assume that Assumption 1' holds and suppose that some sector employs workers and managers whose abilities form the intervals $I_{L}=\left[q_{L a}, q_{L b}\right]$ and $I_{H}=\left[q_{H a}, q_{H b}\right]$, respectively. To simplify notation, we drop the sectoral index $i$ and denote $q_{H}$ by $q$, and we consider the following industry equilibrium conditions corresponding to (7) - (9) for one particular sector:

$$
r(q)=\bar{\gamma} p^{\frac{1}{1-\gamma}} \psi[q, m(q)]^{\frac{1}{1-\gamma}} w[m(q)]^{-\frac{\gamma}{1-\gamma}}, \quad \bar{\gamma}=\gamma^{\frac{\gamma}{1-\gamma}}(1-\gamma)
$$




$$
\begin{gathered}
\frac{\psi_{L}[q, m(q)]}{\gamma \psi[q, m(q)]}=\frac{w^{\prime}[m(q)]}{w[m(q)]}, \\
\bar{H} \frac{\gamma r(q)}{(1-\gamma) w[m(q)]} \phi_{H}(q)=\bar{L} \phi_{L}[m(q)] m^{\prime}(q),
\end{gathered}
$$

and the boundary conditions,

$$
\begin{aligned}
m\left(q_{H z}\right) & =q_{L z}, \quad z=a, b \\
q_{L b} & >q_{L a}>0, \quad q_{H b}>q_{H a}>0 .
\end{aligned}
$$

Equation (29) is taken from (7), (30) is taken from (6) and (31) is taken from (9). We seek to characterize the solution for the three functions, $w(\cdot), r(\cdot)$ and $m(\cdot)$.

We use (29) and (30) to obtain

$$
\begin{gathered}
\ln r\left(q_{H}\right)-\ln r\left(q_{H 0}\right)=\int_{q_{H 0}}^{q_{H}} \frac{\psi_{H}[x, m(x)]}{(1-\gamma) \psi[x, m(x)]} d x, \text { for } q_{H}, q_{H 0} \in I_{H}, \\
\ln w\left(q_{L}\right)-\ln w\left(q_{L 0}\right)=\int_{q_{L 0}}^{q_{L}} \frac{\psi_{L}[\mu(x), x]}{\gamma \psi[\mu(x), x]} d x, \text { for } q_{L}, q_{L 0} \in I_{L},
\end{gathered}
$$

where $\mu(\cdot)$ is the inverse of $m(\cdot)$. We substitute (29) into (31) to obtain

$$
\begin{aligned}
\frac{1}{1-\gamma} \ln w[m(q)]= & \frac{1}{1-\gamma} \ln \gamma+\ln \left(\frac{\bar{H}}{\bar{L}}\right)+\frac{1}{1-\gamma} \ln p \\
& +\frac{1}{1-\gamma} \ln \psi[q, m(q)]+\log \phi_{H}(q)-\log \phi_{L}[m(q)]-\log m^{\prime}(q) .
\end{aligned}
$$

The differential equations (30) and (35) together with the boundary conditions (32) uniquely determine the solution of $w(\cdot)$ and $m(\cdot)$ when the productivity function $\psi(\cdot)$ is twice continuously differentiable and the density functions $\phi_{F}(\cdot), F=H, L$, are continuously differentiable.

By differentiating (35) and substituting (30) into the result, we generate a second-order differential equation for the matching function,

$$
\frac{m^{\prime \prime}(q)}{m^{\prime}(q)}=\frac{\psi_{H}[q, m(q)]}{(1-\gamma) \psi[q, m(q)]}-\frac{\psi_{L}[q, m(q)] m^{\prime}(q)}{\gamma \psi[q, m(q)]}+\frac{\phi_{H}^{\prime}(q)}{\phi_{H}(q)}-\frac{\phi_{L}^{\prime}[m(q)] m^{\prime}(q)}{\phi_{L}[m(q)]} .
$$

Given boundary conditions $m\left(q_{0}\right)=q_{L 0}, m^{\prime}\left(q_{0}\right)=t_{0}>0$, this differential equation has a unique solution, which may or may not satisfy the boundary conditions (32). The solution to the original matching problem is found by identifying a value $t_{a}$ such that $m\left(q_{H a}\right)=q_{L a}$ and $m^{\prime}\left(q_{H a}\right)=t_{a}$ yield a solution that satisfies the second boundary condition $m\left(q_{H b}\right)=q_{L b}$. Note that this solution depends neither on the price $p$ nor on the factor endowments $\bar{H}$ and $\bar{L}$. Therefore, changes in these variables do no affect the matching function, but they change all wages and salaries proportionately, as can be seen from (35), and (29). Using hats to denote proportional changes, e.g., $\hat{p}=d p / p$, we have

Lemma 1 (i) The matching function $m(\cdot)$ does not depend on $(p, \bar{H}, \bar{L})$. (ii) An increase in the price $p$, $\hat{p}>0$, raises the wage and salary schedules proportionately by $\hat{p}$. (iii) An increase in $\bar{H} / \bar{L}$ such that $\hat{H}-\hat{L}=$ $\hat{\eta}>0$ raises the wage schedule proportionately by $(1-\gamma) \hat{\eta}$ and reduces the salary schedule proportionately by $\gamma \hat{\eta}$. 
We now prove several lemmas that are used in the main analysis.

Lemma 2 Let $\left[m_{\varkappa}(q), w_{\varkappa}\left(q_{L}\right)\right]$ and $\left[m_{\varrho}(q), w_{\varrho}\left(q_{L}\right)\right]$ be solutions to the differential equations (30) and (35), each for different boundary conditions (32), such that $m_{\varkappa}\left(q_{0}\right)=m_{\varrho}\left(q_{0}\right)=q_{L 0}$ and $m_{\varrho}^{\prime}\left(q_{0}\right)>m_{\varkappa}^{\prime}\left(q_{0}\right)$ for $q_{0} \in S_{H \varkappa} \cap S_{H \varrho}$. Then $m_{\varrho}(q)>m_{\varkappa}(q)$ for all $q>q_{0}$ and $m_{\varrho}(q)<m_{\varkappa}(q)$ for all $q<q_{0}$ in the overlapping range of abilities.

Proof. Consider $q>q_{0}$ and suppose that, contrary to the claim, there exists a $q_{1}>q_{0}$ such that $m_{\varrho}\left(q_{1}\right) \leq$ $m_{\varkappa}\left(q_{1}\right)$. Then differentiability of $m_{\iota}(\cdot), \iota=\varkappa, \varrho$, implies that there exists $q_{2}>q_{0}$ such that $m_{\varrho}\left(q_{2}\right)=$ $m_{\varkappa}\left(q_{2}\right), m_{\varrho}(q)>m_{\varkappa}(q)$ for all $q \in\left(q_{0}, q_{2}\right)$ and $m_{\varrho}^{\prime}\left(q_{2}\right)<m_{\varkappa}^{\prime}\left(q_{2}\right)$. This also implies $\mu_{\varrho}(x)<\mu_{\varkappa}(x)$ for all $x \in\left(m_{\varrho}\left(q_{0}\right), m_{\varrho}\left(q_{2}\right)\right)$, where $\mu_{\iota}(\cdot)$ is the inverse of $m_{\iota}(\cdot)$. Under these conditions (35) implies $w_{\varrho}\left[m_{\varrho}\left(q_{0}\right)\right]<w_{\varkappa}\left[m_{\varrho}\left(q_{0}\right)\right]$ and $w_{\varrho}\left[m_{\varrho}\left(q_{2}\right)\right]>w_{\varkappa}\left[m_{\varrho}\left(q_{2}\right)\right]$, and therefore

$$
w_{\varkappa}\left[m_{\varrho}\left(q_{2}\right)\right]-w_{\varkappa}\left[m_{\varrho}\left(q_{0}\right)\right]<w_{\varrho}\left[m_{\varrho}\left(q_{2}\right)\right]-w_{\varrho}\left[m_{\varrho}\left(q_{0}\right)\right] .
$$

On the other hand, (34) implies

$$
\ln w_{\iota}\left[m_{\varrho}\left(q_{2}\right)\right]-\ln w_{\iota}\left[m_{\varrho}\left(q_{0}\right)\right]=\int_{m_{\varrho}\left(q_{0}\right)}^{m_{\varrho}\left(q_{2}\right)} \frac{\psi_{L}\left[\mu_{\iota}(x), x\right]}{\gamma \psi\left[\mu_{\iota}(x), x\right]} d x, \quad \iota=\varkappa, \varrho .
$$

Together with the previous inequality, this gives

$$
\int_{m_{\varrho}\left(q_{0}\right)}^{m_{\varrho}\left(q_{2}\right)} \frac{\psi_{L}\left[\mu_{\varkappa}(x), x\right]}{\psi\left[\mu_{\varkappa}(x), x\right]} d x<\int_{m_{\varrho}\left(q_{0}\right)}^{m_{\varrho}\left(q_{2}\right)} \frac{\psi_{L}\left[\mu_{\varrho}(x), x\right]}{\psi\left[\mu_{\varrho}(x), x\right]} d x .
$$

Note, however, that strict $\log$ supermodularity of $\psi(\cdot)$ and $\mu_{\varrho}(x)<\mu_{\varkappa}(x)$ for all $x \in\left(m_{\varrho}\left(q_{0}\right), m_{\varrho}\left(q_{2}\right)\right)$ imply the reverse inequality, a contradiction. It follows that $m_{\varrho}(q)>m_{\varkappa}(q)$ for all $q>q_{0}$. A similar argument shows that $m_{\varrho}(q)<m_{\varkappa}(q)$ for all $q<q_{0}$.

The key implication of this lemma is that changes in the boundary conditions (32) shift the matching function in such a way as to generate at most one point in common with the original matching function. We next show how the matching function and wage function respond to the boundary conditions. To this end, re-consider Figure 6 in the main text. Let the thick curve between points $a$ and $b$ represent the solution to the matching function when points $a$ and $b$ are the boundary points (32). Now consider the shift of the equilibrium matching function in response to a rise in $q_{L b}$; that is, the end point $b$ shifts upward to $b^{\prime}$. Since point $a$ is common to the old and new matching function, Lemma 2 implies that the two curves can have no additional points in common, which implies that the new inverse matching function - represented by the thin curve between points $a$ and $b^{\prime}$-is everywhere above the old one. It follows that an increase in $q_{L b}$ increases the ability of workers matched with every manager except for the least able manager. Other shifts in the boundary points can be analyzed in similar fashion to establish

Lemma 3 (i) $d m\left(q_{H}\right) / d q_{L a}>0$ for all $q_{H}<q_{H b}$ and $d \mu\left(q_{L}\right) / d q_{L a}<0$ for all $q_{L}<q_{L b}$; (ii) $d m\left(q_{H}\right) / d q_{L b}>$ 0 for all $q_{H}>q_{H a}$ and $d \mu\left(q_{L}\right) / d q_{L b}<0$ for all $q_{L}>q_{L a}$; (iii) $d \mu\left(q_{L}\right) / d q_{H a}>0$ for all $q_{L}<q_{L b}$ and $d m\left(q_{H}\right) / d q_{H a}<0$ for all $q_{H}<q_{H b}$; and (iv) $d \mu\left(q_{L}\right) / d q_{H b}>0$ for all $q_{L}>q_{L a}$ and $d m\left(q_{H}\right) / d q_{H b}<0$ for all $q_{H}>q_{H a}$. 
The rule that emerges from this lemma is that an improvement in the ability of workers at a boundary of $I_{L}$ improves the quality of the matches for all the managers (except those at the other boundary) and deteriorates the quality of the matches for all the workers (except those at the other boundary). Similarly, an improvement in the ability of managers at a boundary of $I_{H}$ improves the quality of the matches for all workers (except those at the other boundary) and deteriorates the quality of the matches for all the managers (except those at the other boundary).

Next consider changes in a boundary $\left(q_{H z}, q_{L z}\right), z=a, b$. For concreteness, suppose that $\left(q_{H b}, q_{L b}\right)$ changes. Then the new matching function coincides with the old one at the other boundary point, $\left(q_{H a}, q_{L a}\right)$, which has not changed. In this case, Lemma 2 implies that either the two matching functions coincide in the overlapping range of abilities or one is above the other everywhere except for at $\left(q_{H a}, q_{L a}\right)$. A similar argument applies to changes in $\left(q_{H a}, q_{L a}\right)$. We therefore have:

Lemma 4 In response to a shift in a single boundary $\left(q_{H z}, q_{L z}\right), z=a, b$, either the new matching functions coincide with the old matching function in the overlapping range of abilities or one matching function is above the other everywhere except for at the opposite boundary point.

We next discuss the impact of boundaries on wages and salaries. We focus on wages, but note that if a shift in boundaries raises the wage of workers with ability $q_{L}$ then it must reduce the salary of managers teamed with these workers. This can be seen from (29) by noting that a change in boundaries has no impact on $r(\cdot)$ through an induced shift in the matching function due to the first-order condition (30) (a version of the Envelope Theorem). Therefore the change in salary $r(q)$ is driven by the change in wages of workers matched with managers of ability $q$. We record this result in

Lemma 5 Suppose that the boundaries $\left(q_{H z}, q_{L z}\right), z=a, b$, change and that, as a result, w $\left(q_{L}\right)$ rises for some $q_{L}$ such that $q_{L}$ and $q=m^{-1}\left(q_{L}\right)$ are in the overlapping range of abilities of the old and new boundaries. Then $r(q)$ declines.

For the subsequent analysis the following lemma is useful:

Lemma 6 Let $\left[m_{\varkappa}(q), w_{\varkappa}\left(q_{L}\right)\right]$ and $\left[m_{\varrho}(q), w_{\varrho}\left(q_{L}\right)\right]$ be solutions to the differential equations (30) and (35), each for different boundary conditions (32), such that $m_{\varkappa}\left(q_{0}\right)=m_{\varrho}\left(q_{0}\right)=q_{L 0}$ and $m_{\varrho}^{\prime}\left(q_{0}\right)>m_{\varkappa}^{\prime}\left(q_{0}\right)$ for some $q_{0} \in S_{L \varkappa} \cap S_{L \varrho}$, and let $r_{\varrho}(q)$ and $r_{\varkappa}(q)$ be the corresponding solutions to (29). Then $w_{\varrho}\left(q_{L}\right)<$ $w_{\varkappa}\left(q_{L}\right)$ and $r_{\varrho}(q)>r_{\varkappa}(q)$ in the overlapping range of abilities.

Proof. From Lemma 2 we know that $m_{\varrho}(q)>m_{\varkappa}(q)$ for all $q>q_{0}$ and $m_{\varrho}(q)<m_{\varkappa}(q)$ for all $q<q_{0}$ in the overlapping range of abilities and $\mu_{\varrho}(x)<\mu_{\varkappa}(x)$ for all $x>q_{L 0}$ and $\mu_{\varrho}(x)>\mu_{\varkappa}(x)$ for all $x<q_{L 0}$ in the overlapping range of abilities. Moreover, $m_{\varrho}^{\prime}\left(q_{0}\right)>m_{\varkappa}^{\prime}\left(q_{0}\right)$ and (35) imply

$$
\ln w_{\varkappa}\left(q_{L 0}\right)>\ln w_{\varrho}\left(q_{L 0}\right)
$$

while (34) implies

$$
\ln w_{\iota}\left(q_{L}\right)-\ln w_{\iota}\left(q_{L 0}\right)=\int_{q_{L 0}}^{q_{L}} \frac{\psi_{L}\left[\mu_{\iota}(x), x\right]}{\gamma \psi\left[\mu_{\iota}(x), x\right]} d x, \quad \iota=\varkappa, \varrho .
$$


Together, these inequalities imply

$$
\begin{aligned}
\ln w_{\varkappa}\left(q_{L}\right)-\ln w_{\varrho}\left(q_{L}\right) & >\int_{q_{L 0}}^{q_{L}} \frac{\psi_{L}\left[\mu_{\varkappa}(x), x\right]}{\gamma \psi\left[\mu_{\varkappa}(x), x\right]} d x-\int_{q_{L 0}}^{q_{L}} \frac{\psi_{L}\left[\mu_{\varrho}(x), x\right]}{\gamma \psi\left[\mu_{\varrho}(x), x\right]} d x \\
& =\int_{q_{L}}^{q_{L 0}} \frac{\psi_{L}\left[\mu_{\varrho}(x), x\right]}{\gamma \psi\left[\mu_{\varrho}(x), x\right]} d x-\int_{q_{L}}^{q_{L 0}} \frac{\psi_{L}\left[\mu_{\varkappa}(x), x\right]}{\gamma \psi\left[\mu_{\varkappa}(x), x\right]} d x .
\end{aligned}
$$

For $q_{L}>q_{L 0}$ the right-hand side of the first line is positive due to the strict log supermodularity of the productivity function and $\mu_{\varrho}(x)<\mu_{\varkappa}(x)$ for all $x>q_{L 0}$, and the second line also is positive for $q_{L}<q_{L 0}$ due to the strict $\log$ supermodularity of the productivity function and $\mu_{\varrho}(x)>\mu_{\varkappa}(x)$ for all $x<q_{L 0}$. It follows that $w_{\varkappa}\left(q_{L}\right)>w_{\varrho}\left(q_{L}\right)$ for all $q_{L}$ in the overlapping range of abilities. A similar argument establishes that $r_{\varkappa}(q)<r_{\varrho}(q)$ for all $q$ in the overlapping range of abilities.

This lemma, together with Lemma 4, have straightforward implications for the impact of boundary points on the wage and salary functions.

Corollary 1 Suppose that the lower boundary $\left(q_{H a}, q_{L a}\right)$ changes and the matching function shifts upwards as a result. Then salaries decline and wages rise in the overlapping range of abilities. The converse holds when the matching function shifts downwards.

Corollary 2 Suppose that the upper boundary $\left(q_{H b}, q_{L b}\right)$ changes and the matching function shifts upwards as a result. Then salaries rise and wages decline in the overlapping range of abilities. The converse holds when the matching function shifts downwards.

Not only do wages and salaries shift in a predictable way in response to a shift in a boundary point, the inequality of wages and of salaries also change in predictable ways. From (34) we see that a change in boundaries that shifts upwards the matching function reduces wage inequality, because for every two ability levels the ratio of the wage of a high-ability worker to the wage of a low-ability worker declines for all types in the overlapping range. For salaries it is the opposite, as one can see from (33). We therefore have

Lemma 7 Suppose that the matching function shifts upwards in response to a shift in the boundaries (32). Then wage inequality narrows and salary inequality widens. The opposite is true when the matching function shifts downwards.

\section{Proofs for Section 6.1}

Consider the two-sector economy for the case of Cobb-Douglas productivity under Assumption 1, and adopt the label for the two sectors such that $s_{H}=\beta_{1} /\left(1-\gamma_{1}\right)-\beta_{2} /\left(1-\gamma_{2}\right)>0$. We establish

Proposition 7 Suppose that $s_{H} \approx 0$. When $\hat{p}_{1}>0$, (i) $\hat{w}_{1}>\hat{w}_{2}$; (ii) if $\gamma_{1} \approx \gamma_{2}$, then $\hat{w}_{1}>\hat{p}_{1}>$ $\hat{r}_{1} \approx \hat{r}_{2}>0>\hat{w}_{2}$; (iii) if $\gamma_{1}>\gamma_{2}$ and $s_{L} \approx 0$, then $\hat{w}_{1} \approx \hat{w}_{2}>\hat{p}_{1}>0>\hat{r}_{1} \approx \hat{r}_{2}$; (iv) if $\gamma_{1}<\gamma_{2}$ and $s_{L} \approx 0$, then $\hat{r}_{1} \approx \hat{r}_{2}>\hat{p}_{1}>0>\hat{w}_{1} \approx \hat{w}_{2}$. 
Proof. Differentiating the equilibrium system (18)-(21), we obtain

$$
\left(\begin{array}{cccc}
1 & -1 & s_{L} & 0 \\
-\frac{\gamma_{1}}{1-\gamma_{1}} & \frac{\gamma_{2}}{1-\gamma_{2}} & 0 & s_{H} \\
0 & \frac{E_{2}}{1-\gamma_{2}} & \Lambda_{2} & -\Theta_{2} \\
\frac{E_{1}}{1-\gamma_{1}} & 0 & -\Lambda_{1} & \Theta_{1}
\end{array}\right)\left(\begin{array}{c}
\hat{w}_{1} \\
\hat{w}_{2} \\
\hat{q}_{L}^{*} \\
\hat{q}_{H}^{*}
\end{array}\right)=\left(\begin{array}{c}
0 \\
-\frac{1}{1-\gamma_{1}} \\
0 \\
\frac{E_{1}}{1-\gamma_{1}}
\end{array}\right) \hat{p}_{1}
$$

where $E_{i}$ is effective labor in sector $i$, defined as

$$
\begin{gathered}
E_{1}=\bar{H}\left(\frac{\gamma_{1} p_{1}}{w_{1}}\right)^{\frac{1}{1-\gamma_{1}}} \int_{q_{H}^{*}}^{q_{H} \max } q_{H}^{\frac{\beta_{1}}{1-\gamma_{1}}} \phi_{H}\left(q_{H}\right) d q_{H}, \\
E_{2}=\bar{H}\left(\frac{\gamma_{2} p_{2}}{w_{2}}\right)^{\frac{1}{1-\gamma_{2}}} \int_{q_{H} \min }^{q_{H}^{*}} q_{H}^{\frac{\beta_{2}}{1-\gamma_{2}}} \phi_{H}\left(q_{H}\right) d q_{H},
\end{gathered}
$$

and

$$
\begin{gathered}
\Lambda_{1}=\bar{L}\left(q_{L}^{*}\right)^{\frac{\alpha_{1}}{\gamma_{1}}+1} \phi_{L}\left(q_{L}^{*}\right), \\
\Lambda_{2}=\bar{L}\left(q_{L}^{*}\right)^{\frac{\alpha_{2}}{\gamma_{2}}+1} \phi_{L}\left(q_{L}^{*}\right), \\
\Theta_{1}=\bar{H}\left(\frac{\gamma_{1} p_{1}}{w_{1}}\right)^{\frac{1}{1-\gamma_{1}}}\left(q_{H}^{*}\right)^{\frac{\beta_{1}}{1-\gamma_{1}}+1} \phi_{H}\left(q_{H}^{*}\right), \\
\Theta_{2}=\bar{H}\left(\frac{\gamma_{2} p_{2}}{w_{2}}\right)^{\frac{1}{1-\gamma_{2}}}\left(q_{H}^{*}\right)^{\frac{\beta_{2}}{1-\gamma_{2}}+1} \phi_{H}\left(q_{H}^{*}\right) .
\end{gathered}
$$

The determinant of the matrix on the left-hand side of this system, $D_{C D}$, satisfies

$$
\begin{aligned}
\left(1-\gamma_{2}\right)\left(1-\gamma_{1}\right)\left(-D_{C D}\right)= & \left(\Theta_{1} \Lambda_{2}-\Theta_{2} \Lambda_{1}\right)\left(\gamma_{1}-\gamma_{2}\right)+s_{H}\left[\Lambda_{1} E_{2}\left(1-\gamma_{1}\right)+\Lambda_{2} E_{1}\left(1-\gamma_{2}\right)\right] \\
& +s_{L}\left(\Theta_{1} \gamma_{1} E_{2}+\Theta_{2} \gamma_{2} E_{1}\right)+E_{1} E_{2} s_{H} s_{L} .
\end{aligned}
$$

Using the equilibrium conditions (20) and (21), we find that

$$
\left(\Theta_{1} \Lambda_{2}-\Theta_{2} \Lambda_{1}\right)\left(\gamma_{1}-\gamma_{2}\right)=\Theta_{2} \Lambda_{1} \frac{\left(\gamma_{1}-\gamma_{2}\right)^{2}}{\gamma_{2}\left(1-\gamma_{1}\right)}>0
$$

Therefore $D_{C D}<0$. We also compute

$$
\begin{aligned}
\hat{w}_{1}\left(1-\gamma_{2}\right)\left(1-\gamma_{1}\right)\left(-D_{C D}\right)= & \left(\Theta_{1} \Lambda_{2}-\Theta_{2} \Lambda_{1}+\Lambda_{2} E_{1} s_{H}\right)\left(1-\gamma_{2}\right) \hat{p}_{1} \\
& +\left[\left(\Theta_{1} E_{2}+\Theta_{2} \gamma_{2} E_{1}\right) s_{L}+E_{1} E_{2} s_{H} s_{L}\right] \hat{p}_{1}, \\
\hat{w}_{2}\left(1-\gamma_{1}\right)\left(-D_{C D}\right)= & \left(\Theta_{1} \Lambda_{2}-\Theta_{2} \Lambda_{1}+\Lambda_{2} E_{1} s_{H}-\Theta_{2} E_{1} s_{L}\right) \hat{p}_{1} .
\end{aligned}
$$

Therefore,

$$
\left(\hat{w}_{1}-\hat{w}_{2}\right)\left(1-\gamma_{1}\right)\left(1-\gamma_{2}\right)\left(-D_{C D}\right)=\left[\left(\Theta_{1} E_{2}+\Theta_{2} \gamma_{2} E_{1}\right) s_{L}+E_{1} E_{2} s_{H} s_{L}+\Theta_{2} E_{1} s_{L}\left(1-\gamma_{2}\right)\right] \hat{p}_{1} .
$$

Since $D_{C D}<0$, it follows that an increase in the price of good 1 results in $\hat{w}_{1}>\hat{w}_{2}$, which proves part (i) of Proposition 7. 
Next, consider the case in which $s_{H} \approx 0$ and $\gamma_{1} \approx \gamma_{2}$. In this case,

$$
\left(1-\gamma_{2}\right)\left(1-\gamma_{1}\right)\left(-D_{C D}\right) \approx s_{L}\left(\Theta_{1} \gamma_{1} E_{2}+\Theta_{2} \gamma_{2} E_{1}\right)
$$

Then

$$
\hat{w}_{1}-\hat{w}_{2} \approx \frac{\Theta_{1} E_{2}+\Theta_{2} E_{1}}{\Theta_{1} \gamma_{1} E_{2}+\Theta_{2} \gamma_{2} E_{1}} \hat{p}_{1}
$$

because $\gamma_{1} \approx \gamma_{2}$ implies $\Theta_{1} \Lambda_{2}-\Theta_{2} \Lambda_{1} \approx 0$. Evidently, in this case, $\hat{w}_{1}>\hat{p}_{1}>0>\hat{w}_{2}$. To complete the proof of part (ii) of Proposition 7, we need to calculate the response of the anchors $r_{1}$ and $r_{2}$ for the managers' salaries. When $p_{1}$ rises, (22) yields $\hat{r}_{1}=\left(1-\gamma_{1}\right)^{-1} \hat{p}_{1}-\gamma_{1}\left(1-\gamma_{1}\right)^{-1} \hat{w}_{1}$ and $\hat{r}_{2}=-\gamma_{2}\left(1-\gamma_{2}\right)^{-1} \hat{w}_{2}$. In case (ii) of Proposition 7 , with $s_{H} \approx 0$ and $\gamma_{1} \approx \gamma_{2}$, these imply

$$
\hat{r}_{1}-\hat{r}_{2} \approx \frac{\Theta_{2} \gamma_{2} E_{1}}{\Theta_{1} \gamma_{1} E_{2}+\Theta_{2} \gamma_{2} E_{1}} \hat{p}_{1}
$$

It follows that $\hat{p}_{1}>\hat{r}_{1} \approx \hat{r}_{2}>0$. So, part (ii) of the proposition is proved.

We turn now to parts (iii) and (iv) of Proposition 7. The antecedents $s_{H} \approx 0$ and $s_{L} \approx 0$ imply

$$
\begin{aligned}
\left(1-\gamma_{2}\right)\left(1-\gamma_{1}\right)\left(-D_{C D}\right) & \approx\left(\Theta_{1} \Lambda_{2}-\Theta_{2} \Lambda_{1}\right)\left(\gamma_{1}-\gamma_{2}\right) \\
\hat{w}_{1}\left(1-\gamma_{1}\right)\left(-D_{C D}\right) & \approx\left(\Theta_{1} \Lambda_{2}-\Theta_{2} \Lambda_{1}\right) \hat{p}_{1} \\
\hat{w}_{2}\left(1-\gamma_{1}\right)\left(-D_{C D}\right) & \approx\left(\Theta_{1} \Lambda_{2}-\Theta_{2} \Lambda_{1}\right) \hat{p}_{1} .
\end{aligned}
$$

It follows that

$$
\hat{w}_{1}-\hat{w}_{2} \approx \frac{1-\gamma_{2}}{\gamma_{1}-\gamma_{2}} \hat{p}_{1}
$$

which implies that $\hat{w}_{1} \approx \hat{w}_{2}>\hat{p}_{1}>0$ for $\gamma_{1}>\gamma_{2}$ and $\hat{w}_{1} \approx \hat{w}_{2}<0<\hat{p}_{1}$ for $\gamma_{1}<\gamma_{2}$. Moreover, since $\hat{r}_{1}=\left(1-\gamma_{1}\right)^{-1} \hat{p}_{1}-\gamma_{1}\left(1-\gamma_{1}\right)^{-1} \hat{w}_{1}$ and $\hat{r}_{2}=-\gamma_{2}\left(1-\gamma_{2}\right)^{-1} \hat{w}_{2}$, we have

$$
\hat{r}_{1}-\hat{r}_{2} \approx-\frac{\gamma_{2}}{\gamma_{1}-\gamma_{2}} \hat{p}_{1}
$$

Evidently, in this case, $\hat{r}_{1} \approx \hat{r}_{2}<0<\hat{p}_{1}$ when $\gamma_{1}>\gamma_{2}$ and $\hat{r}_{1} \approx \hat{r}_{2}>\hat{p}_{1}>0$ when $\gamma_{1}<\gamma_{2}$. This completes the proof of Proposition 7.

\section{Proofs for Section 6.2}

Consider a two-sector economy with strictly log-supermodular productivity under Assumption 1'. We first prove the result for an $H H / L L$ equilibrium and then for an $H L / L H$ equilibrium. We label sectors such that the best workers sort into sector 1 .

$H H / L L$ Equilibrium

In an $H H / L L$ equilibrium the cutoffs $\left\{q_{H}^{*}, q_{L}^{*}\right\}$ satisfy:

$$
\begin{aligned}
& w_{1}\left(q_{L}^{*}\right)=w_{2}\left(q_{L}^{*}\right), \\
& r_{1}\left(q_{H}^{*}\right)=r_{2}\left(q_{H}^{*}\right),
\end{aligned}
$$

where $\left[w_{i}(\cdot), r_{i}(\cdot), m_{i}(\cdot)\right]$ is a solution to the single-sector differential equations (30) and (35) for $i=1,2$ 
with the boundary conditions

$$
\begin{aligned}
& m_{2}\left(q_{H \min }\right)=q_{L \min }, \quad m_{2}\left(q_{H}^{*}\right)=q_{L}^{*}, \\
& m_{1}\left(q_{H}^{*}\right)=q_{L}^{*}, \quad m_{1}\left(q_{H \max }\right)=q_{L \max } .
\end{aligned}
$$

Clearly, the solutions for the wage function, the salary function, and the matching functions depend on the parameters of the model, such as prices and factor endowments, as do the equilibrium cutoffs $\left\{q_{H}^{*}, q_{L}^{*}\right\}$. We denote by $d w_{i}\left(q_{L}\right) / d p_{i}$ the derivative of the wage function in sector $i$ with respect to price $p_{i}$, where this derivative accounts for the endogenous adjustments of all three functions. This derivative contrasts with $w_{i}^{\prime}\left(q_{L}\right)$, which is the slope of the wage function for given parameters. We use similar notation to represent derivatives of the salary function.

For now, we are interested in $\eta=p_{2} / p_{1}$ and we shall use the following elasticities

$$
\varepsilon_{w_{i}, \eta}^{*}=\left.\frac{d w_{i}\left(q_{L}\right)}{d\left(p_{2} / p_{1}\right)} \cdot \frac{p_{2} / p_{1}}{q_{L}}\right|_{q_{L}=q_{L}^{*}}, \quad \varepsilon_{r_{i}, \eta}^{*}=\left.\frac{d r_{i}\left(q_{H}\right)}{d\left(p_{2} / p_{1}\right)} \cdot \frac{p_{2} / p_{1}}{q_{H}}\right|_{q_{H}=q_{H}^{*}} .
$$

Differentiating (37)-(38) with respect to $\eta \equiv p_{2} / p_{1}$ yields

$$
\begin{gathered}
{\left[\frac{w_{1}^{\prime}\left(q_{L}^{*}\right)}{w_{1}\left(q_{L}^{*}\right)}-\frac{w_{2}^{\prime}\left(q_{L}^{*}\right)}{w_{2}\left(q_{L}^{*}\right)}\right] d q_{L}^{*}=\varepsilon_{w_{2}, \eta}^{*}-\varepsilon_{w_{1}, \eta}^{*},} \\
{\left[\frac{r_{1}^{\prime}\left(q_{H}^{*}\right)}{r_{1}\left(q_{H}^{*}\right)}-\frac{r_{2}^{\prime}\left(q_{H}^{*}\right)}{r_{2}\left(q_{H}^{*}\right)}\right] d q_{H}^{*}=\varepsilon_{r_{2}, \eta}^{*}-\varepsilon_{r_{1}, \eta}^{*} .}
\end{gathered}
$$

The assumptions that the equilibrium is of the $H H / L L$ type and that the best workers and managers sort into sector 1 imply that the expressions in the square brackets are positive in both equations; that is, at the boundary $\left\{q_{H}^{*}, q_{L}^{*}\right\}$ between the two sectors the slopes of the wage and salary functions have to be steeper in sector 1 into which the more able employees sort. It follows that $q_{L}^{*}$ rises in response to an increase in the relative price of sector 2 if and only if $\varepsilon_{w_{2}, \eta}^{*}>\varepsilon_{w_{1}, \eta}^{*}$ and the cutoff $q_{H}^{*}$ rises if and only if $\varepsilon_{r_{2}, \eta}^{*}>\varepsilon_{r_{1}, \eta}^{*}$.

To understand the elasticities $\varepsilon_{w_{i}, \eta}^{*}$ and $\varepsilon_{r_{i}, \eta}^{*}$, note that a shift in $p_{2} / p_{1}$ impacts wages and salaries through two channels. First, there is the direct effect described in part (ii) of Lemma 1, which means that wages and salaries grow proportionally to the price within the sector when boundaries remain unchanged. But wages cannot increase everywhere by more in sector 2 than in sector 1 , since in equilibrium the wages at the cutoff type $q_{L}^{*}$ have to equalize across sectors. Therefore, re-matching in each sector is necessary, which impacts in turn the wage and salary functions, as implied by Lemmas 3-6 and Corollaries 1 and 2 to Lemma 6. In other words, the impact effect of a rise in the relative price of sector 2 increases the cutoffs for both workers and managers, but we also have to account for the induced change in matching in order to obtain the full effect. To this end, we now express the elasticities $\varepsilon_{w_{i}, \eta}^{*}$ and $\varepsilon_{r_{i}, \eta}^{*}$ as follows:

$$
\begin{gathered}
\varepsilon_{w_{i}, \eta}^{*}=\hat{\eta}+\varepsilon_{w_{i} L}^{*} \hat{q}_{L}^{*}+\varepsilon_{w_{i} H}^{*} \hat{q}_{H}^{*}, \quad i=1,2, \\
\varepsilon_{r_{i}, \eta}^{*}=\hat{\eta}+\varepsilon_{r_{i} L}^{*} \hat{q}_{L}^{*}+\varepsilon_{r_{i} H}^{*} \hat{q}_{H}^{*}, \quad i=1,2,
\end{gathered}
$$

where the first term captures the direct effect from part (ii) of Lemma $1, \varepsilon_{w_{i} L}^{*}$ is the elasticity of $w_{i}(\cdot)$ with respect to the boundary $q_{L}^{*}$ through the induced re-matching (evaluated at $q_{L}^{*}$ ), and $\varepsilon_{w_{i} H}^{*}$ is the elasticity of $w_{i}(\cdot)$ with respect to the boundary $q_{H}^{*}$ through the induced re-matching (evaluated at $q_{L}^{*}$ ). From (29) and 
(30) we also have

$$
\varepsilon_{r_{i} F}^{*}=-\frac{\gamma_{i}}{1-\gamma_{i}} \varepsilon_{w_{i} F}^{*}, \quad F=H, L ; \quad i=1,2 .
$$

Now substitute these equations into (41) and (42) to obtain

$$
M_{h}^{H H / L L}\left(\begin{array}{c}
\hat{q}_{L}^{*} \\
\hat{q}_{H}^{*}
\end{array}\right)=\left(\begin{array}{c}
\hat{p}_{2}-\hat{p}_{1} \\
\hat{p}_{2}-\hat{p}_{1}
\end{array}\right),
$$

where

$$
M_{h}^{H H / L L}=\left(\begin{array}{cc}
q_{L}^{*}\left[\frac{w_{1}^{\prime}\left(q_{L}^{*}\right)}{w_{1}\left(q_{L}^{*}\right)}-\frac{w_{2}^{\prime}\left(q_{L}^{*}\right)}{w_{2}\left(q_{L}^{*}\right)}\right]+\varepsilon_{w_{1} L}^{*}-\varepsilon_{w_{2} L}^{*} & \varepsilon_{w_{1} H}^{*}-\varepsilon_{w_{2} H}^{*} \\
\frac{\gamma_{2} \varepsilon_{w_{2} L}^{*}}{1-\gamma_{2}}-\frac{\gamma_{1} \varepsilon_{w_{1} L}^{*}}{1-\gamma_{1}} & q_{H}^{*}\left[\frac{r_{1}^{\prime}\left(q_{H}^{*}\right)}{r_{1}\left(q_{H}^{*}\right)}-\frac{r_{2}^{\prime}\left(q_{H}^{*}\right)}{r_{2}\left(q_{H}^{*}\right)}\right]+\frac{\gamma_{2} \varepsilon_{w_{2} H}^{*}}{1-\gamma_{2}}-\frac{\gamma_{1} \varepsilon_{w_{1} H}^{*}}{1-\gamma_{1}}
\end{array}\right)
$$

From Lemmas 3-6 we have

$$
\varepsilon_{w_{1} L}^{*}>0, \quad \varepsilon_{w_{2} L}^{*}<0, \quad \varepsilon_{w_{1} H}^{*}<0, \quad \varepsilon_{w_{2} H}^{*}>0 .
$$

These equations provide a solution to $\hat{q}_{L}^{*}$ and $\hat{q}_{H}^{*}$.

The determinant of the matrix $M_{h}^{H H / L L}$ is

$$
\begin{aligned}
D_{M_{h}^{H H / L L}}= & \left\{q_{L}^{*}\left[\frac{w_{1}^{\prime}\left(q_{L}^{*}\right)}{w_{1}\left(q_{L}^{*}\right)}-\frac{w_{2}^{\prime}\left(q_{L}^{*}\right)}{w_{2}\left(q_{L}^{*}\right)}\right]+\varepsilon_{w_{1} L}^{*}-\varepsilon_{w_{2} L}^{*}\right\} q_{H}^{*}\left[\frac{r_{1}^{\prime}\left(q_{H}^{*}\right)}{r_{1}\left(q_{H}^{*}\right)}-\frac{r_{2}^{\prime}\left(q_{H}^{*}\right)}{r_{2}\left(q_{H}^{*}\right)}\right] \\
& +\left(\frac{\gamma_{2} \varepsilon_{w_{2} H}^{*}}{1-\gamma_{2}}-\frac{\gamma_{1} \varepsilon_{w_{1} H}^{*}}{1-\gamma_{1}}\right) q_{L}^{*}\left[\frac{w_{1}^{\prime}\left(q_{L}^{*}\right)}{w_{1}\left(q_{L}^{*}\right)}-\frac{w_{2}^{\prime}\left(q_{L}^{*}\right)}{w_{2}\left(q_{L}^{*}\right)}\right]-\frac{\gamma_{1}-\gamma_{2}}{\left(1-\gamma_{1}\right)\left(1-\gamma_{2}\right)}\left(\varepsilon_{w_{2} H}^{*} \varepsilon_{w_{1} L}^{*}-\varepsilon_{w_{1} H}^{*} \varepsilon_{w_{2} L}^{*}\right) .
\end{aligned}
$$

The first two terms on the right-hand side are positive. We now show that the third term also is positive. To this end, note from Lemma 2 that if we change a single boundary and the new boundary is on the original matching function then the new matching function coincides with the old one in the overlapping range of abilities. Therefore, if we choose $d q_{L}^{*}=m_{i}^{\prime}\left(q_{H}^{*}\right) d q_{H}^{*}$, where $m_{i}(\cdot)$ is the solution of matching in sector $i$, then a change in the boundary $\left(d q_{H}^{*}, d q_{L}^{*}\right)$ does not change the wage $w_{i}\left(q_{L}^{*}\right)$. In other words,

$$
\varepsilon_{w_{i} H}^{*}+\varepsilon_{w_{i} L}^{*} \varepsilon_{m_{i}}^{*}=0
$$

where $\varepsilon_{m_{i}}^{*}$ is the elasticity of $m_{i}(\cdot)$ evaluated at $q_{H}^{*}$. On the other hand, (31) implies for the $H H / L L$ case that

$$
\varepsilon_{m_{i}}^{*}=\frac{\kappa_{m} \gamma_{i}}{1-\gamma_{i}}
$$

where

$$
\kappa_{m}=\frac{\bar{H} r\left(q_{H}^{*}\right) \phi_{H}\left(q_{H}^{*}\right) q_{H}^{*}}{\bar{L} w\left(q_{L}^{*}\right) \phi_{L}\left(q_{L}^{*}\right) q_{L}^{*}}
$$

Therefore,

$$
\varepsilon_{w_{i} H}^{*}=-\frac{\kappa_{m} \gamma_{i}}{1-\gamma_{i}} \varepsilon_{w_{i} L}^{*}
$$

Using this expression, we obtain

$$
-\frac{\gamma_{1}-\gamma_{2}}{\left(1-\gamma_{1}\right)\left(1-\gamma_{2}\right)}\left(\varepsilon_{w_{2} H}^{*} \varepsilon_{w_{1} L}^{*}-\varepsilon_{w_{1} H}^{*} \varepsilon_{w_{2} L}^{*}\right)=-\frac{\left(\gamma_{1}-\gamma_{2}\right)^{2} \kappa_{m} \varepsilon_{w_{1} L}^{*} \varepsilon_{w_{2} L}^{*}}{\left(1-\gamma_{1}\right)^{2}\left(1-\gamma_{2}\right)^{2}}>0
$$

which proves that $D_{M_{h}^{H H / L L}}>0$. 
Therefore, solving (46) implies that $\hat{q}_{L}^{*}>0$ and $\hat{q}_{H}^{*}>0$ if and only if $\hat{\eta}>0$. In other words, a rise in $\bar{H} / \bar{L}$ increases both cutoffs if and only if the relative price in sector 2 increases. That is, an increase in the relative price of good 2 raises both cutoffs and therefore raises output in sector 2 and reduces that in sector 1.

Next consider further implications of a rise in the price of good 2 on re-matching. Since the most able workers and the most able mangers sort into sector 1, we can use the differential equations (30) and (35) for $i=1,2$ with the boundary conditions (39) and (40) to characterize the solution to the matching functions $m_{i}\left(q_{H}\right)$ for $i=1,2$, given the equilibrium cutoffs $\left(q_{H}^{*}, q_{L}^{*}\right)$. An increase in $p_{2}$ shifts both cutoffs up, and this shift in boundary changes the matching functions in each sector. Also note that the solution to the differential equations extends beyond the range of abilities of workers and mangers who sort into a sector, so that $m_{i}\left(q_{H}\right)$ can be extended to abilities that are not employed in sector $i$.

The first thing to note is that due to the continuity of the wage and salary functions (31) implies:

$$
\frac{\gamma_{i} /\left(1-\gamma_{i}\right)}{\gamma_{j} /\left(1-\gamma_{j}\right)}=\frac{m_{i}^{\prime}\left(q_{H}^{*}\right)}{m_{j}^{\prime}\left(q_{H}^{*}\right)}
$$

Therefore the matching function is steeper in the labor intensive sector at the cutoff $q_{H}^{*}$, and if labor intensity is the same in both sectors then $m_{1}^{\prime}\left(q_{H}^{*}\right)=m_{2}^{\prime}\left(q_{H}^{*}\right)$. Next note that if $d q_{L}^{*}$ and $d q_{H}^{*}$ are the changes in the boundaries in response to $\hat{p}_{2}>0$, then:

$$
\frac{d q_{L}^{*}}{d p_{2}}=m_{i}^{\prime}\left(q_{H}^{*}\right) \frac{d q_{H}^{*}}{d p_{2}}+\frac{\partial m_{i}\left(q_{H}^{*}\right)}{\partial p_{2}} \text { for } i=1,2
$$

where $\partial m_{i}\left(q_{H}^{*}\right) / \partial p_{2}$ is the change in matching of a manager of ability $q_{H}^{*}$ in response to the price rise. Evidently, if $\gamma_{1}=\gamma_{2}$, in which case $m_{1}^{\prime}\left(q_{H}^{*}\right)=m_{2}^{\prime}\left(q_{H}^{*}\right)$, this equation implies

$$
\frac{\partial m_{1}\left(q_{H}^{*}\right)}{\partial p_{2}}=\frac{\partial m_{2}\left(q_{H}^{*}\right)}{\partial p_{2}}
$$

This implies that in Figure 10 the matching functions in both sectors shift from point $b$ either to the right or to the left. Therefore small changes $\hat{p}_{2}>0$ cannot lead to a shift in matching of the $a b_{3} c$ type. Also note from (47) that:

$$
\frac{\partial m_{i}\left(q_{H}^{*}\right)}{\partial p_{2}}=\frac{\partial m_{j}\left(q_{H}^{*}\right)}{\partial p_{2}}+\left[m_{j}^{\prime}\left(q_{H}^{*}\right)-m_{i}^{\prime}\left(q_{H}^{*}\right)\right] \frac{d q_{H}^{*}}{d p_{2}} .
$$

It follows that $\partial m_{i}\left(q_{H}^{*}\right) / \partial p_{2}>\partial m_{j}\left(q_{H}^{*}\right) / \partial p_{2}$ if an only if $m_{j}^{\prime}\left(q_{H}^{*}\right)>m_{i}^{\prime}\left(q_{H}^{*}\right)$, or if and only if $\gamma_{j}>\gamma_{i}$. This implies that if the matching function for $q_{H}=q_{H}^{*}$ shifts in this figure to the right in one sector and to the left in the other, the leftward shift has to be in the labor intensive sector. Finally, note that Lemma 4 implies that if $\partial m_{i}\left(q_{H}^{*}\right) / \partial p_{2}>0$ then $\partial m_{i}\left(q_{H}\right) / \partial p_{2}>0$ for all ability levels $q_{H}$ between $q_{H}^{*}$ and the other end point $\left(q_{H \text { min }}\right.$ for sector 2 and $q_{H \text { max }}$ for sector 1$)$. And if $\partial m_{i}\left(q_{H}^{*}\right) / \partial p_{2}<0$ then $\partial m_{i}\left(q_{H}\right) / \partial p_{2}<0$ for all ability levels $q_{H}$ between $q_{H}^{*}$ and the other end point.

$H L / L H$ Equilibrium

In an $H L / L H$ equilibrium, the cutoffs $\left\{q_{H}^{*}, q_{L}^{*}\right\}$ also satisfy the continuity conditions (37) and (38), but 
the boundary conditions are different. Assuming as before that the best workers sort into sector 1, this means that in an $H L / L H$ equilibrium the best managers sort into sector 2 and the boundary conditions are

$$
\begin{aligned}
& m_{1}\left(q_{H \min }\right)=q_{L}^{*}, \quad m_{1}\left(q_{H}^{*}\right)=q_{L \max }, \\
& m_{2}\left(q_{H}^{*}\right)=q_{L \min }, \quad m_{2}\left(q_{H \max }\right)=q_{L}^{*} .
\end{aligned}
$$

Figure 7 depicts the pattern of sorting and matching in this type of equilibrium. The more-able workers sort into sector 1 only if

$$
\frac{w_{1}^{\prime}\left(q_{L}^{*}\right)}{w_{1}\left(q_{L}^{*}\right)}>\frac{w_{2}^{\prime}\left(q_{L}^{*}\right)}{w_{2}\left(q_{L}^{*}\right)}
$$

and the more-able managers sort into sector 2 only if

$$
\frac{r_{1}^{\prime}\left(q_{H}^{*}\right)}{r_{1}\left(q_{H}^{*}\right)}<\frac{r_{2}^{\prime}\left(q_{H}^{*}\right)}{r_{2}\left(q_{H}^{*}\right)}
$$

To derive the comparative statics, we use as before conditions (41) and (42), which apply in this case too. We also can use the decomposition of elasticities (43) and (44), which still apply. Now, however, the relationship between the elasticities of the salary and wage functions, as described by (45), does not apply, because workers of ability $q_{L}^{*}$ do not pair with managers of ability $q_{H}^{*}$, as is evident from Figure 7 . Instead, from (29) and (30) we now obtain

$$
\begin{aligned}
& \varepsilon_{r_{1} F}^{*}=-\frac{\gamma_{1}}{1-\gamma_{1}} \varepsilon_{w_{1} F}^{\max }, \quad F=H, L, \\
& \varepsilon_{r_{2} F}^{*}=-\frac{\gamma_{2}}{1-\gamma_{2}} \varepsilon_{w_{2} F}^{\min }, \quad F=H, L,
\end{aligned}
$$

where $\varepsilon_{r_{i} F}^{*}$ is defined in the same way as before, $\varepsilon_{w_{1} F}^{\max }$ is the elasticity of $w_{1}(\cdot)$ with respect to the boundary $q_{F}^{*}$ through the induced re-matching in sector 1 (evaluated at $q_{L \max }$ ) and $\varepsilon_{w_{2} F}$ is the elasticity of $w_{2}(\cdot)$ with respect to the boundary $q_{F}^{*}$ through the induced re-matching in sector 2 (evaluated at $q_{L \text { min }}$ ). Using these results the system of equations (46) is replaced by

$$
M_{h}^{H L / L H}\left(\begin{array}{c}
\hat{q}_{L}^{*} \\
\hat{q}_{H}^{*}
\end{array}\right)=\left(\begin{array}{c}
\hat{p}_{2}-\hat{p}_{1} \\
\hat{p}_{2}-\hat{p}_{1}
\end{array}\right),
$$

where

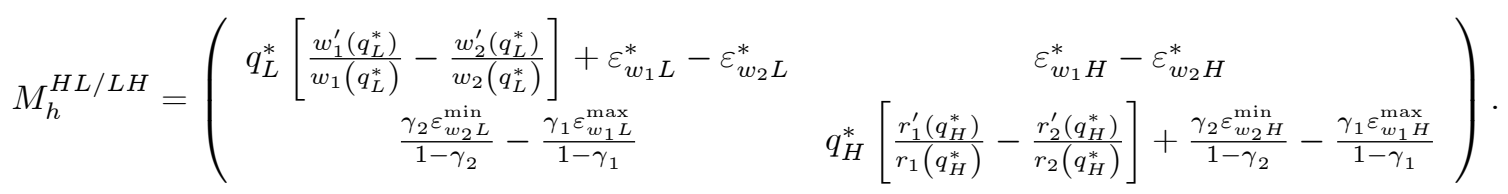

From Lemmas 3-6, we have $\varepsilon_{w_{1} L}^{*}>0>\varepsilon_{w_{2} L}^{*}, \varepsilon_{w_{1} H}^{*}>0>\varepsilon_{w_{2} H}^{*}, \varepsilon_{r_{1} H}^{*}<0<\varepsilon_{r_{2} H}^{*}, \varepsilon_{r_{1} L}^{*}<0<\varepsilon_{r_{2} L}^{*}$. This implies that both entries in the top row in (49) are strictly positive and both entries in the bottom row are strictly negative.

The previous observations imply that a positive term $\hat{p}_{2}-\hat{p}_{1}$ either raises $q_{L}^{*}$ and reduces $q_{H}^{*}$, or it reduces $q_{L}^{*}$ and raises $q_{H}^{*}$. The cutoffs cannot both move in the same direction, because the effect in the top row on the left hand side of (48) would then be opposite to those in the bottom row, whereas on the right hand side 
both effects have the same sign. We will show that only a rise in $q_{L}^{*}$ and a reduction $q_{H}^{*}$ can be associated with equilibrium responses, which implies that the determinant of $M_{h}^{H L / L H}$ must be negative $\left(D_{M_{h}^{H L / L H}}<0\right)$. To prove this, consider an increase in the price $p_{2}$ to $p_{2}^{\prime}>p_{2}$ while the price $p_{1}$ stays constant. Let $X_{1}$ and $X_{2}$ denote the output in each sector prior to the price change, and let $X_{1}^{\prime}$ and $X_{2}^{\prime}$ denote the corresponding output after the price change. Since only prices have changed (and not endowments), under each set of prices both the outputs $\left(X_{1}, X_{2}\right)$ and $\left(X_{1}^{\prime}, X_{2}^{\prime}\right)$ are feasible. Since the competitive equilibrium is efficient, the value of output is maximized given prices, which implies that

$$
\begin{aligned}
& p_{1} X_{1}+p_{2} X_{2} \geq p_{1} X_{1}^{\prime}+p_{2} X_{2}^{\prime} \\
& p_{1} X_{1}+p_{2}^{\prime} X_{2} \leq p_{1} X_{1}^{\prime}+p_{2}^{\prime} X_{2}^{\prime}
\end{aligned}
$$

where the first inequality states that prior to the price change the value of output is higher under production bundle $\left(X_{1}, X_{2}\right)$ than under $\left(X_{1}^{\prime}, X_{2}^{\prime}\right)$, while the opposite holds after the price change. Subtracting and rearranging gives

$$
\left(p_{2}-p_{2}^{\prime}\right)\left(X_{2}-X_{2}^{\prime}\right) \geq 0
$$

which implies that $X_{2} \leq X_{2}^{\prime}$. An increase in output in sector two cannot be achieved with a fall in $q_{L}^{*}$ and a rise $q_{H}^{*}$, because in this case there would be less worker types and less manager types in sector 2 . Therefore, an increase in the relative price of good 2 leads to a rise in $q_{L}^{*}$ and a reduction $q_{H}^{*}$. 